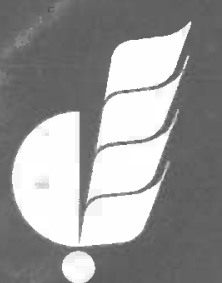

\title{
ICRISAT
}

\section{About HPG}

The Humanitarian Policy Group at the Overseas Development Institute is dedicated to improving humanitarian policy and practice. It conducts independent research, provides specialist advice and promotes informed debate.

\section{Agricultural rehabilitation}

Mapping the linkages between humanitarian relief, social protection and development

Publented by the Humanimati Policy Grobs at ODI

Catherine Longley, Ian Christoplos and Tom Slaymaker

\section{(4⿻)丨

Overseas Developinent Institute 111 Westminster Bridge Road London $5 \mathrm{E} 17 \mathrm{ID}$

United Kingdom

Tel. +44 (0) 2079220300 Fax. +44 (o) 2079220399

E-mail: hpg@odi.org.uk Websites: www.odi.org.uk/hpg and www. odihpn.org 


\section{The authors}

Catherine Longley is a Research Fellow with the Humanitarian Policy Group at the Overseas Development Institute. She is based in Nairobi, where she works in collaboration with the International Crops Research Institute for the Semi-Arid Tropics (ICRISAT) in Eastern and Southern Africa. She is currently undertaking research into how agricultural markets can be promoted in chronically vulnerable areas.

Ian Christoplos is a researcher at the Swedish University of Agricultural Sciences and an independent consultant focusing on risk, recovery, rural development and agricultural services. He has worked as a researcher and practitioner in both development cooperation and humanitarian assistance. He is the co-editor, together with John Farrington, of Poverty, Vulnerability, and Agricultural Extension: Policy Reforms in an Era of Globalization, published by Oxford University Press in 2004.

Tom Slaymaker is a Research Fellow and member of the Water Policy Programme at the ODI. He specialises in water resource development and is currently engaged in applied policy research in support of improved strategies for poverty reduction in Africa and South Asia.

\section{About ICRISAT}

The International Crops Research Institute for the Semi-Arid Tropics (ICRISAT) is a non-profit, nonpolitical international organisation for science-based agricultural development. Established in 1972, ICRISAT is one of the 15 international agricultural research centres supported by the Consultative Group on International Agricultural Research (CGIAR). Further information can be found at www.icrisat.org. ICRISAT and the ODI have worked in partnership since 2001 to undertake collaborative research on agricultural relief, rehabilitation and development.

Humanitarian Policy Group

Overseas Development Institute

111 Westminster Bridge Road

London

SE1 7JD

United Kingdom

Tel: $+44(0) 2079220300$

Fax: +44(0) 2079220399

Website: www.odi.org.uk/hpg

Email:hpgadmin@odi.org.uk

\section{ISBN: 0850037859}

(C) Overseas Development Institute, 2006 


\section{Contents}

\section{Acknowledgements \\ Acronyms}

\section{Executive summary}

Chapter 1 Introduction

1.1 Introduction

1.2 Background to the research

1.3 Chronic conflict and post-conflict situations

1.4 Agricultural support in conflict situations

1.5 Humanitarian action: saving lives and livelihoods

1.6 Politics and principles in humanitarian perspectives

1.7 'Rehabilitation' and the elusive link between relief and development

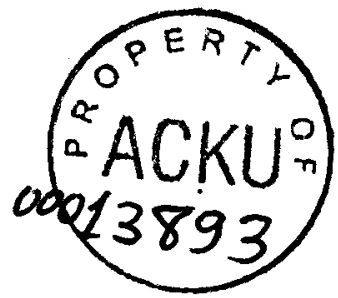

1.8 The case studies

1.8.1 Afghanistan

1.8.2 Sierra Leone

1.9 Structure and argument of the paper

\section{Chapter 2 The impacts of conflict on agriculture and rural livelihoods}

2.1 Introduction

2.2 The role of agriculture in rural livelihoods and the 'yeoman farmer fallacy'

2.3 Analytical concepts: livelihood strategies, vulnerability and resilience

2.4 Impacts of conflict on agriculture

2.4.1 Impacts on agricultural production and produce markets

2.4.2 Impacts on consumption and nutrition

2.4.3 Implications for agricultural interventions

2.5 Impact of conflict on agricultural inputs and services

2.6 Rural labour markets, migration and return

2.7 Land and natural resources

2.8 Summary and implications for post-conflict agricultural interventions

\section{Chapter 3 Post-conflict agricultural programming in Afghanistan and Sierra Leone}

3.1 Introduction

3.2 Food aid, seed aid and beyond

3.2.1 Afghanistan: agricultural 'subsidies' and technology transfer

3.2.2 Seeds and tools in Sierra Leone: from distribution to production

3.2.3 Lessons emerging

3.3 Non-seed inputs and agricultural services

3.3.1 Extension services: Farmer Field Schools in Sierra Leone

3.3.2 Microfinance and credit

3.3.3 Lessons

3.4 Promoting markets in the agricultural sector

3.5. Rights-based approaches

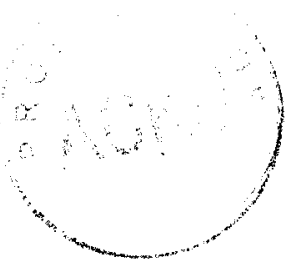

3.6 Summary

\section{Chapter 4 Addressing vulnerability through social protection and livelihood promotion}

4.1 Introduction

4.2 Limitations in addressing vulnerability through post-conflict agricultural interventions

4.3 Social protection and livelihood promotion

4.3.1 Social protection

4.3.2 The interface between social protection, rights-based approaches and humanitarian protection in post-conflict recovery

4.3.3 Social protection and livelihood promotion in post-conflict agricultural interventions 
Chapter 5 Enhancing institutions

5.1 Introduction

5.2 Formal and informal institutions: aid imperatives, political conundrums and farming realities

5.3 The need for institutional reform

5.4 (Re)engaging with the state

5.4.1. New Public Management: towards a leaner state in Afghanistan?

5.4.2. Decentralisation in Sierra Leone

5.5 Strengthening the private sector

5.6 Civil society capacity-building

5.7 Summary

Chapter 6 Policies, programming and principles in post-conflict transitions

6. 1 Introduction

6.2 Aid architecture and policy considerations

6.2.1 Looking beyond project fixes

6.2.2 Coordination

6.2.3 Agency capacity and mandates

6.2.4 Donor funding

6.2.5 Aid policies

6.2.6 Aid and politics: peacebuilding, sovereignty and social transformation 50

6.3 Principled agricultural programming in post-conflict transitions 50

6.3.1 Multiple transitions

6.3.2 Dynamic and pragmatic principles

6.3.3 Principled agricultural programming in post-conflict transitions

\section{Figures, boxes and tables}

Figure 1: Adapted livelihoods framework to support analysis in situations of chronic conflict and political instability

Figure 2: The interface between social protection and promotion in crisis contexts

Box 1: Impacts of conflict on agricultural production 14

Box 2: Social protection and growth 33

Box 3: Analysis of approaches to social protection in Sudan 36

Box 4: Formal and informal seed systems in Southern Sudan $\quad 40$

Box 5: Reform of local authorities in Sierra Leone 41

Box 6: Creating an enabling environment for private sector development in Sierra Leone 43

Box 7: Shuras and agricultural development in Afghanistan 44

Table 1: Trends in food crop production in Sierra Leone, 1989/90-2001/2002

Table 2: Informal social protection mechanisms $\quad 34$

Table 3: Formal social protection mechanisms $\quad 34$

Table 4: FAO's Twin Track Approach and the dimensions of food security $\quad 49$

Table 5: Core principles from humanitarian relief, livelihoods and rights-based approaches $\quad 52$

Table 6: Contextual considerations and principles necessary to achieve specific aims 54 


\section{Acknowledgements}

We are particularly grateful to our institutional collaborators, FAO and ICRISAT. At FAO, we would like to acknowledge the inputs of Richard China and his colleagues in Rome who helped in the initial stages of the project, providing conceptual inputs and generously sharing a wealth of experience with us. In Sierra Leone, we thank Dr Farah and Zein Muzamil of FAO for their personal interest, support and logistical assistance. In Afghanistan, we are grateful to the Afghan Research and Evaluation Unit, and particularly to Alexia Coke. At ICRISAT-Nairobi, we thank Richard Jones for his interest in the research, for his patience, and for promoting the application of the research findings to other war-affected contexts. Finally, we are grateful to colleagues James Darcy, Paul Harvey, Matthew Foley and Jo Macrae of ODl's Humanitarian Policy Group. Jo Macrae deserves special mention for her never-ending support and constructive criticisms; this paper has undoubtedly been enhanced as a result of her inputs. Any faults or inadequacies, however, remain the responsibility of the authors. This research project is one of 23 funded by EC-PREP, a programme of research sponsored by the UK Department for International Development. All ECPREP research studies relate to one or more of the six focal areas of the EC's development policy in the context of their link to poverty eradication. EC-PREP produces findings and policy recommendations which aim to contribute to improving the effectiveness of the EC's development assistance. For more information about EC-PREP and any of the other research studies produced under the programme, please visit the website: www.ec-prep.org. 


\section{Acronyms}

\begin{tabular}{|c|c|}
\hline ADB & Asian Development Bank \\
\hline AREU & Afghan Research and Evaluation Unit \\
\hline ARTF & Afghan Reconstruction Trust Fund \\
\hline ASR & Agricultural Sector Review \\
\hline CBR & community-based recovery \\
\hline CRS & Catholic Relief Services \\
\hline DDR & disarmament, demobilization and reintegration \\
\hline DFID & Department for International Development (UK) \\
\hline DRC & Democratic Republic of Congo \\
\hline DRC & District Recovery Committee (Sierra Leone) \\
\hline EC & European Commission \\
\hline ECHA & Executive Committee on Humanitarian Affairs (UNDP) \\
\hline ERSF & Emergency Recovery Support Fund (Sierra Leone) \\
\hline EU & European Union \\
\hline FAO & Food and Agriculture Organisation of the United Nations \\
\hline FFS & farmer field school \\
\hline FIFC & Feinstein International Famine Center \\
\hline GoA & Government of Afghanistan \\
\hline GoSL & Government of Sierra Leone \\
\hline ICRC & International Committee of the Red Cross \\
\hline ICRISAT & International Crops Research Institute for the Semi-Arid Tropics \\
\hline IDP & internally displaced person \\
\hline IFAD & International Fund for Agricultural Development \\
\hline IFI & international financial institution \\
\hline LRRD & linking relief, rehabilitation and development \\
\hline MAAH & Ministry of Agriculture and Animal Husbandry (Afghanistan) \\
\hline MAFFS & Ministry of Agriculture, Forestry and Food Security (Sierra Leone) \\
\hline MRRD & Ministry of Rural Rehabilitation and Development (Afghanistan) \\
\hline NaCSA & National Commission for Social Action (Sierra Leone) \\
\hline NDF & National Development Framework (Afghanistan) \\
\hline NGO & non-governmental organization \\
\hline NPM & new public management \\
\hline NRC & National Recovery Strategy (Sierra Leone) \\
\hline NSAP & National Social Action Project (Sierra Leone) \\
\hline ODA & overseas development aid \\
\hline ODI & Overseas Development Institute \\
\hline PRSP & Poverty Reduction Strategy Paper \\
\hline RAMP & Revitalising Agricultural Markets Project (Afghanistan) \\
\hline RBA & rights-based approaches \\
\hline
\end{tabular}




\section{SACB Somalia Aid Coordination Body}

SAPA Social Action for Poverty Alleviation (Sierra Leone)

TCER Rehabilitation and Policies Unit (FAO)

UN United Nations

UNDP United Nations Development Programme

UNODC United Nations Office on Drugs and Crime

USAID United States Agency for International Development

WARDA West African Rice Development Association

WFP World Food Programme 


\section{Executive summary}

This paper addresses the question of how to support the livelihoods of rural people who have been affected by conflict. Specifically, it focuses on how international actors might move beyond conventional seeds and tools interventions to address vulnerability and support the agricultural component of rural livelihoods in countries emerging from conflict. It examines, both conceptually and practically, how agricultural rehabilitation can contribute to linking humanitarian assistance, social protection and longer-term development through the provision of effective support in ways that are consistent with core humanitarian principles as well as with livelihoods and rights-based approaches. The paper is based on lessons from Afghanistan and Sierra Leone, and draws its analysis from livelihoods work and social protection.

Although crop and livestock agriculture is certainly the most important factor in rural livelihoods, agriculture is not synonymous with rural livelihoods, which encompass a far wider variety of livelihood strategies. Yet the belief that virtually all rural people strive (and should strive) to become own-account farmers continues to permeate much agricultural rehabilitation policy and programming. Transcending this belief requires more detailed livelihoods analysis in order to understand the complexity of how rural people 'hustle' to survive. Agricultural production is surprisingly resilient in the face of conflict, and it is essential to step back and reassess the basic assumptions about how conflict impacts on agricultural production, consumption and markets. Two particular sets of challenges exist in understanding the impact of conflict on agriculture: the first surrounds understanding shifts in livelihood activities and strategies, and the second in identifying and understanding market shifts in conflict and post-conflict settings.

Given the role of agriculture in rural livelihoods and the resilience of agricultural production in response to conflict, the paper suggests that agricultural support should not focus solely on increasing production, but should also aim to enhance consumption and markets and livelihoods more broadly, including institutional support. However, the crisis thinking that appears to influence programming results in piecemeal, project-based approaches that fail to reflect the resilience, capacities and ingenuity of rural populations. At the same time, there are other approaches being implemented from an almost contradictory perspective, in which efforts to promote self-sufficiency and sustainability are based on an inadequate understanding of local livelihoods and the causes of vulnerability. Such efforts have been seen to fail to match local-level interventions with the meso and macro institutions and policies necessary to support them more sustainably. Support to each level of a market chain is one way in which these meso- and macro-level interventions can be realised. Though market approaches are now beginning to attract the attention of donors and programme planners, they are fraught with practical difficulties in a post-conflict environment and remain a major challenge. Careful monitoring and impact assessment, together with analysis informed by a political economy perspective, are needed to improve existing market approaches.

Despite the apparent emphasis on targeting for vulnerable groups, current agricultural interventions are ill-suited to addressing the causes of vulnerability. We suggest that the key to appropriate social protection in post-conflict situations lies in an understanding of vulnerability that incorporates notions of powerlessness. Possible synergies between the concepts of social protection and livelihood promotion potentially provide a means of achieving greater convergence of purpose across relief and development, i.e. by supporting interventions that not only allow people to cope with adverse circumstances but that also promote livelihoods, both in economic and social terms. Although this is relatively uncharted territory, there exists - at least at a conceptual level - considerable scope for strengthening the linkages both between livelihood protection and promotion and relief and development. In practice, however, various challenges remain, and there is relatively little evidence from the case study countries to suggest that social protection and promotion are being applied successfully in linking relief and development. Moreover, there is a very real risk that social protection may merely serve to exacerbate the political and social inequalities that characterise chronic and post-conflict situations. Addressing such inequalities is by no means easy, and may require lengthy processes of institutional reform.

Agricultural institutions - of the government, private sector and civil society - provide the primary entry point through which the aid community has an opportunity to intervene to support rural livelihoods in more sustainable ways. In the agricultural sector, however, the seemingly self-evident priority for public sector capacity building is particularly unclear, since agriculture is considered to be primarily a responsibility of private and civil society actors. Despite policy visions stating that agricultural development should be private-sector led, there appears to be very limited understanding of what this might entail in practice. In particular, the tendency for NGOs to promote supply-driven approaches risks 'crowding out' potential private sector providers by upsetting the establishment of a 'level playing field' for commercial competition. Another challenge lies in ensuring that efforts to rebuild formal institutions remain cognisant of the strengths and importance of the informal 
institutions that have inevitably taken centre stage in agricultural systems during the conflict years. Yet it must also be recognised that some of these institutions may serve to reinforce rather than alleviate structural vulnerability. There is often a perceived need to fundamentally reform or even replace institutions, but questions about whether crisis can be used to motivate reform, and about the ability of outsiders to set up viable institutions, mean that institutional reform is by no means easy in countries emerging from conflict.

In conclusion, the paper proposes that the essence of agricultural support in countries emerging from conflict should be to facilitate the transition from supply-led programming to the establishment of sustainable (marketdriven) systems for service delivery, and that this should be developed within a framework of broad-based efforts to protect and promote rural livelihoods. This transition can be broken down into a number of measures, as follows:

- To ensure that vulnerable farmers have access to agricultural inputs and services (food for agriculture, seed, irrigation, pest control, animal health, microfinance, extension), either through direct distribution or interventions designed to stimulate choice, such as vouchers.

- To increase agricultural production through access to appropriate technology options.

- To increase rural incomes through the promotion of agricultural product and labour markets.

- To establish the capacity, structures and institutions necessary for the sustainable delivery of inputs and services.

- To address vulnerability and social inequality through social protection and livelihood promotion.

- To promote the reforms necessary to address the structural causes of vulnerability.

Some of the types of interventions represented by each of these steps are already being implemented in practice in both case studies. Thus, what we are suggesting is not necessarily a dramatic change (though more effort needs to be placed on promoting markets), only that these interventions are regarded as part of a broader transition, and that there is greater emphasis placed on addressing vulnerability and institution-building. Most importantly, the overall aim of moving from supply-led programming to the establishment of sustainable systems for service delivery offers a strategic vision that allows for the projectised nature of agricultural interventions to be overcome. For this transition to take place, there must be a fundamental shift in the role of NGOs, massive capacity building efforts at all levels are required, and there must be clarity and consensus on the role of the state vis-à-vis the private sector.

Given the multiple and dynamic contextual transitions taking place as countries emerge from conflict, we suggest that the range of different principles that agencies strive to observe in the provision of external assistance cannot remain static, but must be pragmatically applied according to the broader political and security environment. Humanitarian actors run up against particular challenges in maintaining principles of neutrality and independence in the transition to democratic forms of governance, in which a newly formed state is struggling to establish formal institutions. If humanitarianism is defined by the objective of saving lives and a strict adherence to humanitarian principles, then - in our view - what is commonly referred to as 'agricultural rehabilitation' should not be seen as strictly humanitarian. However, that is not to say that it cannot be principled. The paper puts forward a framework to help determine the specific principles - including those drawn from relief, livelihoods and rights-based approaches - that are appropriate to particular types of interventions and broader contextual considerations. Greater clarity of both the political agenda and the impact of conflict on local livelihoods and informal institutions is required if a pragmatic approach to principles is to be adopted. 


\section{Chapter 1 Introduction}

\subsection{Introduction}

Can relief be linked to agricultural development in ways that contribute to the livelihood strategies of rural people? Has our growing understanding of the political economy of conflict impacted on the ways in which international aid structures and national political actors create rural development policies in countries emerging from conflict? What are the guiding principles that underpin interventions that fit neither humanitarian assistance nor development cooperation? These questions would seem to be at the core of decision-making processes in determining what to do 'after food aid', when people are returning to their farms and villages, but when the 'playing field' for rebuilding rural economies is not yet level, and may even still be mined.

The discourse on agricultural rehabilitation has been slow in digesting these complexities. This paper looks at current experience in moving beyond long-standing 'seeds and tools' modalities to see how and why these issues have been difficult to integrate into operations in countries emerging from conflict. Suggestions are put forward for ways to rethink where relief could and should meet and support prevailing development trajectories, and where developmentalism needs to be reassessed in order to enhance its relevance for rural livelihoods that are facing shifting combinations of acute crisis and chronic vulnerability in countries emerging from conflict.

\subsection{Background to the research}

This paper reviews the findings from two case studies looking at the relationships between agricultural rehabilitation and the livelihoods of rural people. It constitutes the final report of an Overseas Development Institute (ODI)-led research project on 'The changing roles of agricultural rehabilitation: linking relief, development and support to rural livelihoods', focusing on countries emerging from conflict. 'The aim of the overall project was to develop a greater level of conceptual clarity and identify practical strategies on how changing agricultural rehabilitation policies and practice can contribute to linking humanitarian assistance and longer-term development through the provision of effective, principled support to rural livelihoods in chronic conflict and postconflict situations. The specific objectives of the research were:

\footnotetext{
1 This 16-month project was undertaken in collaboration with the International Crops Research Institute for the Semi-Arid Tropics (ICRISAT) and the Rehabilitation and Humanitarian Policies Unit (TCER) of FAO, funded by the EC Poverty Reduction Effectiveness Programme.
}

- To develop a detailed empirical and conceptual understanding of the complex nature of how agricultural rehabilitation efforts impact on and relate to poverty, vulnerability and institutional configurations in chronic conflict and post-conflict situations, based on an understanding of the ways in which rural people access resources, and the role that local institutions and political factors play in the adaptation of local livelihood strategies.

- To analyse critically the relationship between food security strategies, agricultural rehabilitation and poverty reduction in contexts where the roles of relief and development programming are shifting. Particular attention was placed on reviewing how aid to agricultural services can be adapted in post-conflict and politically unstable environments to ensure that investments support effective, accountable and legitimate institutions, so protecting humanitarian principles and promoting sustainability.

- To develop greater conceptual clarity and policy/ institutional/programming options for donors and operational agencies to support rural livelihoods of poor and vulnerable groups through agricultural rehabilitation in countries emerging from conflict.

\subsection{Chronic conflict and post-conflict situations}

The specific focus of this paper is countries emerging from conflict, including both chronic conflict and post-conflict situations. Common usage of the term 'post-conflict' does not necessarily imply absolute peace. The distinction between 'conflict' and 'post-conflict' is often very unclear. Despite ceasefire agreements or negotiated peace deals, today's conflicts tend to be chronic, in that they persist over years or even decades. Pockets of apparent stability (either geographical or temporal) may revert to insecurity, and it is often difficult to know whether or when the conflict is truly over. Other terms that are commonly used to describe chronic conflict include 'complex political emergency', 'protracted crisis' or 'chronic political instability'. Goodhand \& Hulme (1999) define five characteristic features used to denote conflicts as complex political emergencies: conflict within and across state boundaries; political origins; protracted duration; social cleavages; and predatory social formation. Features of chronic political instability include a state in which public institutions (executive, judicial, legislative) are seriously weakened or non-existent; the external legitimacy of the state is withheld or contested; a strong parallel or extra-legal economy exists; existence or high susceptibility to violence and forced displacement; sections of the population are deliberately excluded from enjoying basic rights; 
livelihoods are highly vulnerable to external shocks; and the existence of serious poverty (Schafer, 2002). Our use of the term 'chronic conflict and post-conflict' implicitly accepts that such situations are not only 'complex' but also protracted. Chronic conflicts exist or have existed in Afghanistan, Angola, Colombia, the Caucasus, the DRC, Liberia, Sierra Leone, Somalia, Southern Sudan and Sri Lanka.

The majority of contemporary conflicts are internal and associated with a dramatic rise in numbers of non-military deaths; as such they have been referred to as 'new wars' (Kaldor, 1999). Declines in ODA (and military aid) have arguably resulted in weakened states and a shift away from state-sponsored conflict towards decentralised selffinancing conflicts (de Waal, 1997; Duffield, 1998). Others have documented the increased involvement of armies or militias in illicit commercial activities (e.g. Keen, 1998 on Sierra Leone), and highlight the extra-legal or violent means by which powerful groups actively and deliberately undermine the entitlements of marginalised groups. In contemporary conflict, the emphasis on economics is such that a distinction between combatants and non-combatants becomes increasingly blurred or even irrelevant (Leader, 2000). It is further argued that internal wars create 'alternative' political and economic systems and 'forced', 'parallel' markets with restricted entry controlled by elite groups. The concept of 'conflict entrepreneurs' is used to describe individuals or groups who seek to manipulate conflict situations to serve specific political (and economic) objectives, often manipulating historical constructions of identity in order to mobilise others (Eide, 1997).

While some analysts have focused on the role of economic agendas in causing and sustaining violent conflict (as described above), other commentators have placed emphasis on the political processes associated with war. Although it is clearly acknowledged that there is a close relationship between the economic and political causes and consequences of conflict, it has been argued that conflict cannot be understood without appreciating the crisis in political authority and governance that lies at their root (Cliffe and Luckham, 2000). This crisis involves the inability of a state to fulfil its core functions ${ }^{2}$ to the extent that the contract between a state and its citizens completely breaks down. (Re)establishing this contract between a state and citizens in a country emerging from conflict is a key feature of post-conflict recovery. In the agricultural sector, it is achieved through the establishment of both public support and a dynamic but regulated private sector that provide appropriate and high-quality agricultural inputs and services

2 The core functions of the state include administrative control, the sound management of public finance, investments in human capital, the creation of citizenship rights, investing in infrastructure, managing intangible assets, and maintaining the rule of law (Ghani et al., 2005).

\subsection{Agricultural support in conflict situations}

The impetus for the research on which this paper is based came from the emerging critique of conventional 'seeds and tools' programming (Longley \& Sperling, 2002). Seeds and tools distributions have constituted the dominant response of the international aid community to assist farmers affected by disaster, and is widely regarded by relief agencies as a necessary step in the transition away from food aid towards more developmental programming for food security. Conventional approaches to seeds and tools interventions tended to involve the distribution of seed of improved varieties of staple food crops procured from outside the country. Various changes in recent years have been such that conventional seed aid is no longer the norm for seed interventions. ${ }^{3}$ However, as with other relief interventions, the monitoring and evaluation of relief seed projects has tended to look only at the type and quantity of inputs distributed and the number of beneficiaries or the area planted, rather than the actual impact of relief seed on farmers and farming systems.

Although the logistical aspects of relief seed distribution have improved considerably over the years, with more timely distributions of better quality seed of more appropriate varieties and in more appropriate quantities, studies in a number of different countries have shown that seeds and tools have limited impact. In many cases farmers do not plant the seed provided to them - sometimes because it arrives late or is of an unknown quality - but often quite simply because they already have seed of their own or have been able to acquire seed from other farmers or from local markets. There is a general lack of understanding of how farmer seed systems function in times of crisis, illustrated by the fact that seed needs assessment data have tended to be extrapolated from food aid assessments rather than constituting a more accurate assessment of need (Longley et al., 2002).

In general, the impacts of conventional seed relief programmes have been rather less than might be assumed, particularly in chronic emergency contexts where seed aid is distributed repeatedly (see Longley and Sperling, 2002). This is because the assumptions on which seed relief is premised - that seed is not available, or that the seed that is available is of poor quality - have been found to be misplaced (Remington et al., 2002; Jones et al., 2002). Conventional seed relief programmes are designed to address a lack of seed availability when in fact it is more

\footnotetext{
3 Rather than staple grain crops, seed distributions often involve vegetable and other crops (e.g. legumes) that tend not to be so easily multiplied and stored by farmers; large-scale procurement of seed from commercial seed companies in neighbouring countries is giving way to procurement within country, often involving the establishment of farmer seed multiplication schemes and training in seed production; and rather than providing seed itself, vouchers (or in some cases cash) are increasingly being used to allow farmers to access seed and other locally available agricultural inputs (see Bramel et al., 2004).
} 
often lack of seed access that is the problem. Despite these criticisms and concerns, at a political level, seed aid remains attractive to those involved. ${ }^{4}$ For such interventions to have greater impact (particularly in the longer term), they must look beyond the provision of seed aid by providing support to seed systems, agricultural systems and broader livelihood systems. Given that many of the problems faced by farmers in emergency situations relate more to poverty, vulnerability and the disposal of agricultural assets (land, livestock, labour) rather than to seed per se, we suggest that a livelihoods approach might be appropriate in addressing the needs of farmers in such situations.

\subsection{Humanitarian action: saving lives and livelihoods}

Though not always explicit, livelihoods perspectives are becoming increasingly accepted within humanitarian thinking and interventions. Conventional humanitarian aid was essentially designed to save lives in the face of temporary threats to life and well-being. However, the increasingly protracted nature of modern conflict has led to the realisation that external assistance should be provided in ways that enable beneficiaries and households to better cope with securing their basic needs when confronted by the more enduring adversities associated with chronic conflict. As such, there is a need for external assistance not only to save lives but also livelihoods; it is perhaps through efforts to protect and promote livelihoods that humanitarian agencies can save lives most effectively. Humanitarian agencies operating in protracted emergencies, while primarily concerned with saving lives in the short term, are increasingly interested in protecting and promoting livelihoods in the longer term. However, as we shall see in Chapter 4, efforts to protect and promote livelihoods go well beyond both the mandate and the capacity of humanitarian agencies.

Early efforts to promote livelihoods within humanitarianism were based on the observation that efforts to save lives in the short term only are insufficient, and that efforts to foster self-sufficiency and productivity in the longer term are also necessary (Lautze, 1997). Over the past four to five years, efforts have been made to adapt the sustainable livelihoods framework to make it more appropriate to protracted crises, particularly chronic conflict (see Figure 1, page 12). These efforts have involved emphasis on the notion of vulnerability as opposed to sustainability (Pain \& Lautze, 2003); greater attention to the political economy of conflict (Collinson et al, 2003); and a recognition of the primacy of violence (Lautze \& Raven Roberts, 2003). Livelihood support is increasingly being conceptualised not as an end in itself,

\footnotetext{
4 Seed aid provides an effective way for donors to spend their money and to be seen to be assisting rural populations more sustainably; implementing agencies benefit from contracts to deliver the seed; seed companies profit from seed sales; and farmers are unlikely to complain about receiving free inputs particularly since the seed can be exchanged or eaten if it is not planted.
}

but as a means by which to achieve the ultimate objective of protecting human, social and economic rights i.e. operationalising rights-based approaches. Livelihoods programming requires a deeper level of contextual understanding than conventional humanitarian relief. It demands a more holistic analysis (multi-sectoral and multilevel) of factors affecting people's ability to survive and make a living and suggests, for example, that activities like food distribution ought to be complemented by activities designed to address the underlying causes of food insecurity.

Livelihoods approaches are thought to be particularly helpful in promoting greater synergy or coherence between relief and development modes of aid, yet various challenges remain. While the concept of livelihoods programming is attractive, practical experience of applying livelihoods approaches in chronic conflict and post-conflict situations remains limited (Longley \& Maxwell, 2002). Perhaps the biggest unresolved issue in the application of livelihoods approaches to situations of chronic conflict is how to reconcile livelihood principles ${ }^{5}$ with principles of humanitarian action (in particular neutrality, impartiality and independence). The question of how and when livelihood principles such as participation and sustainability should be introduced is controversial, and major practical challenges surround building effective micro-macro linkages. Effective intervention in livelihoods means engagement in the social, political and economic structures that (re)create poverty. Can this be accomplished while maintaining humanitarian principles? In practice this question is often side-stepped through a micro-macro division of labour: NGOs and others tend to address the micro level, and thereby keep a certain distance from the political arena, but (apart from NGO advocacy work) it is up to the UN, donors and IFIs to address the macro/ structural/political level. Problems arise, however, in that effective agricultural programming - in any context - is reliant on micro-macro linkages. Subsistence farming is increasingly rare, and the impact of increased agricultural production on livelihoods is ever-more dependent on markets for production, inputs, finance and labour.

There is also a fear amongst some humanitarians that the long-term perspective of livelihoods analysis may lead to a 'normalisation' of crisis situations, in which humanitarian needs relating to ongoing acute vulnerability may be ignored as aid is reallocated to beneficiaries with greater potential for 'sustainable development'. In these respects, it is important to retain a humanitarian lens when examining the potential for livelihoods approaches in chronic conflict and post-conflict situations. An understanding of the

\footnotetext{
5 Livelihoods approaches are based on the following principles: people-centred; responsive and participatory; multi-level; conducted in partnership with both public and private sector; sustainable; dynamic (DFID, 1999). Two additional principles that have been suggested are: holistic and builds on people's strengths and addresses vulnerabilities (Goldman, 2000).
} 
political economy of conflict is particularly important if livelihoods support is to be both principled and effective (Le Billon, 2000; Collinson, 2002).

\subsection{Politics and principles in humanitarian perspectives}

Changes in the nature of conflict since the end of the Cold War have particular implications for the ways in which humanitarian actors intervene in conflict situations. If humanitarian responses are to provide effective assistance to food-insecure groups, for example, it has been argued that humanitarian agencies must understand how and why the economic and political processes associated with war have led these groups to become vulnerable (Collinson et al., 2002). As such, a political economy perspective in understanding the dynamic patterns of power and vulnerability that exist within any given conflict situation can help agencies to intervene more effectively and apply an ethical framework to their work (Collinson et al., 2002). If it is accepted that humanitarian action is an inherently political activity (Leader, 2000), then political economy analysis can help humanitarian actors to reach principled and accountable decisions about how to engage with local political and commercial actors. However, the ways in which humanitarian agencies adopt a principled approach is currently the topic of considerable debate within the sector.

Within the humanitarian sector, a somewhat confusing array of slightly differing sets of principles of humanitarian action, with differing interpretations, has been put forward by different agencies and different commentators. ${ }^{6}$ This continual renegotiation of the principles of humanitarian action is closely related to the changing nature of contemporary conflict described above. In this paper, we consider three core humanitarian principles: impartiality (the provision of aid according to and in proportion to need); neutrality (dealing equally with both sides to a conflict and not discriminating on the basis of gender, ethnicity, class or other traits); and independence (the independence of humanitarian objectives from any political, military or economic considerations). We also consider key principles from livelihoods and rights-based approaches. Much of the recent literature on humanitarian principles notes the difficulties in applying the principles in practice (e.g. Charny, 2004; Keen, 1998; Weiss, 1999), and events in

\footnotetext{
6 Approved in 1991, UN General Assembly Resolution 46/182 states that 'humanitarian assistance must be provided in accordance with the principles of humanity, neutrality, and impartiality' (cited in FIFC, 2004). The Red Cross Movement espouses principles of humanity, impartiality, neutrality, universality, independence, voluntary service, and unity (Pictet, 1979). Related to these are the principles contained in the widely-endorsed Code of Conduct for the International Red Cross and Red Crescent Movement and NGOs in Disaster Relief. These include the primacy of the humanitarian imperative, and impartiality of relief, including non-discrimination on political grounds (but not neutrality per se). To these are added independence of relief actions, respect for culture and custom, building local capacity, involvement of beneficiaries, reducing future vulnerabilities through relief, accountability, and respect for the dignity of disaster victims.
}

Iraq and Afghanistan are widely considered by humanitarian actors and academics to have seriously compromised the principles on which the very integrity of humanitarian action is founded (FIFC, 2004).

Three broad - and, at times, overlapping - positions have been identified at a conceptual level among humanitarians in relation to humanitarian principles (in particular the role of neutrality) and political agendas (FIFC, 2004; Leader, 2000; Weiss, 1999):

(a) 'Principle-centred' (FIFC, 2004) or 'neutralityelevated' (Leader, 2000). Also referred to as 'classicists' (Weiss, 1999), these agencies and individuals share a continuing commitment to the core humanitarian principles, particularly that of neutrality. Proponents of this position argue that the more highly politicised the terrain, the more urgent is unswerving and unabashed fidelity to the core principles (Harroff-Tavel, 2003). In such contexts, the manipulation of humanitarian action by political actors should be minimised through operational rules. They believe that humanitarian action should be restricted to saving lives and protecting civilians, and many also feel that humanitarian actors should avoid becoming politically engaged in activities such as reconstruction or advocacy for human rights.

(b) 'Pragmatists' (Weiss, 1999; FIFC, 2004) or 'third-way humanitarianism' (Leader, 2000). This position accepts that politics and humanitarianism are intimately intertwined in the reality of contemporary conflict. Principles are seen not as absolutes but as reference guidelines: something to be strived for, but not always attainable in all contexts. Although they resist taking sides, pragmatists believe that the principle of neutrality is not an absolute necessity for aid to be effective and impartial. Pragmatists have also been referred to as 'political humanitarians', within which a distinction can be made between those who pursue minimalist ('do no harm') or maximalist (peace-building) political agendas (Weiss, 1999).

(c) 'Solidarists' (Weiss, 1999; FIFC, 2004) or 'neutrality abandoned' (Leader, 2000). These agencies and individuals hold the view that neither humanitarian principles nor saving lives are enough in aid responses to conflict. They believe that there is also an obligation to become politically engaged (which may mean taking sides) in addressing the root causes of conflict through actions to uphold justice and human rights. Neutrality and impartiality are seen as an impediment to effective action. Rather than viewing themselves first and foremost as humanitarian agencies, solidarists see themselves as rights-based agencies whose agenda includes both poverty alleviation and social transformation, as well as the more traditional humanitarian activities in contexts where other activities are not possible. 
In practice, field-level attempts to adopt principled approaches to humanitarian interventions have been based on the development of inter-agency voluntary codes. ${ }^{7}$ Recent case studies of these codes, however, have concluded that they require more effective enforcement mechanisms, possibly through an external monitoring agency to improve accountability and performance (Leader, 2000). Whether or not agricultural support in countries emerging from conflict is considered to be 'humanitarian' in and of itself (and in this paper we subscribe to the view that it is not), for such support to be principled and politically informed, it is necessary to learn from the humanitarian debates and controversies that have been outlined above.

\section{7 'Rehabilitation' and the elusive link between relief and development}

Rehabilitation is often regarded as the process that links relief and development, but persistent challenges (both practical and conceptual) in the so-called 'transition' from relief to development indicate the need to develop greater clarity as to what rehabilitation ought to be about, particularly in conflict and post-conflict situations. At the conceptual level, the topic of research relates to what has been referred to as the relief-to-development continuum or contiguum: i.e., concerns to achieve greater coherence or synergy between relief and development interventions (DFID, 1997); to bridge the 'gap' (Scott and Bannon, 2003); and to link relief, rehabilitation and development more effectively (EC, 1996; EC, 2001). Such concerns are particularly problematic in countries emerging from conflict, with continuing violence, weak or absent formal institutions, a lack of political legitimacy, and insecurity of economic investments.

Various definitions of rehabilitation have been put forward by different experts (see Christoplos et al., 2004): some regard it as displaying features of both relief and development aid (e.g. Brigaldino, 1995; Green, 2000; White, 1999), while others (e.g. Macrae, various) argue that it constitutes more of a gap than a link between two kinds of aid with very different objectives, mandates and operating rules. Rehabilitation is also thought to overlap with 'reconstruction' and the 'resumption of sustainable development' (EC, 1996). However, the problem with all 're' words (rehabilitation, reconstruction, rebuilding, recovery, revitalisation, among others) is the implicit assumption of a re-turn to a former, supposedly stable and desirable state of affairs. Such an assumption is particularly inappropriate in a post-conflict context, since a return to the pre-conflict situation may merely recreate the conditions that led to war in the first place.

7 Examples include the Joint Policy of Operation (Liberia), the Principles and Protocols of Humanitarian Operation (Liberia), the Agreement on Ground Rules (South Sudan), the Code of Conduct (Sierra Leone), and the SACB Guiding Principles of Operation (Somalia).
Given the association of 'rehabilitation' with the elusive and controversial link between relief and development, these words (rehabilitation, relief, development) risk remaining trapped in these concepts. The language used in this paper, therefore, avoids such terms as far as possible, and instead draws its analysis from two growing bodies of work that have recently begun to be applied to conflict and post-conflict situations: livelihoods analysis and social protection. The question is raised whether social protection can contribute both practically and conceptually to addressing vulnerability and establishing a social contract between governments and citizens in post-conflict contexts. A brief synopsis of the argument is given in Chapter 1.9, and these concepts are explored more fully in Chapters 3 and 4 . Whilst the topic of research is concerned with these broader conceptual debates on relief-development linkages, we address this issue through the lenses of livelihoods and social protection insofar as these relate to the agricultural sector.

\subsection{The case studies}

The programming approaches that are possible in postconflict contexts are of course closely related to the nature and extent of the conflict; this determines opportunities or 'spaces' for intervention. This paper is based on the lessons learned from existing agricultural and livelihoods approaches in the two case study countries, Afghanistan and Sierra Leone. In both countries, efforts are under way to explore ways to complement (or at least combine) short-term efforts to save lives with longer-term strategies for protecting and promoting livelihoods.

\subsubsection{Afghanistan}

Afghanistan has long been affected by a variety of natural disasters and complex political emergencies. In addition to the conflicts of the past 30 years, Afghanistan has been hit by devastating droughts and earthquakes, as well as floods, sandstorms and other natural hazards. The most recent political emergency dates back to the Soviet occupation of 1979-89, when one-third of the population (over six million people) fled Afghanistan to neighbouring Pakistan and Iran. Following the Soviet withdrawal, fighting subsequently continued among the various anticommunist mujahideen factions. The fundamentalist Islamic Taliban movement eventually gained control over most of the country in 1996 and ruled until 2001, when the US initiated aerial attacks that paved the way for the ousting of the Taliban by opposition groups. An interim administration led by Hamid Karzai was inaugurated on 22 December 2001 , followed by a transitional government in June 2002. National elections took place on 9 October 2004, with Hamid Karzai elected as President for a fiveyear term. Central government remains weak, however, on-going political manoeuvring by warlords has at times been violent, and military action to root out terrorists and remaining Taliban elements creates a potentially highly unstable environment. 
The Afghanistan case study (Christoplos, 2004) reviews the relationship between agricultural rehabilitation in Afghanistan and the livelihoods of rural Afghans. It analyses how rehabilitation modalities have taken into account continuing violence, the weakness of formal and informal institutions, unclear political legitimacy, large-scale population displacement, and the insecurity of economic investments. It has been widely acknowledged that Afghanistan is in danger of becoming locked into a 'narcomafia state' if stability is not quickly achieved. But the international community has yet to fully live up to its commitments to Afghanistan's future security and stability. Agricultural recovery has been portrayed as both the fundamental problem and the essential solution for Afghanistan. The recovery of poppy production is the primary threat, but it is at the same time acknowledged that alternatives to the illicit economy will primarily be found in agriculture.

\subsubsection{Sierra Leone}

During the civil conflict in Sierra Leone (March 1991 to January 2002), an estimated 50,000 people were killed, some 1.5 million people (approximately two-thirds of the total population) were displaced, with approximately 600,000 seeking refuge in neighbouring Guinea and Liberia. Though analyses may differ in their emphasis of specific factors, it is generally agreed that there were multiple causes of war, including long-term abuse of human rights, social exclusion of youth from educational and employment opportunities, and the struggle to control the country's diamond resources. As with any conflict, it is important to recognise the differential impacts of the war across different parts of the country and at different times; the relative impacts on local livelihoods were thus very varied. In its early years (1992-94), the conflict initially only directly affected the south-eastern part of the country. Up until 1997, the rebels did not control any large areas of territory for any significant periods of time, and the nature of insecurity was defined by sporadic rebel attacks involving looting and considerable violence: the killing and maiming of civilians, or the abduction of children for forcible conscription. Between 1998 and 2001, rebel forces held control of a major portion of the northern, southern and eastern provinces, including the rich diamond mining areas in the east. A peace accord in July 1999 led to the arrival of UN.forces and the beginning of disarmament, but the peace did not hold. Another peace agreement in May 2001 led to the gradual restoration of civil authority as peacekeepers gained control over the country, district by district. On 18 January 2002, President Alhaji Dr Tejan Kabba officially announced that the war was over, and national democratic elections took place in May 2002.

The Sierra Leone case study (Longley, 2006 forthcoming) focuses on the impacts of conflict in the north-western district of Kambia, and the agricultural and livelihood interventions in the period 2002-2004. National processes and community-based activities to promote peace, reconciliation, resettlement and rehabilitation in the aftermath of the war were supported by multilateral and bilateral donors, with assistance being delivered through a complex array of government ministries, commissions and committees, UN agencies, international and local NGOs, and communitybased organisations. Though early rehabilitation focused largely on construction projects to rebuild the infrastructure that had been damaged by war, later efforts recognised that the political and economic mismanagement that took place in the decades prior to the war had a profound effect on poverty and vulnerability. In effect, the contract between the state and its citizens for the delivery of basic services had broken long before the onset of war in 1991.

\subsection{Structure and argument of the paper}

This paper is primarily concerned with how aid can best be used to support rural livelihoods in countries emerging from conflict. More specifically, it is concerned with how international actors might best support the agricultural component of rural livelihoods. The paragraphs above have indicated that relief is not enough in chronic conflict, and that there is a need also to support livelihoods. This is particularly so in the agricultural sector, where there is a need to move beyond conventional seeds and tools interventions to support rural livelihoods more broadly.

Chapter 2 of the paper examines the role of agriculture in rural livelihoods, and how agriculture is affected by conflict. Although crop and livestock agriculture is certainly the most important factor in rural livelihoods, agriculture is not synonymous with rural livelihoods, which encompass a far wider variety of livelihood strategies. Yet the 'yeoman farmer fallacy' (Farrington and Bebbington, 1992) - a belief that virtually all rural people strive (and should strive) to become own-account farmers - continues to permeate much agricultural rehabilitation policy and programming. Transcending the yeoman farmer fallacy requires more detailed livelihoods analysis in order to understand the complexity of how rural people 'hustle' to survive.

Agricultural production is surprisingly resilient in the face of conflict; in both Afghanistan and Sierra Leone production rapidly reached pre-war levels once farmers were able to return to their farms. Existing evidence suggests that drought has relatively greater impact on production. It is increasingly acknowledged that the impact of conflict is multifaceted, involving, for example, shifts in the types of crops or even varieties that are cultivated. In order to understand resilience in the face of conflict, it is essential to step back and reassess our basic assumptions about how conflict impacts on agricultural production, consumption and markets. Two particular sets of challenges exist in understanding the impact of conflict on agricultural production: the first surrounds understanding shifts in 
livelihood activities and strategies, and the second in identifying and understanding market shifts in conflict and post-conflict settings. It is often falsely assumed that markets cease to function in conflict contexts; although market conditions undoubtedly change, there is no sign that markets cease to function altogether.

Given the role of agriculture in rural livelihoods and the resilience of agricultural production in response to conflict, the paper suggests that agricultural support should not focus solely on increasing production but should also aim to enhance consumption and markets and livelihoods more broadly. Chapter 3 examines programming approaches within the agricultural sector, and the challenges that exist in linking relief and development in the case study countries. It argues that the dominance of 'crisis narratives' and a general failure to appreciate and assess the dynamism and resilience of farmers have resulted in programmatic structures which fail to relate adequately to the actual nature and processes of agricultural change and livelihood recovery.

In Chapter 4, the concepts of social protection and livelihood promotion are introduced as a means of potentially providing greater convergence of purpose across relief and development. This chapter examines possible 'synergies' between the two with reference to case study examples from Sierra Leone and Afghanistan. It concludes that, although this is relatively uncharted territory, there exists - at least at a conceptual level - considerable scope for strengthening the linkages both between livelihood protection and promotion and relief and development. In practice, however, various challenges remain and there is relatively little evidence from the case study countries to suggest that social protection and promotion are successful in linking relief and development. Moreover, there is a risk that social protection may merely serve to exacerbate the political and social inequalities that characterise chronic and post-conflict situations.

Recognising that agricultural institutions - of the government, private sector and civil society - provide the primary entry point through which the aid community has an opportunity to intervene to support rural livelihoods, Chapter 5 examines the challenges of institution-building in the case study countries. A pattern is apparent where capacity-building efforts are concentrated among civil society institutions at local level in the midst of the conflict (in those areas where security conditions permit), and attention then shifts to government institutions when a legitimate government is installed. In the agricultural sector, however, the seemingly self-evident priority for public sector capacity building is particularly unclear, since agriculture is considered to be primarily a responsibility of non-state actors (private sector and farmer organisations).
There are a number of challenges to institution-building at various levels in countries emerging from conflict. Firstly, there is often a perceived need to fundamentally reform or even replace institutions, but questions about whether crisis can be used to motivate reform, and about the ability of outsiders to set up viable institutions, suggest that institutional reform is by no means easy in countries emerging from conflict. Secondly, despite policies stating that agricultural development should be private-sector led, there appears to be very limited understanding of what this might entail in practice. In particular, the tendency for NGOs to promote a supplydriven approach risks 'crowding out' potential private sector providers by upsetting the establishment of a 'level playing field' for commercial competition. Thirdly, how to ensure that the efforts to rebuild formal institutions remain cognisant of the strengths and importance of the informal institutions that have inevitably taken centre stage in agricultural systems during the conflict years. Associated with the need to be aware of the strength of informal institutions is the need to recognise that some of these institutions also serve to reinforce rather than alleviate structural vulnerability.

In terms of aid architecture, Chapter 6 describes how agricultural rehabilitation programming tends to consist of collections of projects without clear exit strategies or links to longer-term visions for agricultural reconstruction. The projectised nature of rehabilitation is severely limited by its small scale, and the consequent difficulties for achieving effective coordination, sectoral balance and relevance to broader market imperatives. It is proposed that the essence of agricultural support in countries emerging from conflict should lie in facilitating the transition from supply-led programming to the establishment of sustainable (marketdriven) systems for service delivery, and that this should be developed within a framework of broad-based efforts to protect and promote rural livelihoods. Promoting a transition from supply-led programming to the establishment of sustainable systems for service delivery provides the strategic vision that is currently lacking in post-conflict agricultural programming. For this transition to take place, a fundamental shift must take place in the role of NGOs, massive capacity building efforts at all levels are required, and there must be clarity and consensus on the role of the state vis-à-vis the private sector. We use the notion of "postconflict transitions' to examine the principles that are appropriate to particular contexts and programming objectives. If a pragmatic approach to humanitarian, livelihoods and rights-based principles is to be adopted, then this requires greater clarity of both the political agenda and the impact of conflict on local livelihoods and informal institutions. 


\section{Chapter 2 \\ The impacts of conflict on agriculture and rural livelihoods}

\subsection{Introduction}

This chapter introduces a number of analytical concepts relating to livelihood strategies, and the notions of vulnerability and resilience, and examines the impacts of conflict on various aspects of agricultural systems. Recent thinking from agricultural and rural development regarding agricultural service provisioning and the role of agriculture in rural livelihoods is provided as background information. Each sub-section closes with a short paragraph outlining the implications for external interventions, and these are summarised in section 2.8 .

\subsection{The role of agriculture in rural livelihoods and the 'yeoman farmer fallacy'}

Internationally, there is a growing shift in rural development thinking away from what has been called the yeoman farmer fallacy' (Farrington and Bebbington, 1992), a belief that virtually all rural people strive (and should strive) to alleviate their poverty through increased or more effective investment in their own household farms. Instead, there is a realisation that a growing majority of the rural poor earn most of their income outside of the homestead farm (Ashley \& Maxwell, 2001). It is increasingly recognised that a host of other actual and potential rural and non-rural activities are important to the construction of viable rural livelihoods (Ellis and Biggs, 2001). In Afghanistan, for example, it has been estimated that $65 \%$ of farming families depend heavily on off-farm income (ADB, 2002). Similarly, in Kambia District, Sierra Leone, the WFP Food Security Survey found that the most commonly cited sources of income were: small businesses (cited as one of four main income sources by $36 \%$ of households interviewed); sale of field crops (32\%); petty trade (30\%); and rice sales (23\%) (Kenefick and Conteh, 2003: 39). Data collected by our own survey of 320 households in Kambia District revealed that better-off households relied more on agriculture for their livelihoods than households from the poorer wealth classes (Longley, 2006 forthcoming). Although almost all (94\%) poor households relied on the cultivation of annual crops as one of their five main sources of livelihood, a number of alternative livelihood strategies (unskilled labouring; artisanal work; remittances; ${ }^{8}$ traditional skills; ${ }^{9}$ firewood/

8 Remittances were cited among the top five livelihood strategies by $28 \%$ of poor households and $12 \%$ of better-off households. It is assumed that the remittances the poor receive are neither regular nor large.

9 Traditional skills include working as an imam, herbalist, traditional birth attendant, diviner or witchdoctor. charcoal sales; and hunting) were found to be more important to poor households than to better-off households. Given the importance of off-farm income to poorer households, it is also not surprising to note that the most chronically food insecure households were those who had the highest proportion of expenditure on food (Kenefick and Conte, 2003), a point that we return to in section 2.4.2.

Despite the realisation of the importance of non-farm livelihood strategies in the development field, subsequent sections of this paper will show that the yeoman farmer fallacy continues to permeate much agricultural programming in countries emerging from conflict. These 'yeoman farmers' may be a major target group, but they are not the only - or necessarily the most vulnerable - group of rural people reliant on agricultural production. Interventions that are strictly agricultural are likely to benefit the betteroff more than the poor, suggesting that additional efforts are needed if vulnerability is to be alleviated. A livelihoods approach to agricultural interventions requires transcending the yeoman farmer fallacy and addressing the complexity of how rural people 'hustle' to survive. It is encouraging to note that data collection efforts are increasingly adopting a livelihoods perspective in providing a more solid basis for understanding the ways that rural livelihoods are (and are not) dependent on smallholder production. ${ }^{10}$ However, there remains a gap in moving from livelihood-based assessments to the identification of appropriate livelihood support (Jaspars and Shoham, 2002).

\subsection{Analytical concepts: livelihood strategies, vulnerability and resilience}

Livelihoods analysis can be defined as differentiated and multi-level research that examines changes over time; it is based on empirical investigations into the livelihood strategies of households and communities, in which micro-level findings are situated within a macro context to explain the social, economic and political factors relating to poverty and vulnerability (Murray, 2001). As illustrated by Figure 1, livelihood strategies refer to the ways in which individuals, households or communities use and combine their assets within particular institutional and vulnerability contexts in order to achieve desired outcomes.

10 Examples included Sierra Leone's Rural Food Security, Livelihoods and Nutrition Survey, Afghanistan's National Risk and Vulnerability Assessment and the AREU livelihoods monitoring project. 


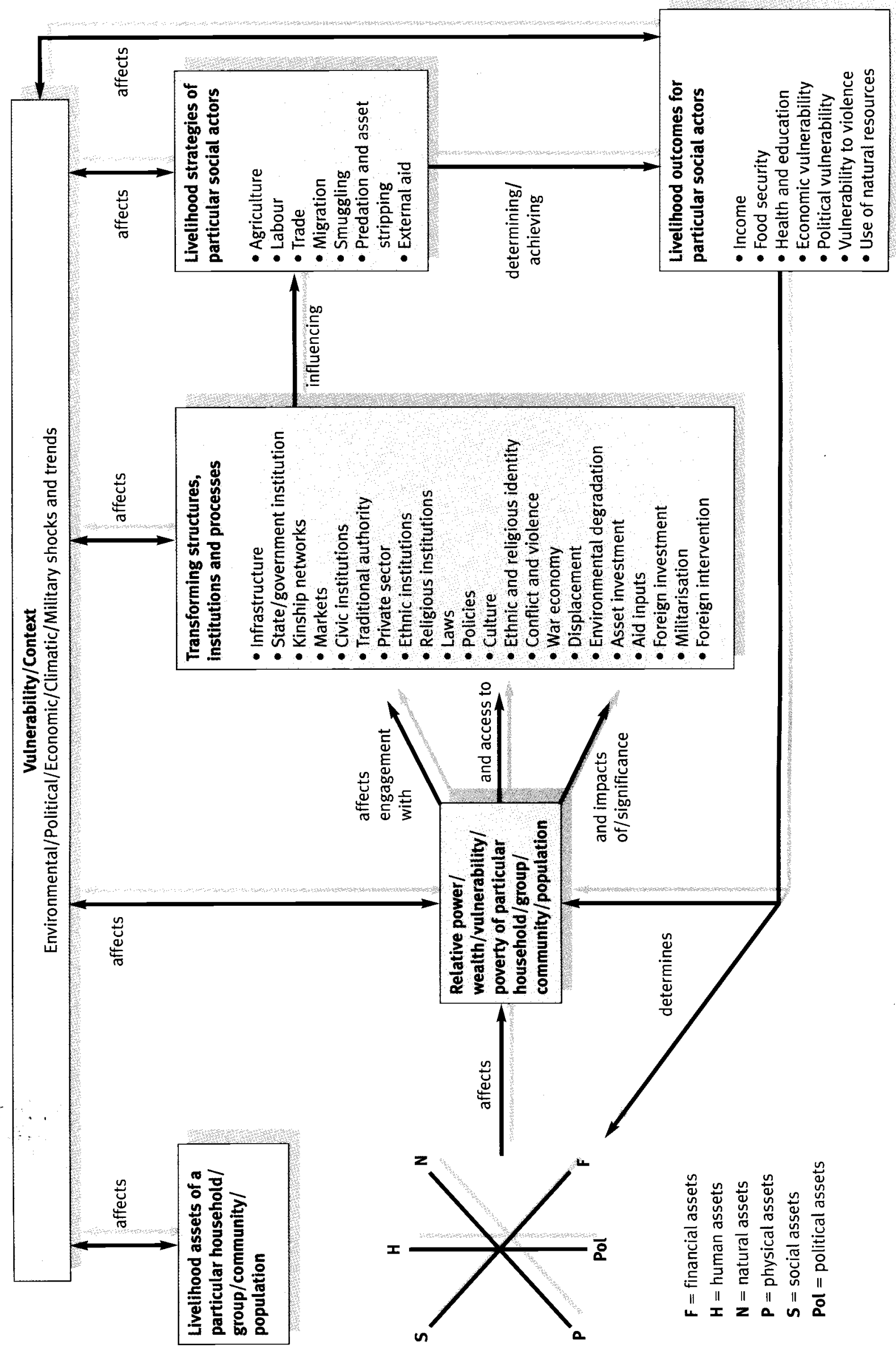

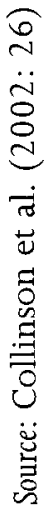


Stephen Devereux $(1992 ; 1999)$ usefully categorises household livelihood strategies in relation to their impacts on household assets. Though the exact boundaries between the different categories may be difficult to ascertain, and a particular household may be pursuing a number of different categories of strategies at any one time, Devereux differentiates between strategies of accumulation, adaptation, coping and survival: accumulation strategies seek to increase income flows and build up assets; adaptation strategies seek to spread risk by adjusting livelihoods or diversifying income; coping strategies aim to minimise the impacts of shocks and may involve changes in the relative balance of assets; survival strategies are a last resort to prevent destitution and death, and lead to the depletion or erosion of essential assets. ${ }^{11}$

In times of crisis, most households will be forced to adopt adaptation and/or coping strategies in order to get by. Many will also be forced to deplete their assets in order to survive; this may involve a range of different mechanisms, from the sale of livestock or other physical assets to early marriage or prostitution. Some survival strategies are clearly more damaging than others. Coping strategies can be described as short-term responses to periodic shocks e.g. those associated with conflict (violence or temporary displacement), or natural disaster (flood, drought), whereas adaptive strategies involve more or less conscious and deliberate adjustments to longer-term contextual changes/trends (chronic insecurity or long-term displacement). The capacity of different households to cope, adapt and survive to changing circumstances basically depends on access to resources or assets, including social and political assets. This, in turn, is determined by the structures, institutions and processes which variously support or constrain livelihood strategies (Figure 1). In adverse circumstances, livelihood strategies typically comprise a portfolio of both short-term coping and long-term adapting strategies. These combine in different ways in different contexts. While conflict is clearly a major factor influencing livelihood strategies in our case study countries, it is often difficult to distinguish between strategies for coping with or adapting to conflict, and strategies for coping with or adapting to chronic poverty. Poverty and food insecurity exist in many areas before conflict, and while compounded by conflict they are equally likely to persist post-conflict. Understanding the extent to which the current poverty and food insecurity of different groups relates to the conflict is clearly important in order to be able to identify and support vulnerable groups post-conflict.

The notion of vulnerability - the extent to which a person or group is likely to be affected by adverse circumstances is one that humanitarian actors are familiar with, and this term is of increasing interest in development thinking.

11CARE uses a similar categorisation that is more explicitly based on household assets and how they are used: strategies are defined as accumulating, maintaining or depleting assets (Westley and Mikhalev, 2002).
Section 4.3.2 examines the notion of vulnerability in more detail, particularly in terms of powerlessness and how it relates to social protection. The related notion of resilience, on the other hand, is perhaps less widely used. Resilience is a term originating from ecology to describe the elasticity inherent in an organism or system that allows it to "spring back' after having been changed by some event. In our use of the term, resilience describes the ability of households, communities or even agricultural systems to deal with change. The key features of resilience are thought to relate to diversification, adaptation and flexibility (e.g. of livelihood strategies, social networks, gender roles, crops, markets). Although resilience might encompass negative aspects (e.g. when coping or survival strategies are erosive), people's actions frequently prioritise the safeguarding of their livelihoods and the assets upon which they are based.

The resilience of rural populations in the face of adversity suggests that the popular perception of people caught up in complex emergencies as helpless victims dependent on humanitarian aid is misleading. It is increasingly recognised that people are often able to manage without aid by coping and adapting their livelihood activities to the circumstances of chronic conflict and political instability. A key question for agencies therefore is: how do people manage to pursue livelihoods amid the day-to-day stress of coping, adapting and surviving in an uncertain and violent environment, and how can they be supported more effectively? In Chapter 4 we will refer to livelihoods support in terms of social protection and livelihood promotion. Social protection is essentially concerned with the ways in which individuals' or households' resilience to adverse events can be strengthened. Livelihood promotion involves measures intended to encourage pro-poor growth and social equity. As is evident from the livelihoods framework of Figure 1, such interventions do not necessarily have to focus on assets per se, but on alleviating structural or institutional constraints that influence them.

\subsection{Impacts of conflict on agriculture}

\subsubsection{Impacts on agricultural production and produce markets}

Box 1 highlights some of the ways in which conflict was found to impact upon agricultural production and markets in the case study countries. Despite these hazards, it must be stressed that agricultural production does, in some ways, fare surprisingly well in the face of conflict. For example, Afghan agricultural production was recovering rapidly under the Taliban during the latter half of the 1990s, before the onset of drought: both horticulture and cereal production were increasing, and farmers were experiencing a modicum of stability despite the destruction of physical and institutional infrastructure (Christoplos, 2004). ${ }^{12}$ The drought at the end

12 The reasons for this include the fact that the Taliban were able to achieve higher levels of security than both their predecessors and their successors, suggesting that the analysis of the Taliban as a regime of conflict rather than a strong state is problematic. 


\section{Box 1: Impacts of conflict on agricultural production}

- Insecurity has prevented labourers, input providers and traders from accessing farms at key times in the production cycle.

- Expanding urban populations ${ }^{13}$ due to displacement has affected market demands and intensified peri-urban production, thus competing with rural producers experiencing increasing transport costs.

- Changing household composition (due to death, abduction, displacement or migration) has reduced family labour and in some cases increased access to remittances.

- The loss or depletion of financial assets has limited access to agricultural inputs.

- Displacement has forced some farmers to abandon their farms and/or production output altogether and associated systems of soil and water management have broken down.

- Access to land, labour and other inputs has been limited in places of refuge.

- Agricultural outputs have been forcibly extorted by warlords and local militia.

- Access to land, pastures and irrigation resources has been subject to unchecked conțrol by warlords and power brokers.

\footnotetext{
13 This relates partly to conflict, but is complex and includes both 'push' and 'pull' factors. Equally, there are both positive and negative implications for rural populations who are left behind.
}

- Latent conflicts between pastoralists and settled farmers have been revived or intensified due to increased access to small arms.

- Formal input delivery systems have ceased to function.

- Formal quality control, regulatory and phytosanitary institutions have ceased to function, leading to shifts in export markets and lower product prices.

- Changes in the local economy (either related to conflict or relief food supply) may have contributed to rendering staple food production unprofitable (though other crops may have become more profitable e.g. fruit and vegetables for growing urban markets).

- Insecurity and taxation systems imposed by local militia may disrupt or alter produce-marketing channels.

- Destruction of common property resources (most notably pistachio forests in Afghanistan or wood used for charcoal production elsewhere) has decreased production of crops/products that have had an important safety-net function, for landless farmers in particular.

- Displacement of the pastoral population from grazing land has depleted livestock production and prevented its recovery after the drought.

- Concentration of displaced populations, e.g. around a few functioning water points, has led to over-exploitation of certain land areas, and may have long-term negative consequences for the natural resource base.

towards cassava turns out to be a temporary or more permanent change will probably depend on whether there is a shift in the market. Groundnuts, which tend to be cultivated more in the north of the country, show a steady increase in production until 1999/2000 (coinciding with the worst period of the war in the north), but a spectacular increase in the two subsequent years, with levels of production rising to over three times that for the pre-war period by $2001 / 2$. At a more localised level, the survey of 320 farming households in Kambia District conducted for this study revealed that almost half $(46 \%)$ were able to continue with at least some of their agricultural activities throughout the war, despite numerous rebel attacks, population displacement and almost two years under rebel occupation. Comparative figures are not available for other parts of the country, but would probably vary considerably.

Table 1:- Trends in food crop production in Sierra Leone, 1989/90-2001/2002 (Mt1,000)

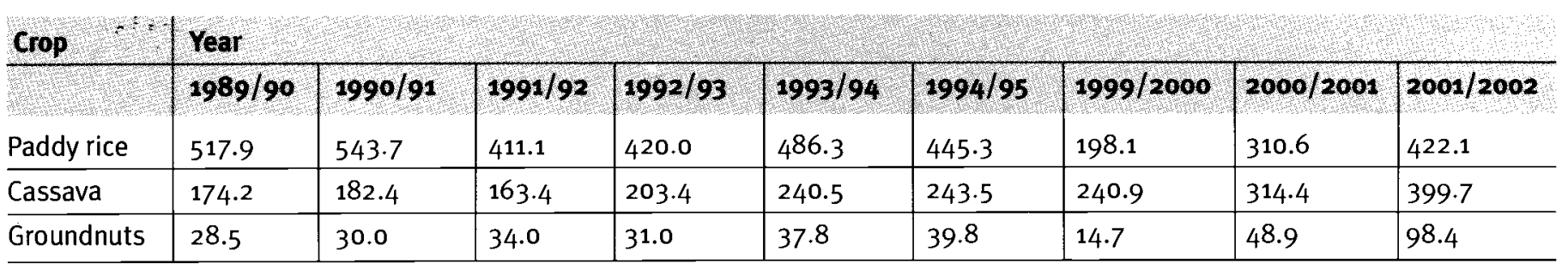


In Afghanistan, there is significant disagreement among researchers about the extent to which Afghan rural livelihoods have undergone a temporary or permanent shift from subsistence production to commercial production and diversified sources of income. The drought of 1999-2002 almost certainly caused a far greater temporary reliance on access to cash (rather than subsistence production) due to the failure of food crops, and the reliance on a cash economy has continued as farmers struggle to repay debts to traders that were incurred during the drought (Lautze et al., 2002). In the search for cash income, household labour resources have increasingly been shifted to expanding opium production (see also section 2.6). This may further lock families into the cash economy as they must purchase more food while they devote available labour resources to poppy (Mansfield, 2002). It is unclear, however, how much poppy production has actually diverted labour away from other crops. The spectacular increases in opium production in recent years have occurred parallel to increased production of cereals and other cash crops.

A key finding of the Afghanistan case study was the lack of detailed empirical analysis of the longer-term prospects for Afghan farmers in regional and international agricultural markets. It is important to understand how producers in neighbouring countries respond to production trends in Afghanistan, and in particular whether market share lost to international competitors during the conflict can realistically be recovered. As noted in Chapter 1, rehabilitation efforts tend to focus on restoring agricultural systems which existed before the conflict, without sufficient attention to changing market conditions. With the notable exception of the opium economy there has been a general failure to locate household food security within the wider context of regional and international agricultural markets.

Evidence from Afghanistan and Sierra Leone, among other countries, suggests that conflict has a much more multifaceted impact on production than might be assumed. Case study analysis highlights significant challenges around identifying and understanding two types of agricultural changes in countries suffering protracted conflicts. First, it is necessary to understand the way in which farmers alter their farming practices and livelihood strategies to cope with the impacts and effects of conflict and displacement. Whether these shifts are short-term, temporary measures to cope with the effects of conflict, or represent more permanent, adaptive strategies is often unclear. A second set of challenges surrounds understanding producer responses to shifting agricultural markets. The impact of conflict on production and markets is often highly uneven, and changing markets and market opportunities do not always follow conventional assumptions about the stage of conflict in a given country. Conflict presents both risks and opportunities. Its ebb and flow also affects patterns of demand for agricultural produce. Disruption to farming systems in one location may mean new market opportunities for farmers in other areas. Some localised or informal markets (seeds, for example) remain surprisingly resilient, and other 'obnoxious markets' (Kanbur, 2001) such as narcotics and other contraband actually thrive. There may be surprisingly little impact on food markets, as has been shown by the extraordinary stability of local wheat prices relative to urban wages and international market prices in Afghanistan (Maletta, 2002).

\subsubsection{Impacts on consumption and nutrition}

Humanitarian approaches have a tendency to regard nutrition solely in terms of reducing mortality and morbidity, but it is also important to address nutrition in terms of increasing productivity and alleviating poverty. Hunger has substantial economic costs for individuals, families and whole societies. Labour, often the only asset of the poor, is devalued for the hungry. Mental and physical health is compromised by lack of food, cutting productivity, output and the wages that people earn. Chronically hungry people cannot accumulate the financial or human capital that would allow them to escape poverty, and hunger has an intergenerational dimension, with undernourished mothers giving birth to underweight children (IFAD, 2001; WFP, 1998; FAO, 2002). Arguably nutrition (as the engine of labour productivity and creativity) is just as important as technical inputs (Bonnard, 2001).

A common coping strategy for rural populations affected by conflict is to reduce consumption by reducing the number of meals eaten each day and/or to eat less desirable foods. In reversing this situation, entitlement theory (Sen, 1981) tells us that an increase in food production does not necessarily lead to a consequent impact on consumption. Not all of the food consumed by a household is necessarily produced by the agricultural activities of that household; it is not uncommon for rural households to purchase significant proportions of the food they consume. In Sierra Leone, for example, food security profiling revealed that the most chronically foodinsecure households were those who had the highest proportion of expenditure on food (Kenefick and Conte, 2003). In theory, an increase in food production would lead to lower food prices, but there is a surprising dearth of information from the two case studies to show whether increases in food production actually lead to increased consumption

In Afghanistan, information about nutritional levels is patchy, and data that can be correlated with the prevalence of conflict is completely absent. What data are available have consistently shown surprisingly low levels of acute malnutrition, paired with very high levels of chronic and micronutrient malnutrition, both during and after the drought. This suggests that coping strategies have provided 
for the most basic survival needs under very high levels of stress. Repeated shocks create a situation of chronic vulnerability, and over $50 \%$ of children under five are estimated to be chronically malnourished (WFP, 2003). Acute malnutrition appears to be primarily a seasonal problem during the summer, and is related to diarrhoeal diseases rather than food shortage. Low levels of acute malnutrition have been interpreted as suggesting highly equitable distribution of food within the household. High rates of micronutrient malnutrition (and scurvy) point to the importance of dietary habits, and possibly food preservation and post-harvest practices, rather than aggregate cereal production per se. Horticultural production had, before the drought, significantly increased during the conflict years (FAO, 2003) largely for home consumption (most export markets for these commodities had collapsed). However, there is very little consumption of fruits and vegetables during the winter months.

Evidence available for Sierra Leone clearly indicates that food availability is not a major problem (Lawrence and: Banham, 2002). Though reference is commonly made to the annual 'hungry period' just prior to the main rice harvest, this seasonal variation is not so much a deficit but a shift away from the preferred food type. Malnutrition among mothers and their children in Sierra Leone is thought to be more closely related to health and hygiene than to food consumption (Kenefick and Conte, 2003). Chronic malnutrition and childhood stunting is a major problem for all food security profiles: $44 \%$ of children (whether from households considered to be food secure or insecure) are reported to be stunted (ibid). Although considerable improvement in child malnutrition was reported between 2000 and 2003, indicators for chronic malnutrition remained high and stunting of children was still on the rise (GoSL, 2004). The potential for rapid improvement in the nutrition situation of children remains, but the data suggest that this will not be achieved though production increases alone.

\subsubsection{Implications for agricultural interventions}

It is essential to step back and reassess our basic assumptions about how conflict impacts on agricultural production and produce markets, nutrition and consumption. The resilience of agricultural production is rarely alluded to, much less analysed, in current planning efforts for agricultural interventions. Rather, post-conflict production increases tend to be taken as evidence of the apparent success of agricultural interventions. There is a need to understand the ways in which farmers and farming systems have adapted to change, and to attempt to understand whether these are related to short-term shocks linked to conflict or to longer-term market dynamics. Much more detailed information is also needed to understand the links between agricultural production, consumption and nutrition.

\subsection{Impact of conflict on agricultural inputs and services}

Farmers need access to a wide spectrum of inputs and services in order to produce effectively, especially when their products need to compete in commercial markets. Within agricultural development, it is increasingly recognised that the potential gains that can be achieved through one service, such as provision of quality seed, may be dependent on access to other inputs, such as fertilizer, water for irrigation, pest control, and extension advice, as well as access to credit to finance these other services. Large-scale cereal production may require access to mechanised ploughing services, and effective market agriculture often requires interventions at various stages in the 'value chain', such as market price information services, in addition to services for processing, post-harvest storage, transport and certification. When producing for export, high-quality services in these areas are essential. Phytosanitary and veterinary services are vital for livestock production.

Although the value of any one of these services is largely dependent on the availability of other services, it is rare that aid interventions alone can 'solve' this need for broader service 'packages'. The integrated rural development programmes that were popular in the 1970 s and 1980s failed due to an overestimation of what could be accomplished by the aid community, and an underestimation of the coordination costs involved in trying to manage the myriad links between these services. New concepts of how to manage area development efforts have instead stressed the need to design interventions that are cognisant of the variety of services that farmers require, while realising that different actors from the public sector, private sector and civil society will have different roles (Farrington et al., 2002). Some of these services, such as phytosanitary control and services related to common property resources are public goods, which will need a large degree of public financial support. Others, most notably input supply and marketing related services, will in most cases be primarily managed by the private sector and paid for directly by producers. These different services cannot all be coordinated (nor should they be), but strategic efforts to help farmers to put together their own 'packages' may lead to greater synergy.

In Sierra Leone, the level of formal agricultural service provision before the war was minimal: what formal agricultural advice was available to farmers tended to be provided through NGOs or donor-funded integrated agricultural development programmes (subsequently renamed farmers association support programmes). These projects also provided credit to farmers, usually in the form of seed or fertiliser or (in some areas) mechanised ploughing services. Such services effectively ceased with the conflict as insecurity spread throughout the country. Apart from petty 
traders providing credit and other inputs to small-scale farmers, private sector involvement in the supply of agricultural inputs and services was limited to the commercial agricultural sectors (coffee, cocoa, oil palm). The private sector fared considerably better than NGO or government projects; private-sector seed enterprises, for example, expanded considerably throughout the conflict period to meet the demand for seed by donor-funded emergency seed projects (Longley, 2006 forthcoming).

Given the lack of public sector agricultural service provision in Sierra Leone prior to the conflict, inputs such as seed and credit were generally sought through informal mechanisms, either through what might be called the informal social protection institutions existing within communities (e.g. for gifts of seed through social networks or access to credit through local 'osusu' savings groups) or the more marketbased systems for the supply of inputs on credit from local traders. Though subject to considerable strain, these informal systems tended to be much more resilient than the more formal systems in the face of conflict. Following the 'liberation' of Kambia District, for example, $84 \%$ of households interviewed reported receiving some form of agricultural support through local social networks, and this was fairly evenly spread among wealth groups. Such assistance is an important part of normal agricultural practice in Sierra Leone, and the fact that this support was clearly still available to farmers in the post-conflict period illustrates the resilience of social support networks, an observation that has also been documented for Somalia (Narbeth, 2001). The majority of the farmers surveyed (63\%) reported providing assistance to others in re-establishing their agricultural activities, including just over half of those farmers considered to be poor. ${ }^{15}$ The data suggest that agricultural support provided through local social networks played a very significant role in helping farmers of all wealth classes to reestablish or continue with their farming activities.

In Afghanistan, local social networks that have proved to be the most resilient are those based on patron-client relationships. There is also much more private sector involvement in the supply of agricultural inputs and services, but problems exist in relation to high transaction costs, trust, quality, reliability and efficiency. Extraordinarily high transaction costs in. accessing inputs and services result from a combination of insecurity, uncertainty, weak formal (regulatory) institutions and destruction of physical infrastructure. Diminished trust due to the legacy of conflict, current insecurity or the capricious nature of aid flows has prevented the emergence of a sufficient array of service providers offering farmers a choice of services. Patron-client relationships (often based on ties between landlords and

15 Data results show that $52 \%$ of poor farmers, $65 \%$ of middle-wealth farmers and $74 \%$ of better-off farmers provided agricultural assistance to others. Poorer farmers were most likely to provide labour and the use of tools, whereas better-off farmers were more likely to provide seed, cash or land. tenants) are currently the most viable way that many farmers in Afghanistan seek to lower (or at least stabilise) their transaction costs. There is a tendency within the aid community to see sharecropping and other patron-client relationships as purely a source of exploitation, as certainly it is. While patron-client ties are often extractive, it has long been internationally recognised that near-destitute farmers usually look first at what is left for the family to survive on, rather than the costs (Scott, 1976). Furthermore, secure relations with a local patron are worth paying for in order to ensure that the overall range of necessary services can be accessed. Various studies in Afghanistan have pointed out that access to credit is highly dependent on ties to patrons (Mansfield, 2001; Alden Wily, 2004). Even other services, such as ploughing (Allen, 1999), are easier to access where strong ties to a patron exist.

The lack of policies for, or regulation of, technical standards for agricultural and veterinary inputs in conflict situations means that the quality of inputs purchased by farmers and pastoralists may be sub-standard. Interviews with farmers in Afghanistan showed that they were furious over their inability to trust the reliability of the inputs that they receive from the private sector and NGOs. Weak public sector institutions and the power of local commanders make attempts to use legal mechanisms to hold service providers to account nearly impossible. Landlords or patrons are in many ways more accountable to their tenants or sharecroppers for the quality of seed that they provide than aid agencies, whose presence is dependent on short-term contracts. This is because it is in the interest of the patron to ensure that inputs are of high quality, and that farmgate prices are high when profits are divided with sharecroppers.

In general, evidence from the case studies suggests that, despite the collapse of government or project-based agricultural inputs and services, farmers are often able to continue to access such inputs and services through local social networks (including patron-client relationships) and - to some extent - private sector providers. However, the quality of the inputs and services available is often very low, and costs can be prohibitive. The challenge for post-conflict external assistance, therefore, is to improve the provision and reliability of inputs and services without undermining these local informal social protection mechanisms or hindering the role of private sector providers.

\subsection{Rural labour markets, migration and return}

One of the assumptions that underpins the yeoman farmer fallacy in chronic conflict and post-conflict contexts is that conflict reverses 'normal' development trends by wreaking havoc on markets. Vulnerable people are thought to retreat towards subsistence as best they can. There is no sign of this happening in Afghanistan, where labour markets in the cities and in poppy production are of increasing importance. Fears 
that weakened labour markets would be swamped by the massive return of refugees and IDPs have proven unwarranted. Recent surveys have shown strong demand for farm labour and rising wages in many urban and peri-urban areas (Maletta, 2002; Maletta, 2003). Apart from links to the urban economy, the key factor in rural labour markets is opium. As Afghanistan's main commercial agricultural crop, opium is grown on just one percent of the arable land, or less than three percent of the irrigated land area (UNODC/GoA, 2003). It is a crop that absorbs over eight times the labour input per unit of land as wheat (Mansfield, 2001). This suggests that the link between agriculture and livelihoods is not a matter of how farmers decide to use their land, but rather how rural people, landed and landless, use their labour.

In both case study countries, growing numbers of returning refugees appear to be choosing to settle in urban areas. This apparent rural-urban migration indicates a response to several factors:

- loss of land and other assets that make rural livelihoods unviable;

- preference for continuing urban lifestyles among returning refugees;

- increased exposure to urban livelihoods, including skills development;

- shortage of off-farm employment in isolated rural areas that rules out a gradual re-accumulation of assets through rural livelihoods alone; and

- a perceived need to build up assets necessary to make rural livelihoods viable (in this case urban settlement is regarded as a temporary, interim measure before an eventual return to rural areas).

In Sierra Leone, the observation that many returnees were choosing to return to urban centres rather than rural areas led to debates about whether the rural labour force would be sufficient to produce enough food to meet national demand.

These observations suggest a need to understand how rural households relate to the agricultural economy beyond the farm. An overall understanding of labour markets indicates that, both in terms of securing livelihoods and stimulating economic growth, labour force mobility is in many respects a highly positive factor. This runs counter to the views and stated objective of many NGOs in 'helping people to stay in their villages'. With the exception of pastoralism, migration is seen by many agencies and some researchers (Lautze et al., 2003) as a symptom of failed livelihoods, not as a solution to inherently weak local subsistence and market economies. The assumption that migration is inevitably and inherently 'bad', or that returnees will necessarily return to rural areas, distorts priorities and underpins programming that takes farming to be the norm (Kerr-Wilson \& Pain, 2003).

\subsection{Land and natural resources}

Though the case study research did not collect data on natural resources degradation specifically, documented evidence from various countries would suggest that protracted conflict has detrimental effects on natural resources and natural resource management. In Somalia, for example, environmental damage includes serious degradation of rangelands due to charcoal production and minimal rangeland management, the depletion of renewable fresh water sources, over-exploitation of fishing grounds and reduced numbers and diversity of wildlife (Wilson et al., 2004: 29). This situation has been brought about by ecologically damaging coping strategies that increasingly impoverished rural households are forced to adopt, together with the lack of effective regulation in the use and exploitation of natural resources. Elsewhere, natural resources may provide the basis for local war economies, and their uncontrolled extraction has negative impacts on the environment, e.g. mineral extraction in Sierra Leone, DRC and Angola; timber and tree crops in Casamance (Evans, 2002). Similarly, land and access to land is often inextricably linked to the causes of conflict and/or local grievances. Access to land and natural capital upon which rural livelihoods depend is considered vital for post-conflict recovery (Addison, 2005), and - in some cases - this may require significant reform of tenure arrangements.

In Afghanistan, the nature of land tenure insecurity has been vividly described by Alden Wily (2003: 1):

from the returning refugee widow who is unable to wrest her
husband's land from his family, to the community evicted by
a land-hungry warlord, to the drought-defeated smallholder
who has sold his last plot for food and cannot find a landlord
willing to enter a sharecrop arrangement. It may also be a case
of clan heads carving up local pasture for new cultivation, land
that poorer villagers thought was theirs to share, that the
government thought was its own to distribute, that visiting
nomads thought was theirs to graze - and often have the
documents to 'prove it'.- documents that may conflict with
others issued at different times, with the law, or with human
rights and justice norms. At this point in time, multiple
claims, each with its own historical legitimacy, may exist over
the same land. The law, and the documents or testimony it
generates, is plural, complex, uncertain, incomplete and
currently unenforceable.

Conflict over rural space has been one of the key factors driving and sustaining internal conflicts in Afghanistan for over 25 years, yet recent approaches to land tenure issues have tended to be superficial (Alden Wily, 2003). Given the deep structural nature of the challenges facing the landless and destitute in Afghanistan, modest project-based agricultural interventions are severely limited in the extent to which they are able to modify the context of these groups' 
vulnerability. Land relations must form part of the development agenda, but the process of addressing land relations will not be easy.

In rural Sierra Leone, land relations are not nearly as complex as in Afghanistan, but there is some degree of similarity in that the current problems stem not only from the conflict, but are also rooted in more structural aspects of rural communities. Access to land within a chiefdom is dependent on one's identity as a 'citizen' (as opposed to 'stranger') of that chiefdom. Despite the existence of formal, bureaucratic structures that allow one to prove one's identity through a birth certificate, in practice the vast majority of rural Sierra Leoneans rely upon the chiefs to authorise and guarantee the identity that confers their rights to land (Fanthorpe, 2001). Thus, land rights are inextricably linked to the powers of the paramount chief. The land tenure issue has been a source of much debate among aid agencies, government actors and legal professionals in post-conflict Sierra Leone - some consider land reform to be a vital aspect of rehabilitation; others regard it merely as a 'red herring' when in fact what is needed is a more thorough agrarian reform (Richards et al., 2003). It has also been suggested that land tenure reform is necessary for agricultural development, particularly for effective commercial agriculture in allowing landowners to use land as collateral in accessing credit (GoSL, 2004). The question of whether or not land reform is necessary in a post-conflict context depends very much on the role of land tenure as a contributory factor to war (see section 5.3).

\subsection{Summary and implications for post-conflict agricultural interventions}

Subsistence production may be a cornerstone of rural livelihood strategies, but it is not sufficient as a guarantee for survival. Farmers - especially the poorest and most vulnerable - rely on a range of different livelihood activities. The relative importance of agriculture as part of broader livelihood strategies varies for different households and changes over time and in response to adverse effects. Survey data from Sierra Leone clearly indicate that the importance of agricultural production to household livelihood strategies had changed as a result of war, but there was no clear pattern as to whether it had become more or less important to different types of households, thus making it difficult to predict such changes. It is necessary for interventions within the agricultural sector to recognise that agriculture may not be the only or the most important source of livelihood to rural households. Focusing on agricultural production alone is unlikely to be sufficient to solve the problems faced by the most vulnerable households. The role of agricultural markets must also be taken into consideration - not only for the sale of agricultural products but also as a source of food for vulnerable households, and the supply of agricultural inputs. More broadly, it is also necessary to understand rural labour patterns and recognise that migration is an important coping strategy. Not all of those displaced from rural areas will necessarily return to rural areas.

The resilience of agricultural production is such that it will recover fairly quickly once farmers are able to return to their farms, provided that rainfall is sufficient and that environmental degradation has not been so severe as to prevent production. The assumption that there is a need to 're-establish' farming activities is often inaccurate; in communities where not all households were displaced, agricultural activities may continue (albeit with changes in cropping patterns and/or reduced areas of cultivation). Although the public-sector provision of agricultural inputs and services may have ceased, and inputs supplied through the private sector may be of poor quality and involve high transaction costs, local forms of social support are remarkably resilient and often play a crucial role in helping farmers to access the inputs and services required. It is important that external efforts to enhance agricultural input provisioning do not undermine these social support mechanisms. In the longer term, productivity increase is not just a matter of diffusing agricultural inputs or 'modern' technologies, but involves addressing the risks and opportunities facing farmers, traders and other stakeholders in the rural economy. Finally, it is also important to understand the ways in which agricultural systems may have changed, both in response to conflict and changing livelihood strategies and in response to changing market trends. As we shall see in Chapter 3, however, these factors are rarely considered in current agricultural programming during and after conflict. 



\section{Chapter 3 \\ Post-conflict agricultural programming in Afghanistan and Sierra Leone}

\subsection{Introduction}

Chapter 2 suggests that interventions that focus solely on agricultural production are unlikely to be sufficient to solve the problems faced by the most vulnerable households. It is also necessary to recognise the importance of agricultural markets to rural communities. This section examines postconflict agricultural interventions in Afghanistan and Sierra Leone, and the extent to which they actually address the problems faced by rural communities. It starts by looking at the various seed-based approaches, and then considers the provision of other agricultural inputs and services. Approaches to promoting markets are examined, and recent developments with rights-based programming are described.

\subsection{Food aid, seed aid and beyond}

Interviews with agency staff responsible for rehabilitation programming indicate a widespread belief that the phasing out of food aid, through its replacement with seed aid, is a necessary step in the transition towards more developmental approaches to food security. Indeed, a major driving force behind the promotion of agricultural rehabilitation efforts has been an often-intense anti-food aid discourse, particularly in Afghanistan. Although evidence to substantiate either pro-food aid or anti-food aid views is notably lacking from such debates, food aid is thought to contribute to dependency among beneficiaries and undermine agricultural production through price distortions, resulting in a lack of growth in primary production sectors, and thus hindering efforts for longer-term developmental approaches.

In Sierra Leone, the debate is less heated - possibly because the food aid grain provided (mainly bulghur wheat) is neither a crop that is cultivated in Sierra Leone nor a preferred food type - and the transition from free food distribution to 'food for agriculture' (i.e. for inland valley swamp development; upland farm cultivation; and tree crop rehabilitation) and 'food for work' (i.e. for road and jetty construction and rural structures such as stores and drying floors) is very much part of agricultural rehabilitation. Survey data confirm this: 124 out of 230 sample households reported receiving food 261 times. The bulk of the food received was used to feed agricultural labourers (252 times, or 97\%), indicating the importance of food aid for agricultural activities. Rather than trying to phase out food aid altogether, the Ministry of Agriculture is instead trying to gain greater control over it. Food aid is used as an incentive to promote agriculture. It is also coming to be seen as a safety net (we will return to this in section 4.5.1).

It should be stressed that, although food aid attracts vitriolic criticism relating to perceived concerns over dependency, other dependency issues receive notably less attention. Consideration of how to avoid dependency on free seed and other heavily subsidised agricultural support is, by comparison, rare, yet many of the arguments that are applied to the anti-food aid discourse can also be used in reference to seed aid. However, given that there is little evidence to suggest that relief (whether food or seed) undermines initiative, or that its delivery is reliable enough for people to depend on it, a more important question concerns what form of assistance is most appropriate (Harvey and Lind, 2005). As described in section 1.6, various commentators have argued that there is a need to move beyond seeds and tools (see Longley \& Sperling, 2002), or to 'get off the seeds and tools treadmill' (Remington, 2002). Such efforts have taken various forms in each of the case study countries, as described below.

\subsubsection{Afghanistan: agricultural 'subsidies' and technology transfer}

Afghanistan represents a classic example of the 'treadmill tendency'. Support was given to seed programming throughout the 1990s. At the end of 2001, plans were made for a major expansion of distributions in the 'post-war' phase to address what were assumed to be serious levels of seed insecurity (see, e.g., Grünewald, 2001). Agencies based in Pakistan planned their emergency and rehabilitation programmes with little first-hand information. The 'crisis narrative', fuelled by easy access to donor resources, superseded accurate needs assessment. After bumper harvests in 2003, most actors acknowledged that the initial assumptions of a seed crisis after the fall of the Taliban regime were grossly exaggerated. Large-scale seed distributions nonetheless continued throughout 2003, before finally being scaled down (Christoplos, 2004).

The justification for seed programmes gradually shifted away from addressing an absolute absence of seeds. Instead, interviewees explained that continued seed aid was important as a way to use institutional structures and experience to subsidise ${ }^{16}$ agricultural production, thereby

\footnotetext{
16 The term 'subsidy' is almost never explicitly used in aid and agricultural policy discussions given its associations with weak sustainability. There is, however, a general agreement that Afghan farmers need an injection of capital (i.e. a subsidy) to increase their production.
} 
accelerating recovery (Christoplos, 2004). Second, there was a perceived need to increase access to 'improved' seed and speed up genetic renewal. ${ }^{17}$ These two justifications for seed aid - subsidisation and technology transfer - are relevant in many respects, but there remains the wider question of whether seed aid is the most appropriate type of intervention.

Particularly given the sensitivities around providing 'agricultural subsidies', seed distributions are primarily promoted as a way to push new technologies on 'ignorant' farmers. Agricultural officers from most agencies interviewed stressed the primary importance of changing the attitudes of villagers. It is thus the behaviour of the villagers, rather than the conditions in which they live, that is seen to constrain livelihoods. When compared to the massive provision of inputs, there is little evidence of matching activities on the ground to help these apparently 'ignorant' farmers assess and learn about the new varieties that they are receiving. The concentration on input distribution has drained limited human resources from extension activities, on-farm varietal trials and demonstrations (Solidarités, 2003).

The ethics of the mass introduction of new varieties in lieu of a considerable level of on-farm trials and demonstrations deserve critical attention for two reasons. First, at a technical level new varieties often require changes in planting depth, watering requirements and fertiliser use. A failure to provide extension advice about these changes can easily lead to failed harvests and failed transfer of technology. If the seed programmes across Afghanistan are largely intended to induce technology transfer, this would seem to imply that extension advice is a responsibility of those agencies providing seed. Second, there is the accountability of the aid agencies providing seed of improved varieties. In a development context, extension agents striving to promote new technologies must retain the confidence of the clients if their targets are to be achieved. They cannot risk alienating their clients by recommending inappropriate inputs and then leaving. ${ }^{18}$ But aid agencies are by nature relatively free from accountability to those that they ostensibly serve (see Martens et al., 2002).

These criticisms regarding weak accountability relate to the modes of technology transfer, but not the broader need for new technologies. There are technological interventions that could presumably go a long way to buttressing subsistence and helping farmers to take advantage of market

\footnotetext{
17 The success in this latter objective has been exceptional (and was so even during the Taliban regime). In interviews agency staff have proudly declared that, in some areas, local varieties have disappeared entirely, a tendency that is disturbing for those who see a value in retaining Afghanistan's extraordinary and unique genetic diversity.

18 Some agencies have engaged in 'hit-and-run' seed distributions, by making free distributions in a given area and then withdrawing. This unaccountable behaviour is underpinned by the technology transfer ethic: if the scientists are automatically assumed to know best, follow-up and downward accountability to farmers are not required.
}

opportunities. The question is how technology transfer can be promoted in an ethical manner that recognises farmers' rights to know what they are getting involved in when presented with an 'improved' technology.

\subsubsection{Seeds and tools in Sierra Leone: from distribution to production}

In Sierra Leone, there was massive distribution of seeds (mostly rice and groundnuts) and tools throughout the war years, and then subsequently for returnees (Longley 2006, forthcoming). Much of the seed was purchased within the country from local entrepreneurs ${ }^{19}$ or commercially-oriented NGOs or through Lebanese traders who procured seed within the region (Sierra Leone, Guinea or Côte d'Ivoire). Such companies barely existed prior to the war, and many lacked experience of handling seed and were unable to provide seed of acceptable quality. Much of the rice being distributed was for a small number of improved varieties which some farmers in Sierra Leone were probably already familiar with, but the varietal specifications requested by agencies were often based on what was available through the traders, rather than on any detailed assessments at ground level. The repeated distribution of a small number of improved varieties over several years led to a concern among some agencies over the potential loss of local varieties. This prompted efforts to rescue sought-after or 'cherished' local varieties that were held in small amounts by a few families, and that were relatively inaccessible to the majority of farmers due to food insecurity (and the difficulty of saving seed in large quantities) and the disruption of social networks (through which farmers acquire seed from others) (Kent and Mokuwa, 2001). Such efforts allowed farmers to obtain their preferred varieties much more quickly than would otherwise have been the case.

The ethics of technology transfer described above for Afghanistan have not been such an issue in Sierra Leone, with the exception of one agency in particular that made considerable efforts to undertake field trials for new varieties and provide extension advice to farmers. ${ }^{20}$ Of much greater concern was the lack of regulation over the companies entering into the seed business (for which profits were large), the quality of the seed being distributed, and the myriad of different approaches used by different agencies. The apparent need for regulation led initially to the standardisation of seed 'packages' provided to farmers, and then to more developmental efforts to avoid the need for external procurement altogether through the promotion of local seed production.

19 Entrepreneurs were often agricultural researchers who had close ties with the seed sector.

20 Technology transfer approaches were being promoted in the south of the country at a time when the security situation was still very unstable. Whether one supports the promotion of improved varieties in an emergency phase, the experience illustrates what can potentially by achieved in terms of trials, demonstrations and extension in an unstable and insecure country. 
FAO and the district-level Agriculture Technical Committees (composed of UN, NGO and government representatives involved in food security and agricultural interventions) promoted the standardisation of seeds and tools packages in Sierra Leone by stipulating that a minimum input package of $40 \mathrm{~kg}$ seed rice and $20 \mathrm{~kg}$ groundnut seed should be given to each farmer. ${ }^{21}$ Considerable attention was also paid to targeting procedures, to ensure that the most vulnerable would benefit and to avoid the repeat supply of seed to the same farmers from one season to the next. A post-distribution monitoring survey conducted by FAO and implementing partners in 2002 indicated that $90 \%$ of the seed distributed by agencies was planted (Agrisil, January 2003), though the actual impact on agricultural production and food security was not assessed. Much of the seed distributed by agencies was provided on a loan basis, whereby beneficiaries were expected to pay back the seed after the harvest to establish a local community seed bank that would then provide seed to other farmers in subsequent years. Anecdotal reports from a small number of beneficiary farmers suggest that in some areas the shift from seed hand-outs to loans was perhaps premature, taking place at a time when the security situation was still unstable and harvested outputs were liable to be looted by rebels or thieves.

Since 2002, the procurement and distribution of seeds and tools has been gradually replaced by efforts to promote the local production of seeds and tools. Blacksmithing was identified as a skill that could readily be adopted by wardisabled persons and ex-combatants, and tool-making workshops were established by FAO as an income-generating activity. Groups of ex-combatants and war-disabled people were provided with vocational and small-business training to enhance their income-earning potential. Rice seed production was initially promoted through a project involving FAO, the Ministry of Agriculture, the Rice Research Station and ICRC: 500 farmers with experience in seed multiplication were trained to multiply foundation seed provided by the Rice Research Station (Agrisil, January 2003). Subsequent projects have constructed drying floors, stores and seed banks. The promotion of local seed production and community seed banks is a common food security intervention in both rehabilitation and developmental settings, and there are various different models for the ways in which such projects can be designed. However, experience with such projects has so far provided few examples of successful and sustainable activities (Tripp, 2001).

\subsubsection{Lessons emerging}

In broadest terms, the main question is whether

21 Similar efforts to standardise emergency seed provision were made in Afghanistan through the "Guiding Principles Governing the Production, Distribution and Import of Seed and Planting Material of Field Crops in Afghanistan' (FAO, 2003a). Interviews indicated that field staff were largely unaware of these guidelines and developed modalities based on their own distribution targets, agency objectives and local interpretations of FAO's regulatory framework (Christoplos, 2004). interventions that focus on seed are congruent with the nature of challenges that rural people face in re-establishing their livelihoods. While there is certainly a place for seed aid in agricultural rehabilitation, and it is encouraging to see an increasingly wide range of ways in which seed can be programmed, its dominant role in the sector is questionable. The slow shift away from seed aid appears to be due to the legacy of humanitarian and early rehabilitation programming, where seed was perceived to be the only feasible form of intervention. It is also a reaction to the institutional weaknesses (see Chapter 5) that have made other activities difficult to establish. Another reason for the persistence of seed aid no doubt relates to the fact that seed projects are highly visible and can easily be reported on in terms of numbers of beneficiaries assisted, quantities of seed provided and expected food production; seed projects appear to provide valuable inputs that allow farmers to increase their production (Tripp, 2001). But without any impact assessments, the value of such projects cannot be taken as read. Where such assessments have been undertaken, they have often shown that farmers' own seed systems are more resilient than assumed, and external seed projects can weaken, rather than strengthen, these local systems.

One way in which local seed systems are potentially weakened is through the genetic erosion of local varieties as a result of the repeated distribution of a limited number of improved varieties. Although there is very little data on this issue, the apparent failure of agricultural experts in Afghanistan to recognise the value of local germplasm is a serious concern. In Sierra Leone, it appears that local varieties had not been lost entirely, but that access to them was limited. The promotion of new, improved varieties as part of relief and recovery programmes has been criticised for introducing unfamiliar varieties to farmers at a time when they are perhaps least able to cope with the unknown. However, the introduction of new, appropriate technologies such as improved crop varieties can potentially have significant impacts, particularly where these varieties address known problems within the farming systems (e.g. through disease resistance).

\subsection{Non-seed inputs and agricultural services}

Attention to the role of agricultural services in conflict and post-conflict situations has generally focused on the relevance of specific interventions. While these findings are useful from a project management perspective, there is a shortage of analysis of the service markets and communitylevel support systems to which these projects would be expected to contribute, or which they could be expected to strengthen. Anecdotal accounts exist of relatively positive experiences regarding para-veterinary services (Ostrom, 1997; Sauvinet-Bedouin \& Erikson, 2001) or communitybased animal health services (Catley, 1999; Fox et al., 2001; Jones et al., 1998). There has been somewhat more analysis 
of the potentials and pitfalls in introducing microfinance in countries emerging from conflict (Wilson, 2002), but evidence from Afghanistan and Sierra Leone suggests that much work still needs to be done in enhancing practical programming approaches to microfinance (see section 3.3.2). Methods have been developed for the analysis of informal seed markets (Jones et al., 2002; Longley et al., 2002), but the findings of these studies have yet to be applied on a broad scale in project planning and design. As section 2.5 suggested, analyses of agricultural service markets and community mechanisms for agricultural support, and how these have been affected by the conflict (or by aid), are virtually non-existent.

In Afghanistan, input provision is perhaps the most obvious area of concern for farmers. Fertilisers, pesticides, seeds and veterinary medicines are widely available in markets, but farmers in isolated areas experience high costs in transporting inputs. Others are primarily concerned about the low quality of inputs, and their inability to obtain redress when they believe that the inputs they have purchased were of poor quality. Similar complaints are expressed about poor-quality seed provided by NGOs, particularly in the emergency phase. Provincial and district agricultural staff recognise the importance of monitoring and regulating private sector and NGO input provision, but they have no capacity to perform such tasks.

Access to irrigation water in Afghanistan is in many cases dependent on ties to local (and in some instances national) political or military leaders. The capacity of aid agencies to investigate power structures is usually weak. Even if they are aware of how these structures affect access to water resources, they may have little capacity to exert pressure for equitable distribution, or to influence the multifarious social and political processes by which access to resources is negotiated. Commanders have been widely cited as having abused their power by appropriating irrigation resources. In addition to direct injustices, this has also weakened the mirabs, the traditional water management authorities (GoA, 2004b), which may have repercussions on efforts to re-establish a strong role for civil society.

In Sierra Leone, the importance of private sector regulation has been mentioned above in relation to emergency seed provision. Given the low levels of formal input delivery systems prior to the war (see section 2.5), Sierra Leonean farmers do not have high expectations in terms of input provision. Agricultural service delivery has focused on extension advice, and this is detailed in the following section. Although not always explicitly agricultural, microcredit has been widespread (section 3.3.2). The delivery of agricultural inputs and services is closely related to promoting market-based agriculture (section 3.4).
3.3.1 Extension services: Farmer Field Schools in Sierra Leone Although the Sierra Leone government's Medium-term Agricultural Strategic Plan (MAFFS, 2002) proposes the nationwide application of the Unified Agricultural Extension System, what is actually being implemented on the ground is a Farmer Field School (FFS) approach, as put forward by FAO (FAO/MAFS, 2002). ${ }^{22}$ The FFS approach in Sierra Leone aims 'to build on partnerships which have been developed during the emergency operations, engaging civil society organisations, especially representatives farmers' organisations, as true partners to supplement the efforts of the public sector' (FAO/MAFS, 2002: 17). It is recognised that 'the current emergency operations could lead to the development of undue dependency on external assistance' (ibid: 11) and that the farmers' associations that emerged to handle the provision of free inputs may disappear without support. FFS thus represent a clear shift in the type of assistance provided: from seeds and tools distribution towards support aimed at building farmers' self-confidence and self-reliance, and the long-term sustainability of initiatives originating within farmer communities (ibid: 12).

Although capacity-building is certainly an important aspect of the FFS approach (specifically the capacity of farmers to experiment with new technologies), FFS was originally designed as an approach to agricultural extension or technology transfer that was more effective than earlier topdown methodologies. In Sierra Leone, the emphasis that has been given to institution-building and community-based development, however, has detracted from more technical concerns relating to the actual activities in which FFS are expected to engage (Longley, 2006 forthcoming). The opportunity to link FFS with experimentation on genuinely new technologies that might have a positive impact on production (e.g. Nerica rice varieties ${ }^{23}$ ) had not been realised at the time of the research. Regardless of the extension approach used, extension systems must focus on appropriate technologies that can usefully be extended to farmers. This appears not to be the case with FFS as they were being implemented in Sierra Leone up to late 2004.

In Sierra Leone, part of the rationale of FFS is 'to increase the accountability of service providers, whether in government or civil society, to the farming community' (FAO/MAFS, 2002: 11). The weakened state of government institutions, combined with the government's commitment to decentralisation, is regarded as an 'outstanding opportunity' for new institutional approaches (such as FFS), but exactly how FFS will promote the accountability of service

22 Such divergence in the plans and proposals put forward by different agencies is not uncommon in post-conflict situations, when agencies are hurriedly drafting proposals for different donors and effective coordination mechanisms are lacking.

23 'Nerica' stands for 'New Rice for Africa'. Nerica refers to a group of rice varieties developed in the late 1990 s by a Sierra Leonean rice breeder at the West African Rice Development Association (WARDA) by crossing the hardy, indigenous Oryza glaberrima species with the high-yielding O. sativa species. 
providers, and who these service providers are, is not made explicit.

The justification for the adoption of FFS in Sierra Leone rests partly on the failure of previous extension approaches in the country, caused by various factors including the high recurrent costs of travelling to meet farmers and the inadequacy of extension agents' training (ibid: 13-14). Yet the cost of travel and the level of training required for facilitators are also challenges in implementing FFS, requiring substantial financial investment. Informal conversations with a small number of facilitators who had completed their FFS training some weeks previously suggested that they were ill-equipped to convey the concept of FFS to farmers. Farmer field schools are far from cheap to implement. The current move towards self-financing FFS (including in Sierra Leone) may have achieved a certain level of success in more stable, developmental contexts (e.g. Okoth et al., 2003). However, given the increased levels of rural poverty in postconflict Sierra Leone only time will tell if farmers are willing and/or able to pay for the transport costs of the extension agents' visits. Internationally, the record of financial sustainability of FFS is poor (Anderson \& Feder, 2004).

In short, there are a number of reasons for questioning the appropriateness of FFS in a post-conflict situation such as Sierra Leone, where capacity-building among farmers' organisations might be achieved more effectively through explicit capacity-building approaches, and where technology transfer focuses on technologies that are appropriate to farmers' needs.

\subsubsection{Microfinance and credit}

In both Afghanistan and Sierra Leone, there has been a rapid expansion of microcredit services in the post-conflict period. In Afghanistan, since interest is formally prohibited in Islam, informal credit is a sensitive topic. The quality of services provided informally varies greatly, and is intertwined with wider patron-client relationships. Interest may or may not be charged. Patrons reap their profits through other aspects of their relationships with clients, such as taking a larger profit from crops. The expansion of microfinance is driven partly by a desire to provide an alternative to traditional systems of credit, whereby farmers are locked into poppy production in order to access loans. Aid programming varies from extremely soft credits from NGOs at farm level (often repayment for seed distributions) to the First MicroFinance Bank, supported by the Aga Khan Fund for Economic Development. In the long run, microfinance has the potential to have significant impact. In the short run, rural Afghanistan is unlikely to experience a 'microfinance revolution' due to the high costs of establishing institutional infrastructure in the countryside.

In Sierra Leone, a range of agencies (governmental, bilateral and NGO) were implementing micro-credit programmes. Although the design may vary, loans tend to be provided to groups of about five individuals ${ }^{24}$ for which repayment is (hopefully) ensured through peer pressure. Literacy and numeracy skills are also encouraged to enhance record-keeping and business skills. In some parts of the country, the micro-credit programmes were being transformed into rural banking institutions. In Kambia District, 60 out of 320 households surveyed reported receiving a loan or micro-credit from formal aid interventions. Of these, $40(67 \%)$ used the loan for trade involving agricultural products, and $39(65 \%)$ used it for farming activities (mostly the hire of labour and the purchase of food for labourers). ${ }^{25}$ This illustrates the significance of agriculture and trade in agricultural products for income-generation. However, despite a recommendation from the Agricultural Sector Review, current programming approaches have failed to make any explicit link between microfinance and the agricultural sector. This is further discussed in section 3.4.

\subsubsection{Lessons}

As described in section 2.5, the impact of any given service intervention is related to the availability of complementary services. The ultimate measure of the quality of service provision cannot be found in individual credit, input or extension interventions; it is in how farmers can access the mix of services that they need. Individual project interventions for extension and credit do not appear to have been informed by an understanding of how farmers themselves draw down the various services they need to produce and market their crops and livestock. Such piecemeal, project-based approaches need to be linked, not only to a greater understanding of what farmers actually do, but also to an overall strategy for delivery of inputs and services. While the current emphasis is on micro-level or 'community-based' interventions, insufficient attention is given to institutional forms at meso and macro levels.

\subsection{Promoting markets in the agricultural sector}

Chapter 2 highlighted the importance of understanding how markets function in countries emerging from conflict. It argued that promoting markets in the agricultural sector should be a key focus of livelihood support. The major role of the private sector in the provision of inputs and services is increasingly recognised, but challenges surround enabling the emergence of service providers, stimulating demand and improving the quality of inputs and accountability of services provided. Functioning output markets are equally important to

24 Under the government's SAPA project, Le. 100,000 (\$45) is provided per person (i.e. $\$ 220$ per group) and this is repaid over $3-6$ months with $15 \%$ interest. If repayment is successful, the group receives a second, bigger loan, and so on (up to $\$ 220$ per person). The programme encourages savings, and calculates that it takes five or six loan cycles to bring someone out of poverty.

25 Thirty used the loan for both farming activities and trade involving agricultural products. 
enable farmers to sell their produce at profitable prices and to provide security for households dependent on food purchases, but basic transport and information infrastructure linking farmers to markets is often lacking. The case studies in Afghanistan and Sierra Leone suggest that agencies are generally ill-equipped to address these challenges, and found little evidence of coherent strategies for market-oriented programming. Efforts to promote the development of market systems and infrastructure tend to be localised, fragmented and poorly coordinated, and often focus on either input or output markets, with little integration between the two.

One strategy for promoting markets for inputs and services is to focus on stimulating demand by putting resources (cash or vouchers) to purchase services into the hands of beneficiaries, in the hope that they will then become clients or even customers of emerging service providers. This is the rationale behind CRS seed vouchers and seed fairs (Remington et al., 2002), but experience to date is still insufficient to determine whether or not voucher systems are promoting greater accountability among service providers. The CRS voucher programme in Afghanistan was designed to promote local economic growth through the provision of livelihood vouchers worth $\$ 70$, which beneficiaries could exchange for a range of goods: seeds, tools, fertilizer, animal traction or tractor services, livestock, wool and tools for carpet weaving, or tools for masonry, carpentry, tailoring or blacksmithing (Reilly, 2004). However, rather than allowing beneficiaries to use the market to obtain these inputs for themselves, CRS procured, purchased and arranged for the provision of inputs through selected merchants. Similarly in Sierra Leone, the seed fairs conducted were not considered by the seed vendors as an open market, and it was expected that CRS would buy any seed that farmers did not exchange their vouchers for. Also, the level of choice offered to beneficiaries was limited to rice and groundnut seed (Jallow, 2004). In cash- or voucher-based systems, the market is expected to ensure that enterprises selling food, seeds or agricultural advice become accountable to their customers and provide services that are more in tune with their needs. Evidence available to date from voucher systems in the country case studies suggests that the level of management by the implementing NGO is such that this move towards accountability on the part of service providers is not happening.

In Afghanistan, informal discussions reveal a tendency among many observers to assume that efforts to promote the private sector will inevitably lead towards rather than away from opium production, as this is the most profitable business opportunity. The government and the international community have therefore committed themselves to the identification and promotion of 'alternative livelihoods' to replace opium with other profitable cash crops. However, the inclination to see agroindustrial investment as a choice between licit and illicit products may distract from an analysis of actual capital flows and opportunities. The majority of financial flows in agriculture are in one way or another linked to the opium trade. The search for 'alternatives' in private sector development may therefore entail finding ways to encourage diversification in the reinvestment of opium profits into other businesses, rather than as an 'either-or' choice between licit and illicit agriculture. There are indications that wealth does encourage diversification out of poppies (Christoplos, 2004).

In Sierra Leone, efforts to promote agricultural marketing are presently limited to post-harvest processing and storage facilities. Outside of the agricultural sector, some construction of market facilities has been undertaken, and the need to enhance the road network is recognised. The EC has plans to rehabilitate some roads in the north of the country, and this could potentially create new market opportunities in Guinea. Yet this road building plan does not appear to be linked to any real understanding of future potential markets. Although a consortium of NGOs has been exploring potential market development in response to a USAID initiative (Roberts, pers. comm.), one might question whether NGOs are best placed to promote markets. The National Recovery Strategy (2002-2003) was refreshingly imaginative in its proposals for market development, ${ }^{26}$ yet none of these plans appears to have yet been realised. Although lip service is paid to identifying new markets in government plans and policies, the focus is on traditional sectors such as coffee and cocoa, despite high levels of disease and neglect, together with a drop in global prices. Rather than thinking beyond the traditional cash crops of coffee and cocoa towards other crops for which markets might be developed, the Ministry of Agriculture is focusing on increasing subsistence crop production. There is a failure to look beyond pre-war production patterns to the market realities of today (Christoplos, 2004). Although the Ministry of Trade and Industry is working to promote new markets (ginger, livestock, vegetable and fruits studies have been undertaken), these are restricted by limited technical understanding of agriculture and the lack of any active collaboration with the Ministry of Agriculture. Despite the massive number of micro-credit schemes, surprisingly little has been done in linking these to potential new marketing channels.

Market-based approaches remain largely as wishes expressed in policy documents rather than programming reality. As long as the Ministry of Agriculture emphasises production,

26 The National Recovery Strategy (NRC) states that: 'Seeds and tools distribution is a first step, but support through access to markets, transport and infrastructure for storage and processing of products must follow quickly if growth is to progress beyond self-sufficiency' (p. 13). It proposes the identification of products with comparative advantages, niche markets and areas of export potential beyond the traditional sectors. It warns against investment in the coffee sector before conducting a full study of the economic viability of the crop's market potential. This last warning has not been heeded. 
market development risks being overlooked or inadequately addressed by the Ministry of Trade. What initiatives do exist are still too new to learn lessons or assess impact. Moreover, the use of these approaches for improving the response to complex emergencies remains under-researched and inadequately understood. Hopes that the power of the market can be harnessed to solve humanitarian crises and support livelihoods have sometimes superseded empirical analyses of how service provision markets function in the midst of chronic conflict. In Afghanistan there is clearly a lively market for many agricultural services (at least in relatively accessible areas), but little is known about whom this market serves, and on what terms. There is a need for caution about promoting market development without an adequate understanding of the political and economic relations of product and inputs markets, and the social relations through which they are structured in post-conflict situations. This relates to questions of accountability: the promotion of market-based modalities may give legitimacy to a hasty withdrawal of the state from rural service provision (or a failure to ensure that the state returns in post-conflict contexts), without due attention to whether other actors are appearing to fill the gap (Rocha and Christoplos, 2001; Pearce, 1999), and whether the state is capable of fulfilling even a minimal regulatory role.

\subsection{Rights-based approaches}

Although many agencies working with agricultural rehabilitation in Afghanistan have formally declared their adherence to rights-based approaches, there is as yet little indication that this has resulted in significant changes in operational methods, priorities or goals. One reason for this is that rights-based programming would in many cases require confronting powerful local commanders and elites. Some agencies have indicated a readiness to assume limited responsibilities regarding protecting communities from the worst abuses inherent in Afghanistan's power structures. The extent of this commitment is, however, constrained by capacities to intervene in the structural causes of these abuses. A genuine effort to bring rights onto the agricultural rehabilitation agenda would mean addressing issues such as land and resource tenure. Progress is being made in mapping the extent and urgency of these challenges (Alden Wily, 2004), but there is as yet little indication that this has had a considerable impact on programming priorities. It appears to be too sensitive an issue, and beyond the operational scope of humanitarian and rehabilitation interventions.

In Sierra Leone, a rights-based approach has been applied explicitly in both food security programming (by CARE) and policy (the Right to Food). In both cases, it is used as a way of understanding and implementing multi-sectoral, multi-level approaches in a coherent and integrated manner. Right to Food has been described as: an approach which forces us to change our routine way of thinking, our fragmented approach to policies and programmes, in a nutshell, our mindset. To speak of rights is to speak of people first and of human dignity ... It is to define obligations, responsibilities, duties of the different actors and decisionmakers, at different levels, in an interdisciplinary, intersectional, interministerial national framework, itself linked to the international environment (Spitz, 2003).

In a context where the concept of food security is relatively new and not well-understood, a rights-based approach at policy level is being used to help government officials to see that food security requires a long-term, inter-ministerial approach. Given the greater awareness of human rights among the populace, it allows people to voice their concerns in situations where their right to food might be violated (e.g. through lack of access to productive land), whilst also recognising their own obligations in agricultural production. Although FAO and the Intergovernmental Working Group on the Right to Food are beginning to explore the role that food safety nets can play in realising the right to food (IGWG RTFG, 2004), such rights-based safety nets have yet to come onto the agenda in Sierra Leone.

CARE's rights-based approach to food security emphasises the need to address the causes of conflict as well as its consequences. Detailed social science research undertaken at community level prior to the project emphasised the need to address a number of issues: the crisis in the agrarian structure and the lack of opportunities for rural youths; injustice (i.e. maladministration of customary law by chiefs and local court officials); and 'traditional' or 'cultural' practices regarded by rural youth as oppressive (CARE-SL, 2004). Furthermore, the research revealed that CARE's own projects had served to fuel existing conflicts within and between communities (Archibald \& Richards, 2002; CARESL, 2004). Practical ways in which these issues could be addressed were identified through discussions with local communities about rights-oriented principles such as inclusion, participation, representation, accountability, transparency and justice. The project was designed in such a way that the promotion of rights and justice was clearly linked to material needs (CARE-SL, 2004). Project implementation encompasses a broad range of key elements and activities, including: seed distribution; Peace and Rights Days; conflict resolution and the promotion of social justice; community capacity-building; and promotion of good governance (CARE International in Sierra Leone, 2003).

The project is essentially about bringing about the positive social changes necessary for sustainable peace - changing ways of life, changing expectations, and changing attitudes (CARE-SL, 2003). The project progress review reveals that - in the eyes of local communities - the approach has demonstrated 'new ways of working' based on transparency, honesty and respect, and the project is clearly 
identified with peace building, the promotion of unity, cooperation and awareness about human rights issues (CARE-SL, 2003). Whilst the project has been successful in bringing about positive social change at the community level, it is recognised that additional efforts are needed among government officials, service providers and other duty holders. One of the major challenges in undertaking a project that emphasises principles such as participation, inclusion, community capacity-building and empowerment is that success often ultimately depends more on the processes through which it is implemented than on the material outputs that are generated (CARE-SL, 2004). As such, the pace at which the project is implemented must be determined by the communities themselves, rather than by project logframes and donor-induced deadlines.

Although those directly involved with the project have come to view it as promoting the social changes necessary to overcome some of the root causes of the war, it has been fundamentally misunderstood by many other agencies. The fact that it was focused on food security and provided seed inputs led other agencies to think that it was a seed project aimed at the re-establishment of local seed stocks within post-conflict communities. As such, it was heavily criticised by agencies working in the seed sector for not respecting the standard seed quantities agreed as 'good practice'. Not only is the capacity for understanding rights-based approaches limited among those coordinating and implementing emergency projects, but significant capacity-building efforts were required among CARE field staff, in order for them to have the skills needed to implement the project as well as sharing the visions and attitudes it promoted.

\subsection{Summary}

Current post-conflict programming appears to consist of piecemeal, project-based approaches with little evidence of coordinated strategy. Despite a multitude of policy or strategic documents, these are not necessarily matched in programming realities. This piecemeal approach is thought to respond essentially to 'crisis thinking' and the yeoman farmer fallacy described in section 2.2. The rapid expansion of agricultural rehabilitation assistance in Afghanistan since 2002 has not been in response to a 'new' crisis generated by the fall of the Taliban; a drought-induced collapse in food security before then generated little international support, just as a rapid upswing in food production before the drought was little recognised. In Sierra Leone, the 1991-2002 war provides the 'crisis' that aid agencies are ostensibly responding to, yet the need for assistance also stems from government mismanagement since the 1970 s. The 'monotonous landscape of interventions' (Pain, 2002: 11) of the aid response has been only marginally related to the diversity of challenges faced by rural people struggling to maintain their livelihoods as governments and NGOs have come and gone. The failure to appreciate and assess the dynamism of farmers has meant that the programmatic structure of agricultural rehabilitation and development has failed to relate to the actual nature of agriculture and processes of recovery in farming and livelihoods. An emphasis on responding to crisis - while in many respects accurate in the case study countries - fails to reflect the resilience, capacities and ingenuity of rural populations. The central reason that the aid agenda is out of step with the realities of agricultural production and livelihoods is that this notion of 'crisis' shapes aid response.

Other approaches are being implemented from an almost contradictory perspective, in which efforts to promote selfsufficiency and sustainability are based on an inadequate understanding of local livelihoods and the causes of vulnerability within agricultural systems. Such efforts have failed to match local interventions with the meso and macro institutions and policies necessary to support them. Support to each level of a market chain is one way in which these meso- and macro-level interventions can be realised. Although market approaches are beginning to attract the attention of donors and programme planners, they are fraught with practical difficulties in a post-conflict environment, and remain a major challenge. Careful monitoring and impact assessment, together with analysis informed by a political-economy perspective, are needed to learn and improve on existing approaches.

Rights-based programming is a relatively new approach, and requires considerable capacity to implement. It represents a significant change in the way things are done, and appears to have the ability to address some of the grievances expressed by communities. However, the potential for rights-based programming to be misunderstood is significant unless capacity-building efforts are made among implementing agency staff. 


\section{Chapter 4}

\section{Addressing vulnerability through social protection and livelihood promotion}

\subsection{Introduction}

This chapter suggests that existing agricultural interventions are ill-suited to addressing the causes of vulnerability. Social protection, and recent thinking on ways in which it might be adapted to post-conflict situations and combined with livelihood promotion, are described. Critiques of existing social protection mechanisms in Afghanistan and Sierra Leone are then presented. The chapter concludes that a rights-based approach to social protection, combined with livelihoods promotion, potentially provides a means of addressing vulnerability that is currently lacking in postconflict agricultural interventions. However, this remains largely uncharted territory, and considerable challenges exist in combining humanitarian action, social protection and livelihood promotion. What has been termed 'transformative social protection' (Devereux \& Sabates-Wheeler, 2004) would appear to be necessary if the political and structural inequalities associated with vulnerability are to be addressed, but this brings with it implications for the humanitarian principle of neutrality that must also be considered.

\subsection{Limitations in addressing vulnerability through post-conflict agricultural interventions}

In section 2.3, vulnerability was defined as the extent to which a person or group is likely to be affected by adverse circumstances'. Such adverse circumstances might be either acute or chronic: an example of the former could be an attack by militia and sudden mass displacement; the latter could be chronic insecurity and displacement over many years. Conflict creates new forms of poverty and social exclusion (e.g. demobilised ex-combatants, IDPs, returnees, widows, orphans, people disabled by war or landmines), but it is also important not to lose sight of the more structural forms of social exclusion and poverty that may have existed prior to the conflict, and that may persist after it: These include sources of vulnerability linked to class or ethnic distinctions, disability, old age, or poverty. An understanding of the causes of poverty and chronic vulnerability can be especially important in helping to analyse some of the factors that contributed to conflict in the first place, particularly where violence is an expression of the failure of development (i.e. the failure to alleviate poverty through addressing the causes of vulnerability) (Longley and Maxwell, 2002). It is often difficult to distinguish the causes and effects of violent conflict from the wider processes at work in poor societies (Collinson et al., 2002).
A livelihoods approach involves greater emphasis on the analysis of underlying causes of conflict and vulnerability. But the conventional livelihoods framework is inadequate for such analysis because it tends to treat vulnerability solely as an external factor relating more to climatic, economic or political shocks, rather than linking people's own livelihoods (particularly their identity and asset levels) to their vulnerability (Pain and Lautze, 2002). For this reason, the adapted livelihoods framework presented in Figure 1 focuses much more centrally on vulnerability (Collinson et al., 2002). Despite the fact that assessment tools are being developed and adapted to provide the information required to inform aid responses to situations of chronic conflict (e.g. benefits-harms analysis; conflict assessments; food economy analysis), these still tend to be used for targeting conventional relief inputs (Jaspars and Shoham, 2002).

In many documents describing post-conflict agricultural interventions, the term 'vulnerable' is followed by the word 'groups'. The labelling of 'vulnerable groups' is a device to link data on shortage of assets to the selection of beneficiaries and the choice of items to be distributed. The process of identifying vulnerable groups thus tends to decontextualise poverty and reconstitute the poor as passive 'beneficiaries', rather than people actively struggling to manage complex livelihoods. Although projects invariably target 'vulnerable groups', little attention is given to understanding the structural causes of their vulnerability and the complex nature of risks they face (both collectively and individually). As long as these remain unspecified, it becomes easier to imagine that short-term project interventions might succeed in 'solving the problem', but experience shows that unless targeting criteria are firmly embedded in a deeper analysis of the nature of risk and vulnerability, agricultural interventions are likely to be ineffective in addressing the complexity of rural poverty. The tendency, for example, to classify all women as vulnerable is problematic. In Afghanistan it glosses over the diverse agricultural activities women are allowed to perform (Kerr-Wilson \& Pain, 2003), and in Sierra Leone it masks the class distinctions that define rural women's relative power or vulnerability (Richards et al., 2004).

In Afghanistan, the vulnerability context is an ephemeral factor in agricultural programming, and in many cases is absent all together. Many critics of seed programming in Afghanistan echo the words of one informant, who complained that 'targeting is a joke'. Critics question the conceptual frameworks used to identify so-called vulnerable groups, and the commitment and capacity of 
agencies to reach them. Despite the proliferation of guidelines on targeting, there is clearly little understanding of how different seed distribution modalities might be used to target different beneficiaries. The link between seed distributions and land ownership is central to any expectation that seed can support 'vulnerable groups'. It is unclear whether free/subsidised seed enables sharecroppers to negotiate better agreements with landlords. It is doubtful that it does, given that seed only accounts for $6-12 \%$ of input costs for cereals. Comprehensive risk and vulnerability analyses would expose the deep structural nature of the challenges facing the landless and destitute, and thereby demonstrate the limits to modest project interventions in modifying the context of their vulnerability. This is not to imply that these interventions are not without significant benefit, but there is a lack of transparency about the palliative nature of many projects.

In Sierra Leone, the annual assessments that have been undertaken to identify 'vulnerable groups' to be targeted by agricultural interventions have failed to examine the vulnerability context, focusing instead on indicators relating to the level of damage to houses and other buildings (2002 assessment) and those relating to agriculture, ${ }^{27}$ consumption and resettlement (2004 assessment). A more structural analysis of vulnerability in Sierra Leone has been undertaken by Richards et al. (2004), who show how key rural institutions governing marriage rules and land rights 'serve to reproduce the advantages of leading lineages, thrusting others into relationships of poverty and dependency' (ibid: ii). The division of rural society into ruling lineages, dependent lineages (commoners) and migrant 'strangers' is perpetuated through the control elders exercise over marriage and, in turn, the labour of young men. ${ }^{28}$ The authors state that 'None of this variation resolves into clear and simple social status differences based on gender, age or local citizenship. The true differences are revealed only by painstaking social analysis' (Richards et al., 2004: 53). Current approaches to agricultural programming generally do not involve the type of social analysis required to understand such variation, let alone begin to address these issues. Adherence to the humanitarian principle of impartiality, i.e. providing aid according to need, implies detailed analysis which is often lacking (Darcy \& Hofmann, 2003).

\subsection{Social protection and livelihood promotion}

\section{4-3.1 Social protection}

In recent years, there has been growing interest in social protection among donor agencies. In its broadest sense, social protection can be defined as 'an approach to thinking

27 Agricultural indicators include the farming population as a proportion of the total population; the estimated level of production, and those who have previously received agricultural assistance.

28 The lack of control that young men have over their own labour power has been likened to domestic slavery (Richards et al., 2004). about the processes, policies and interventions which respond to the economic, social, political and security risks and constraints poor and vulnerable people face' (Shepherd et al., 2004). According to the World Bank, ${ }^{29}$ the purpose of social protection is essentially threefold:

- to reduce the vulnerability of low-income households with regard to basic consumption and services;

- to allow households to shift income efficiently, thus financing consumption when needed; and

- to enhance equity particularly with regard to exposure to, and the effects of, adverse shocks.

Commonly stated aims of social protection include supporting social and political stability (through strengthening the social contract between state and citizen), improving human development outcomes (e.g. health and welfare) and promoting the realisation of human rights and entitlements. Others include relieving market failures and promoting economic growth by allowing poor people to take advantage of market opportunities, and promoting social integration (through protection against discrimination). There is a vast array of mechanisms through which social protection can be provided. These have been variously categorised as state or non-state (Norton et al., 2002); informal, market-based oŕ publicly-mandated (Farrington et al., 2004); or those directed at individuals and households or communities (Darcy, 2004a).

In Section 4.3.4 we propose a matrix that draws on that of Shepherd et al. (2004), and incorporates aspects of each of the others mentioned above (see Tables 2 and 3). This distinguishes between informal and formal social protection mechanisms. Informal mechanisms are further divided into individual or household-based, community-based and market-based. Formal mechanisms are categorised according to those that are provided through the market or private sector, through international, governmental or nongovernmental agencies; and those that can only be provided through governments. These categories may not always be entirely independent of each other; publicly funded mechanisms may be provided through market institutions or the private sector, for instance (Farrington et al., 2004). Within the public sector, social protection cannot be confined to a single ministry, but must be mainstreamed (like food security) across various parts of government (Marcus et al., 2004). It has been argued that this mainstreaming can be achieved through PRSPs (Shepherd et al., 2004). Formal social protection mechanisms cover a wide range, including safety nets and social assistance.

Certain types of humanitarian assistance may also be regarded as a form of social protection. The extension of humanitarianism beyond saving lives to saving livelihoods

29 See www.worldbank.org/sp. 
has introduced new thinking on the nature of risk and vulnerability. This has led in turn to the introduction of more flexible forms of humanitarian assistance, such as cash transfers and vouchers (see Harvey, 2005). In theory, there are fundamental differences relating to the mandates of humanitarian agencies and the lack of any formal mechanisms of accountability to beneficiaries. The nature of the humanitarian system means that coverage is often highly uneven, and assistance may be unpredictable and unreliable from the perspective of recipients (Harvey, 2005). However, in practice there is considerable overlap between the activities of humanitarian and development NGOs. With the growing role of non-state providers in development settings, there would appear to be opportunities for social protection even where the state is weak.

Informal social protection mechanisms include family and kin, community-based social welfare groups, forms of traditional insurance such as burial societies, savings and credit groups and religious bodies. We have also included marketbased strategies as part of informal mechanisms since these tend to persist or evolve under chronic political instability. Chapter 2 illustrates the importance of such communitybased mechanisms in promoting the resilience of agricultural production. In section 5.2 we examine the need to develop formal institutions that build on the strengths and importance of informal institutions or mechanisms. However, it should also be recognised that not all local or informal social protection mechanisms are altruistic, and may involve exploitative relationships in which there are socio-economic costs for protection (Wood, 2003) (e.g. sharecropping arrangements for Afghanistan). Certain individuals or groups may be excluded from local social protection mechanisms. Although we have emphasised the resilience of local social support mechanisms, they are undoubtedly constrained by conflict. Efforts to promote informal social protection in post-conflict situations tend to focus on 'rebuilding' or strengthening social capital (see section 4.4), but the concept has proven difficult to operationalise. It is suggested that social protection provides a more coherent framework for thinking about the rights of poor and vulnerable groups to protection and support, and the duty of others to respond.

The design of appropriate formal social protection measures requires an understanding of the risks and vulnerabilities that need to be addressed, as well as of the informal social protection mechanisms that already exist. Different social protection instruments are appropriate and feasible at different times, suggesting that, over time, any country will experience a 'social protection trajectory' as society's demands and collective capacities change (Shepherd, 2004). Social funds ${ }^{30}$ provide one instrument

\footnotetext{
30 Social funds have been defined as agencies that finance small projects in several sectors targeted to benefit a country's poor and vulnerable groups based on ... demand generated by local groups and screened against a set of eligibility criteria' (Jorgensen and Van Domelen, 2000: 91, cited in Rawlings et al., 2004: 9).
}

for the delivery of social protection (see section 4.5). In most countries, these remain a very small part of social protection activities (Jorgensen and Van Domelen, 2000; Rawlings et al., 2004), but they have been used to provide assistance in a number of post-conflict countries, including Sierra Leone (see section 4.4). Originally established in the late 1980s as a response to the economic shocks that accompanied structural adjustment, their mandate has since expanded to cover a range of different circumstances (Fumo et al., 2000; Rawlings et al., 2004), of which post-conflict recovery is just one (e.g. de Sousa et al., 2001).

\section{4-3.2 The interface between social protection, rights-based approaches and humanitarian protection in post-conflict recovery}

Given that conflict creates risks and vulnerabilities that extend well beyond the economic sphere, the concept of social protection requires some adaptation to the definitions provided above when it is applied to post-conflict situations. Darcy (2004) argues for a redefinition of risk to include risks relating to violence and persecution, coercion and deliberate deprivation. In this section we argue that the notion of vulnerability also needs to be redefined, and that a rightsbased perspective is helpful in adapting the concept of social protection to post-conflict situations. Social protection might thus be defined as 'acts and measures designed to protect people against socially unacceptable levels of risk and vulnerability' (adapted from Darcy, 2004). As such, social protection needs to be expanded to address conflict-related forms of insecurity, and should be seen as part of a wider human security agenda encompassing protection from intimidation and coercion (Darcy, 2004). The paragraphs that follow suggest that the key to appropriate social protection mechanisms in post-conflict situations lies in an adequate definition (and understanding) of vulnerability that incorporates notions of powerlessness.

From a conventional livelihoods or developmental perspective, vulnerability is regarded as an external or exogenous factor. It is commonly defined in terms of the extent to which a person or group is likely to be affected by external shocks or in terms of their exposure to risk, where risk is generally seen to be unpredictable and nonpreventable (Holzmann and Jorgensen, 2000). Individual or household vulnerability depends on the ability to deal with the shock (resilience) together with the severity of the shock itself. Discussions of vulnerability in relation to conflict, however, have noted that the root causes of vulnerability are also often internal or structural, relating to an individual's or a community's identity (Keen, 1994; Le Billon, 2000; Collinson, 2003; Pain \& Lautze, 2002; FIFC, 2002; Goodhand, 2001). While the capacity for collective action may be strengthened in the face of external threats, the mobilisation of local populations against one another (e.g. Dinka and Nuer militias in South 
Sudan) can divide communities and undermine coping capacity (Deng, 2002). Those belonging to particular groups may be the targets of violence or subject to exclusion, and it is not always the poorer or less wellresourced who are the most vulnerable. ${ }^{31}$ Vulnerability and power must be analysed as dynamic political and economic processes in which the relative power and vulnerability of different groups can change over time (Le Billon, 2000). Classic conceptions of vulnerability (as described above) clearly need to be re-examined in situations of chronic conflict (Goodhand, 2001). In such situations, vulnerability might be defined as:

the risk of harm to people's resources as a result of the inability to counter external threats arising from conflict, or as a result of inherited or ascribed traits such as gender, class, race/ethnicity, age, etc., made salient by the nature of the conflict (FIFC, 2002, cited in Pain and Lautze, 2002: 20).

Collinson notes that in situations of conflict, 'People are most vulnerable when their livelihoods and coping strategies are deliberately blocked or undermined, or if their group identity, political position and/or material circumstances (in some cases their wealth) expose them to violence' (2003: 10). Aspects of vulnerability relating to inherited or ascribed traits do not necessarily disappear once a conflict has ended or widespread violence associated with it has apparently ceased.

In such contexts, a rights-based approach is arguably more appropriate. Rights-based approaches have been defined in various ways, and generally involve an approach to development that aims at the realisation of human rights norms and standards (e.g. the Universal Declaration of Human Rights and other international human rights instruments) and operational human rights principles (Piron, 2004). In her analysis of the relevance of rights-based approaches to social protection, Piron (2004) highlights three sets of human rights principles: (i) inclusion, equality and non-discrimination; (ii) citizenship and participation; and (iii) obligation and accountability.

The principles of obligation and accountability relate to what Piron refers to as the 'supply-side' of social protection, whereas the principles of citizenship and participation draw attention to the 'demand-side' which is often overlooked in social protection approaches, which focus on the technical aspects of provision. Piron argues that the principle of participation, and an understanding of the broader social and political context, is key in allowing citizens to claim their right to adequate social protection:

31 In southern Sudan, for example, the Dinka were vulnerable because of their wealth (Keen, 1994), and in the early years of the war in Sierra Leone, it was the wealthy, Mandingo traders who were the targets of violence (Richards, 1996).
Social protection thus needs to be seen as much more than a transfer of resources or greater access to basic services. The realisation of human rights, including the design of, and access to, appropriate social protection schemes, requires developing the capacities of rights-holders to know and claim their rights. Various empowerment strategies are required to achieve this, including those that permit 'active, free and meaningful participation in decision-making processes' (Piron, 2004: 20).

By defining vulnerability in its broadest sense - to include structural vulnerability and powerlessness - and by incorporating a rights-based perspective, the definition of social protection becomes more closely compatible with that of humanitarian protection. In humanitarian practice, protection has been defined as 'any activity ... aimed at creating an environment conducive to the respect for human beings, preventing and/or alleviating the immediate effects of a specific pattern of abuse, and restoring dignified conditions of life through reparation, restitution and rehabilitation' (ICRC, 1999, cited in Narbeth and McLean, 2003: 4). As noted by Piron (2004), the creation of an environment conducive to the respect of human rights may call for a change in power relations that can only be brought about by social and/or institutional reform. (This might best be considered as a part of livelihood promotion rather than protection, and is also discussed in section 4.3.3.) But it is essential to recognise that humanitarian protection is not the direct responsibility of humanitarian agencies. Rather, humanitarian actors can only promote humanitarian protection by 'identifying and denouncing failures of protection and highlighting the proper responsibilities of states, warring parties, mandated international organisations or new non-state actors, like multinational companies and private security firms' (Captier, 2003: 18). Similarly, there are limits to how far social protection provided by non-state actors can promote such reform (see below). In Sierra Leone, a plethora or donor-funded advocacy campaigns and governance projects implemented by NGOs arguably made Sierra Leonean citizens in urban centres considerably more aware of their rights and gave them a basis for determining what was or was not acceptable in terms of levels of service provision and accountability. Such campaigns, however, are less effective in rural areas, where it is more difficult for such messages to reach the rural poor.

The extent to which this (largely conceptual) understanding of linkages between social and human protection is translated into practice in post-conflict situations is explored further in sections 4.4 and 4.5 in the light of evidence from Afghanistan and Sierra Leone.

\subsubsection{Social protection and livelihood promotion in post- conflict agricultural interventions}

At a conceptual level, expanded definitions of social protection encompass not only mechanisms to allow 
people to cope with adverse circumstances, but also mechanisms that enhance opportunities for poverty reduction. Shepherd (2004) argues that social protection alone is insufficient to allow poor and vulnerable people to recover from a crisis. An additional effort in promoting livelihoods is also required.

The term 'livelihood promotion' tends to be used as a shorthand for measures intended to promote pro-poor growth i.e. promoting asset accumulation (not just financial assets but also social assets), helping to correct market failures, reducing inequalities and fostering social cohesion (Farrington et al., 2004). Despite the heavy reliance of many poor and vulnerable people on agricultural livelihoods, the linkages between social protection and pro-poor agricultural growth have been largely neglected in policy debates. Part of the problem is that social protection and livelihood promotion are conventionally handled by different departments within governments and donor organisations. The distinction between protection and promotion is not always clear, particularly in the reality of poor people's everyday lives, since fungibility within the household economy is such that incomes are often invested in productive assets, not just consumption (Devereux, 2002). It has nevertheless been argued that there is substantial unexploited scope for greater synergy between the two (Farrington et al., 2004). It is suggested that strengthening the links between livelihood promotion, social protection and humanitarianism may provide the key to post-conflict recovery.

Social protection has the potential to contribute to propoor growth in a number of different ways (see Box 2). A focus on poverty reduction is considered to be particularly important in post-conflict situations. The World Bank, for example, suggests that, in terms of policy reform and priorities for growth, social policy is more important than macroeconomic policy in post-conflict and transitional contexts (WB, 2002, cited by Harmer, 2005).

The interface between livelihood promotion, social protection and humanitarianism is currently relatively new territory. Figure 2 presents two axes that can be used to begin charting the links between social protection and livelihood promotion as ways of addressing different aspects of vulnerability. Some measures are intended to deal with chronic or structural vulnerability, and others with temporary crises or shocks. Protection mechanisms are designed to prevent human suffering and destitution, whilst livelihood promotion mechanisms are intended to provide opportunities to accumulate assets, reduce inequalities and build more resilient livelihoods for those affected by a livelihood shock.

Although the dichotomies of Figure 2 may appear selfevident, the nature of many humanitarian crises and postconflict contexts means that programming is scattered

\section{Box 2: Social protection and growth}

Social protection can promote growth in the following ways:

- it helps to correct market failures that contribute to poverty;

- it enables risk-taking livelihood strategies;

- it facilitates investment in the human and physical assets that can increase returns on economic activity, as well as reducing the risk of future poverty. In this sense, it contributes to two of the objectives of pro-poor growth and moves well beyond welfare;

- it facilitates more rapid recovery from exposure to risk for those less able to recover quickly;

- it can include the non-active as well as the economically active poor;

- it reduces unwelcome responses to vulnerability, such as postponing healthcare or switching to poor-quality foods;

- it reduces incentives for unproductive and antisocial behaviour; and

- by providing strong safety nets and fostering social cohesion, it facilitates positive social and economic change and reduces the likelihood of conflict.

Source: Shepherd, 2004: 21

\section{Figure 2: The interface between social protection and promotion in crisis contexts}

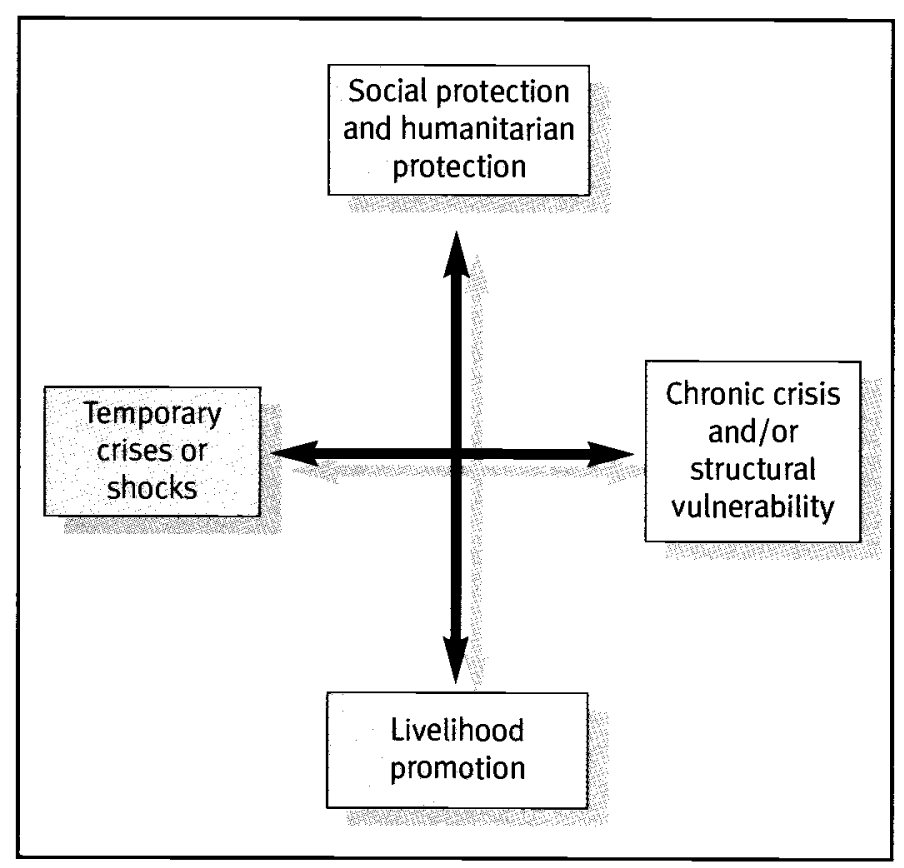

across these two axes, and may even float around according to changing needs, funding levels and agency objectives. Even if it is difficult to categorise the nature of the crisis as chronic or transitory, this does not suggest that it is not important to define what a programme is expected to achieve, and how it is expected to achieve it. The lack of clarity in terminology related to rehabilitation, recovery 
and reconstruction stems partially from a failure to define how humanitarianism, social protection and livelihood promotion relate to one another with respect to values and operational priorities.

Tables 2 and 3 provide examples of mechanisms that primarily provide livelihood protection, and those that provide both protection and promotion. The tables highlight both informal and formal social protection mechanisms, but there is presently a lack of research on the potential for complementarity between formal and informal mechanisms (Farrington et al., 2004), or indeed between humanitarian and indigenous mechanisms in chronic and post conflict settings.

Social protection can be linked with promoting agricultural livelihoods either by infusing agricultural programmes with risk and vulnerability objectives, or by ensuring that social protection mechanisms are also 'productivity enhancing' (Shepherd, 2004). Farrington et al. (2004: 16) point out that linking the two requires a conscious effort, and that failing to do so may result in potentially negative interactions between agriculture and social protection:

\begin{abstract}
In many of the cases where positive effects are not sought, any interaction between protection and promotion may simply be negligible. However, in other cases, poorly managed interventions in one sphere may have negative effects on others. Where, how, and how far this might happen will be highly context specific.... As a general hypothesis, we suggest that policy options selected at the extreme end of the 'protection' spectrum are likely to do nothing for growth, and may even be detrimental to it. Likewise, options at the extreme 'productivity enhancing' end of the growth spectrum are likely to do nothing for vulnerability or risk reduction, and may even be detrimental to them.
\end{abstract}

Farrington et al. (2004) suggest a number of ways in which agricultural programmes can be infused with risk and vulnerability objectives, including: the enhancement

Table 2: Informal social protection mechanisms

\begin{tabular}{l|l|l|l} 
Social protection & Individual and household & Group-based & Market-based \\
& Migration & $\begin{array}{l}\text { Hosting of refugees and IDPs; } \\
\text { resources provided through } \\
\text { churches, mosques or } \\
\text { temples; burial schemes and } \\
\text { other local social welfare } \\
\text { mechanisms }\end{array}$ & $\begin{array}{l}\text { Investments for consumption } \\
\text { (e.g. livestock); savings } \\
\text { groups (e.g. osusu); credit } \\
\text { from local traders }\end{array}$ \\
\hline $\begin{array}{l}\text { Linked social protection } \\
\text { and livelihood promotion }\end{array}$ & $\begin{array}{l}\text { Labour migration; } \\
\text { remittances; loan of milking } \\
\text { livestock to needy relatives; } \\
\text { seed transfers; labour-sharing } \\
\text { arrangements; cash loans }\end{array}$ & $\begin{array}{l}\text { Labour groups; savings and } \\
\text { credit groups; access to } \\
\text { common property resources }\end{array}$ & $\begin{array}{l}\text { Money transfer systems, e.g. } \\
\text { hawala; investment in } \\
\text { livestock, water and irrigation } \\
\text { services; } \\
\text { medicines and health } \\
\text { services; supply of } \\
\text { agricultural inputs; loans from } \\
\text { local traders }\end{array}$ \\
\hline
\end{tabular}

Table 3: Formal social protection mechanisms

\begin{tabular}{|c|c|c|c|}
\hline & Market-based & $\begin{array}{l}\text { International agency, NGO or } \\
\text { government }\end{array}$ & Government \\
\hline Social protection & $\begin{array}{l}\text { Bank savings; insurance } \\
\text { schemes }\end{array}$ & Food aid & $\begin{array}{l}\text { Pensions and other welfare } \\
\text { payments to 'non-productive' } \\
\text { groups }\end{array}$ \\
\hline $\begin{array}{l}\text { Linked social protection } \\
\text { and livelihood promotion }\end{array}$ & Credit and microfinance & $\begin{array}{l}\text { Food for work; cash for work; } \\
\text { public works programmes; } \\
\text { subsidised/free inputs and } \\
\text { technologies }\end{array}$ & $\begin{array}{l}\text { Legislation regarding land } \\
\text { tenure and access to common } \\
\text { property resources; } \\
\text { legislation for minimum } \\
\text { wages for labourers; } \\
\text { subsidised/free inputs and } \\
\text { technologies }\end{array}$ \\
\hline
\end{tabular}


of rural infrastructures (e.g. roads and communications) that have indirect effects on agriculture; provision of the most appropriate types of inputs (e.g. appropriate varieties of appropriate crops), technologies (e.g. pro-poor irrigation technologies) and services (e.g. provision of necessary information and skills enhancement); spreading risk by promoting diversification; promoting regulation (and legislation if feasible) to ensure appropriate, goodquality agricultural inputs; developing a good understanding of the risk and vulnerability contexts faced by different types of farmers; and advocacy to promote reforms that have the potential to address these vulnerabilities (e.g. land reform, minimum wage legislation). As noted above, the particular nature of risk and vulnerability in conflict settings remains poorly understood.

On the other hand, ensuring that social protection mechanisms are also 'productivity enhancing' requires understanding the different impacts that social protection mechanisms have on agriculture. Public works programmes, for example, can have positive or negative impacts on agriculture, depending on their timing in relation to the agricultural calendar; if they clash with key farm tasks, there is a risk that fields may be neglected. The provision of inputs such as seeds and tools can be regarded as either a social protection mechanism or an agricultural growth intervention, but we would argue that such inputs are often provided as a social protection mechanism, and the actual impact on agriculture is rarely considered. Similarly, the impacts of food aid on agricultural production are rarely considered in an empirical manner. In section 6.3.1 we use the distinction between social protection and agricultural growth to present suggested intervention measures.

In much of the literature, however, there is a tendency to regard livelihood promotion more in terms of the economic rather than the more social aspects relating to social equity, inclusion and non-discrimination. The notion of 'transformative social protection' has been proposed as a way of addressing these aspects through "empowering the poor and transforming the conditions in which they struggle to construct viable livelihoods' (Devereux \& Sabates-Wheeler, 2004: 26). The emphasis here is on addressing social risk and vulnerability, and its implicit consideration of power relations introduces an inherently political dimension to livelihood promotion. Again, this more closely resembles the way in which humanitarian protection is understood. Yet it also raises important questions in relation to the humanitarian principle of neutrality. Promoting transformative social protection implies taking a position that has been described as 'solidarist' or 'neutrality abandoned', as presented in section 1.6. This will be further discussed in chapter 6 , but we take the view that such a position is only tenable once a legitimate government has been installed and there is widespread peace and security.

A rights-based approach to social protection brings it closer to humanitarian protection, but we do not wish to suggest that their definitions should become blurred (as appears to be the case in the Joint Assessment Mission document for Sudan - see Box 3, page 36). While conceptually and practically distinct, there would appear to be scope for greater synergy between activities in the areas of humanitarian protection and social protection.

\subsection{Social protection in Afghanistan}

Social protection is on the agenda in Afghanistan. The justifications advanced for the expansion of social protection structures in a policy paper entitled 'From Humanitarian Assistance to Social Protection' (MRRD, 2002) and in other government discussions are sixfold:

- Social protection is a means of ensuring a smooth transition from the chaotic and haphazard collection of relief projects to a more reliable and regularised system that protects the population as a whole.

- The negative impacts of certain forms of humanitarian assistance (e.g., food aid) can be addressed if programming is placed in a more regularised structure under the leadership of the government.

- Social protection can strengthen the legitimacy of the state by allowing it to shoulder its responsibilities for ensuring the survival of its citizens.

- NGOs have been increasingly labelled as amateurish and corrupt, and have wasted aid resources that could be more efficiently used if channelled through government structures and to strengthen government capacities.

- As a country prone to natural disasters and high levels of seasonal stress, Afghanistan requires a system with which to respond to the needs of disaster-affected people.

- Rural people are perceived as shifting to opium production in response to acute livelihood stress, and a social protection system is therefore seen as an important component of a counter-narcotics strategy.

It is clear that a significant proportion of the population faces a structural deficit of assets by which to meet basic livelihood needs. Even if the most optimistic projections of the international community hold, a significant number of people will still experience extreme hardship every year. If the Afghan state (rather than the international community) is to manage its responsibilities, an institutionally sustainable safety net is needed. Concerns are being raised about the untenable nature of organisational roles in the protection of livelihoods. The Ministry of Rural Rehabilitation and Development (MRRD) has pointed out 


\section{Box 3: Analysis of approaches to social protection in Sudan}

In Sudan, the World Bank/UN Joint Assessment Mission (2005) includes a cluster on 'Livelihoods and Social Protection' which encompasses four major components, including communitybased recovery (CBR) programmes within war-affected and leastdeveloped areas. These focus in the short term on vulnerable populations, and address the rights to social protection of those at risk of abuse..$^{32}$ Although a conceptual framework for the cluster is not explicitly described, it is implicit that vulnerability has been defined in terms of internal or structural elements (e.g. relating to age and gender), and that the assessment has been informed by a rights-based approach. The report appears to make very little distinction between social protection and humanitarian protection. and implies that 'this broader approach to social protection' (p. 226) encompasses physical protection, humanitarian protection and social protection. ${ }^{33}$ For example, the report states that 'Social protection ensures the reduction of vulnerability of poor individuals, households and communities through better risk management and seeks to protect the vulnerable from abuses of their human and civil rights' (Eldeen et al., 2005: 216).

The basic forms of social protection recommended for the first phase (2005-2007) in relation to displacement and community-based recovery (which forms the main focus of the

\footnotetext{
32 The other three components are: (i) durable solutions for displaced IDPs and refugees and assistance to communities absorbing refugees; (ii) Disarmament, Demobilisation and Reintegration (DDR); and (iii) mine action.

33 in section 4.3.3, we suggest that the term 'livelihood protection' can perhaps be used to refer to a combination of social protection and humanitarian protection.
}

report), include material support (transport for IDPs and refugees, food assistance, provision of agricultural inputs); monitoring the process of return (to reduce the risk of illegal taxation or physical attack); demobilisation and (humanitarian) protection; quick-impact community-based reintegration programmes in urban areas; as well as advocacy, legal, and basic community social services for the vulnerable. The first phase would also promote the capacity of community committees and provide training for community-driven recovery, so that community-level development initiatives can be implemented (in 2007 or 2008). In the second phase (2008-2011), it is recommended that social welfare systems should be developed for the most vulnerable groups. ${ }^{34}$ in relation to small-scale subsistence and animal husbandry, the report stated that a review of land and water policy will be imperative in the medium term (p. 218). The report notes that well-designed and well-implemented social protection interventions 'support sustainable economic development in a participatory manner' (p. 233), though precisely how social protection will be linked to economic growth is not elaborated beyond stating that the elements of the livelihoods and social protection cluster will be implemented in coordination with the medium- and longer-term efforts of the productive sectors cluster (among others ${ }^{35}$ ) of the Joint Assessment Mission.

Source: Eldeen et al., 2005

$34 \mathrm{It}$ is proposed that these vulnerable groups will be defined by 'vulnerability analysis, taking into account health, income, gender, age and levels of cultural vulnerability' (Eldeen et al., 2005, p.217).

35 The other clusters specifically mentioned are: (i) capacity-building and institutional development (particularly strengthened decentralised government in relation to community development); (ii) governance and rule of law (protection and security for populations of concern); and (iii) basic social services. that 'Accountability is blurred. In the eyes of most Afghans, the government is responsible for social protection, but is not seen to be playing a leadership role in respect to humanitarian resources. As a result, accountability is not clear if things go wrong' (MRRD, 2002: 3). Social protection is thus seen to be an umbrella under which post-conflict humanitarian action is to be subsumed. This builds on an implicit assumption that the profile of risk is shifting from conflict to natural hazards and chronic socioeconomic vulnerability.

The MRRD vision outlined above has significant implications for how the government and the international community seek to ensure security in rural livelihoods. Such a move from humanitarian to more stable modalities involves a shift in responsibilities, from the international community to the government. It will also demand a shift from providing support to loosely defined sets of beneficiaries, consisting of 'vulnerable groups' and disaster victims, to the use of much more refined targeting tools - a major preoccupation in the design of social protection mechanisms (see Devereux,
2002). While overall data collection regarding vulnerability is improving rapidly, the capacity of the government to manage transparent and non-politicised inter-community targeting at field level remains limited. Local government and local governance are still too weak to ensure efficient programming, or to guard against social protection mechanisms being co-opted by local elites (Christoplos, 2004).

While there is no doubt about the desirability of ensuring that social protection structures contribute to agricultural development, weaknesses remain in finding strategies to develop the institutional capacities that would be required to bridge the two. Lack of capacity to assess viability has meant that income generation has been largely left out of the first phase of the National Solidarity Programme. Discussion of agriculture's role in social protection, and with that the possible transition of agricultural rehabilitation programming into social protection, has not occurred, since these issues have been the domain of the MRRD, and not the Ministry of Agriculture and Animal Husbandry (MAAH). 


\subsection{Social protection in Sierra Leone}

Unlike Afghanistan, social protection strategies in Sierra Leone are piecemeal. Two mechanisms described here are food-based safety nets and the use of social funds. ${ }^{36}$ Although Poverty Reduction Strategy Papers (PRSPs) potentially provide a useful way of mainstreaming social protection into broader development approaches, the Sierra Leone PRSP only mentions social protection in relation to future plans for a national social protection policy (GoSL, 2005). This will presumably be designed around the proposed Social Safety Net Scheme (a.k.a. the National Social Security Insurance Trust), which has been devised 'for people who have no regular income and are unable to work, with no means of support and at least 60 years old' (Ministry of Labour Social Security and Industrial Relations, cited in GoSL, 2004, para. 896). Given the overall approach and cost of the scheme, ${ }^{37}$ it remains questionable whether it is appropriate or feasible, in terms of demand as well as capacity. Other forms of social protection, as described below, appear to provide a much more realistic starting point for Sierra Leone's post-conflict 'social protection trajectory', though we would argue that much greater effort is required in developing a demanddriven approach that better addresses vulnerability and is linked to existing informal mechanisms.

\subsubsection{Food-based safety nets}

The World Food Programme (WFP) has proposed the use of a food-based safety net for Sierra Leone, defined as 'collaborative efforts among stakeholders, that use targeted food assistance to prevent poor people's access to food from temporarily falling below minimum acceptable levels' (Imbleau, 2003: 9). Although this definition appears to support consumption only, and not livelihood promotion, the main mechanisms for delivering social protection - school feeding, mother-child health and nutrition programmes, food for training, food for work, ${ }^{38}$ and food for agriculture (primarily seed protection ${ }^{39}$ ) - all provide direct investment in productive assets. The WFP Country Director reported that food for work involving agricultural or rural development work (other than road construction) has proved to be very expensive for WFP in terms of assessment and monitoring, and is best

36 Another form of social protection which we have not described here is the Transitional Safety Net Allowance ( $\$ 300$ in total, in two instalments) paid to excombatants as part of the demobilisation package (World Bank, 1999; ICG, 2001).

37 The full scheme is expected to take care of an estimated 40,000 people and will cost about $\$ 7$ million annually. Given that this scale of funding is extremely unlikely to be made available, a much reduced 'reality' scenario with reduced benefits, covering 10,000 people at about $\$ 2.2$ million, has been put forward.

38 Food for work is primarily for road construction, but can also include other types of rural development work.

39 Food provided for seed protection is delivered at the same time that seed is distributed, and is intended to prevent farmers from eating the seed provided. Food for agriculture in Sierra Leone ceased at the end of 2002. implemented by agencies with the technical capacity required. ${ }^{40}$ However, he also revealed that, when the amount of food aid being brought into the country is reduced, food programmed for safety nets gets cut first, in favour of vulnerable group feeding and therapeutic feeding programmes. It is thus questionable whether food-based safety nets are a realistic option for a post-conflict period when the food pipeline is being reduced. ${ }^{41}$

Given this, it is perhaps surprising that one of the reasons given for supporting food-based safety nets (as opposed to cash-based ones) is that food is thought to be more readily available from donors ${ }^{42}$ (GoSL, 2004). However, the Agricultural Sector Review (ASR) also appears to support food-based safety nets (albeit somewhat cautiously). The ASR outlines some of the current informal family and community-based safety nets currently operating in Sierra Leone, though it is not clear how these might be supported. Finally, the report notes that targeting considerations "might create tension among certain groups of the population, which in turn will lead to civil unrest' (p. 114). Thus, although food-based safety nets may - at least in theory 'represent a vital tool that national governments, WFP and other national and international partners can use to ensure that livelihoods are built upon while assisting those in need' (WFP, 2004: 3), it remains to be seen whether they can be applied in practice in post-conflict situations.

\subsubsection{Social Funds}

The Sierra Leone National Social Action Project (NSAP, 2003-8) provides multi-sectoral funding ${ }^{43}$ to assist waraffected communities to restore infrastructure and services and build local capacity for collective action. Priority is given to areas not previously serviced by the government, and areas that had been under rebel control, and to the most vulnerable population groups within those areas. In terms of implementation, the three main project types are community initiatives, shelter and road development. Whilst the road construction activities carried out under the NSAP contribute to agricultural markets, interventions in the agricultural sector fall under NSAP community initiatives. These are based on a model of communitydriven recovery (derived from approaches to communitydriven development) (Rawlings et al., 2004), in which projects are identified, appraised, implemented and maintained by the beneficiary communities, who assume

\footnotetext{
40 Interviews with implementing agencies suggested that food for agricultural and rural development work has been highly appreciated by rural beneficiaries, not least because it provides support to local forms of community self-help and farm labour.

41 WFP itself appeared to be frustrated by its inability to persuade donors to fund a proposed food for work scheme to rehabilitate coffee and cocoa plantations.

42 Cash - though until recently not favoured by many donors - seems to be becoming increasingly acceptable.

43 The major sectors covered by the project include primary education (25\%), health $(25 \%)$, water, sanitation and flood protection $(20 \%)$, agriculture, fishing, and forestry $(15 \%)$, and roads and highways (15\%).
} 
responsibility for recruiting NGOs and/or local contractors to provide the technical and logistical support necessary for implementation. The National Commission for Social Action (NaCSA) is responsible for overall project implementation, coordination, monitoring and evaluation.

The underlying objective of community-based initiatives is the development of social capital within communities, since it is believed that enhanced social capital makes social action more sustainable in the long term. Communitybased initiatives are promoted using a participatory, demand-driven approach, in which the role of NGOs shifts from implementing agency (as in the previous ERSF approach) to facilitating agency. In practice, however, field visits to the pilot project sites suggest that initiatives were driven less by community demand than by the ability of NaCSA to supply specific types of project inputs, or through 'knowing what was best' for the community. The NaCSA handbook provides lists of projects that are eligible for social fund support. Such 'positive lists' are not uncommon in social funds, and in the case of Sierra Leone eligible agricultural projects include the usual suspects: seed and grain stores; drying floors; small agricultural equipment (e.g. millers, threshers, graters, land preparation machinery); and community seed multiplication.

The interface with local district councils is considered to be key, but this has led to problems because the local councils are prevented from developing the capacity required because NaCSA (a quasi-governmental institution) is effectively playing the local councils' role. Social funds are commonly criticised for establishing such parallel structures for the management and coordination of community-based initiatives (Fumo et al., 2000).

The NaCSA approach aims to address vulnerability through building social capital, and to reduce poverty through community empowerment, but whether there is real understanding of the root causes of vulnerability in agrarian society is questionable (Richards et al., 2003). This suggests that NaCSA may be ill-equipped to tackle issues of vulnerability and inequity. A study by Tendler (1999) of four social fund programmes in north-eastern Brazil argues that social funds are least appropriate in contexts where asymmetries of power are significant. Tendler observes that, rather than reducing such asymmetries, social funds may in fact reinforce them.

\subsection{Summary}

Sector-based agriculture interventions alone are unlikely to reach the most vulnerable, and need to be complemented with specific social protection measures (Marcus et al., 2004). We have defined social protection as 'acts and measures designed to protect people against socially unacceptable levels of risk and vulnerability', and have suggested that the key to appropriate social protection in post-conflict situations lies in understanding vulnerability in a way that incorporates notions of powerlessness. Drawing on the links between social protection, livelihood promotion and humanitarian protection, protection and promotion encompass not only mechanisms that allow people to cope with adverse circumstances, but also mechanisms to promote livelihoods, both in economic and social terms: i.e., to promote opportunities for poverty reduction, inclusion and non-discrimination.

Although this makes sense at a conceptual level, there is very little evidence from the case study countries to suggest that it exists in practice. Given the growing acceptability of cash-based interventions in both the humanitarian and development sectors, there could be potential for NGOs to deliver cash-based social protection in an early phase of a social protection trajectory. As the trajectory develops, there is a need for innovative institutional partnerships between government, donors and NGOs. In combining social protection with agricultural growth, this raises questions around how to coordinate across different ministries, and how to ensure that the necessary capacity is brought in to the agricultural sector and coordinated with other social protection programmes. The challenge of enhancing the logistical and institutional capacities required to deliver agricultural goods and services is addressed in the next section.

Social protection can potentially provide the framework for more effective collaboration. But social protection tends to exacerbate rather than reduce inequality. Addressing such inequalities is by no means straightforward, and may require significant institutional reform. Although the need for such reform is often recognised in countries emerging from conflict, the next section will show that this is by no means easy. 


\section{Chapter 5 Enhancing institutions}

\subsection{Introduction}

A livelihoods approach is multi-level, in that interventions are informed by local-level analysis and supported by the creation of an enabling environment through structures and institutions at meso and macro levels. This chapter addresses the challenges of enhancing three types of institutions: state or public sector institutions; private sector institutions; and those that form part of what is generally referred to as civil society. ${ }^{44}$ The chapter begins with a theme that has been recurrent in earlier chapters the need to recognise and build on informal institutions. A particular challenge in post-conflict situations is that there is often a need both to strengthen and reform formal institutions - either because they may have been one of the causes of the conflict, or because they are no longer appropriate to present circumstances and more receni development thinking (and associated donor preferences).

The humanitarian principle of neutrality suggests a need to be cautious about re-engaging with state structures and institutions in situations of conflict. Close associations with the state may compromise the perceived neutrality of humanitarian agencies, and may make it more difficult for them to access all parts of a country. Chapter 6 goes on to examine the issue of principles in more detail. The question of when it is appropriate to provide support to various different types of institutions is highly contentious and requires detailed political analysis. There is often a tendency for humanitarian organisations to bypass the state entirely, either because it is seen as predatory, corrupt or politically unacceptable, or because it lacks the capacity to be effective. This often results in the establishment of parallel structures which may subsequently add to the challenges of enhancing institutions.

\subsection{Formal and informal institutions: aid imperatives, political conundrums and farming realities}

Efforts to strengthen institutions are concentrated at local level in the midst of the conflict (in those areas where security conditions permit). When a legitimate government is installed, attention shifts to central levels. Questions then emerge about the capacity of fledgling ministries of agriculture to connect with their government colleagues in

44 Civil society refers to the set of institutions, organisations and behaviour situated between the state, the business world, and the family. Specifically, this includes voluntary and non-profit organisations of many different kinds, philanthropic institutions, social and political movements, other forms of social participation and engagement and the values and cultural patterns associated with them. (Cited at http://www.lse.ac.uk/collections/CCS/what_is_civil_society.htm). the countryside, as well as the private sector and civil society. A major conundrum that arises is how to ensure that efforts to rebuild formal institutions remain cognisant of the strengths and importance of the informal institutions that have inevitably taken centre stage in agricultural systems during the conflict years. This conundrum has been the subject of particular concern within the seed sector, where - even in developmental contexts - the question of how to 'link' informal and formal seed systems has received considerable attention (see Box 4).

While formal institutions are essential, more attention could be given to viable, alternative mechanisms through which farmers can access the inputs and services they require. Aid flows are by nature biased by assumptions that the revival of agricultural production can only be achieved through reestablishing formal institutions for input supply and credit. For example, Securing Afghanistan's Future makes no mention of the informal sector in its discussion of engagement with the private sector. Although aid agencies need relatively formal institutional counterparts, farmers have less stringent demands. Experience in Pakistani cotton farming has shown that informal structures can provide high-quality agricultural services, and can create effective links to the formal sector (Smith et al., 1999). Some surprisingly strong informal Afghan institutions have appeared in response to gaps in formal capacity. The hawala money exchange system in Somalia and Afghanistan provides an efficient and reliable structure for financial transfers that reaches well into rural areas (Maimbo, 2003; Ahmed, 2000). ${ }^{45}$ In Somalia, remittances via the hawala system are important for livelihoods and are increasingly invested in small businesses, including in the agricultural sector (UNDP, 2002). In Sierra Leone, DFID has proposed supporting small businesses (including those in the agricultural sector) by guaranteeing loans to allow Sierra Leonean citizens in the diaspora to invest in the country.

Whilst attention should be given to supporting informal institutions, this must be on the basis of a sound understanding of what is appropriate. Attempts to regulate or formalise hawala into banking institutions, for example, are likely have a negative effect on poorer people. In the seed sector, misdirected attempts to support informal

45 After being portrayed in the Western press and by many politicians after $9 / 11$ as a shady enterprise that finances terrorism, views on hawala have begun to undergo a reassessment. It is now increasingly acknowledged to be a highly efficient and essential structure for linking the rural economy to the international system by channelling vital remittances - 'it can be argued that what hawala is vilified for (speed, trust, paperlessness, global reach, fluidity) are precisely the attributes that modern globalising investment banking aspires to (de Goede 2003: 517). 
systems have merely recreated formal systems at community level (see Box 4). In the case of Sierra Leone, Farmer Field Schools are regarded as 'community-based extension systems' and are in part justified by the fact that more formal agricultural institutions would require considerably more capacity-building efforts than are at present possible. But the assumption that informal institutions require less capacity-building, or that capacitybuilding for informal institutions is somehow easier than with formal institutions, needs to be carefully considered.

Informal trading networks have also proved very resilient. In Afghanistan, the domestic market for dried fruit has remained strong despite the collapse of export markets

\section{Box 4: Formal and informal seed systems in Southern Sudan}

Starting in the mid-1990s, increasing amounts of relief seed distributed in southern Sudan were sourced from three donorfunded projects in Western Equatoria. One of the reasons for establishing these local seed production schemes was to strengthen and support informal seed production capacity, which could potentially lead to the establishment of a formal seed sector in southern Sudan. But this rationale was based on a fundamental misunderstanding of both formal and informal seed systems. Without a commercial farming sector, the conditions for the development of a formal seed sector do not exist. There is no commercial farming sector in southern Sudan. In other developing countries, the formal seed sector only finds it profitable to market seeds of hybrid varieties, vegetables and some cash crops such as cotton and sunflowers.

The complexity of local farming systems makes it extremely hard for outside agencies to provide appropriate seed, and repeated interventions run the risk of undermining local institutions. The three seed schemes in Western Equatoria multiplied Serena sorghum, an early-maturing 'improved' variety developed in Uganda in the early 1960s as a commercial crop. The variety was developed with high tannin content to reduce the incidence of bird damage; the tannin also gives Serena a slightly bitter taste that many people do not like. Despite repeated distributions of relief seed of this variety to farmers in southern Sudan, they have largely continued to plant seed of their preferred local varieties. In terms of marketing, contract farmers working under the three seed schemes were unable to sell their seed surpluses without the presence of the NGOs. The only market for seed in southern Sudan was provided by relief agencies. Even without the added complexities of chronic political instability, it is worth noting that the seed sector in SubSaharan Africa is not well developed; despite considerable donor investment in community seed production, projects have not been sustained.

Jones et al., 2002.
(FAO, 2003c), and the country has retained its export market for pistachios to India, even though production has decreased due to the destruction of pistachio forests. Although the lack of an effective, controlling state may often allow trade to flourish, particularly for certain products (e.g. opium in Afghanistan), extortive taxation systems set up by local warlords and militia can also create constraints. The lack of a state can be particularly problematic for the export of agricultural products when negotiations with other countries might be necessary to overcome trade barriers. Somalia, for example, has not been able to undertake the negotiations necessary to reverse livestock bans imposed by the Gulf States. In Sierra Leone, on the other hand, the lack of state controls for cross-border trade with Guinea has enabled the expansion of Barmoi market in Kambia District, and the market has become one of the biggest in the country.

\subsection{The need for institutional reform}

Detailed conflict analysis rarely plays a significant role in planning for agricultural rehabilitation, yet the institutions governing land tenure or the power of local authorities can potentially be crucial in determining the success of agricultural interventions. In many conflict or post-conflict situations, there is a need to reform such institutions as part of broader peace-building efforts, yet this must be done in such a way that production is not threatened and the needs of vulnerable or marginalised segments of rural society are adequately addressed. At the same time, betterresourced parts of society, who tend to play an important role in the informal provision of inputs and services, must not be alienated. Similarly, within the more formal institutions of the public sector, a balance needs to be found between the need for institutional reform and the need to ensure that farmers can access the inputs and services they need for reconstruction. This is further explored in the next section in relation to Afghanistan.

The apparent need for institutional reform in Sierra Leone is emphasised by the recommendations of the National Recovery Strategy Assessment:

The war has provided an opportunity for Sierra Leoneans to rethink fundamental issues relating to their national dynamics and identity. This should include the rebuilding of sustainable institutions as part of a new foundation responsive to the particular conditions and needs of the people they are intended to serve. The lessons from the war and this recovery effort would be valueless without fundamental questions about what in the national system of doing business may have contributed to the war starting in the first place and its inherent destructiveness. The recovery and development phase must guard against merely recreating institutions and focus on fundamentally reforming or replacing them (Moore et al., 2003: v). 
The perceived need to 'fundamentally reform or replace' institutions is common in countries emerging from conflict, but neither is easy. The defining characteristics of institutions are that they are 'significant' and 'established' (Ottaway, 2003), implying that existing institutions are very difficult to change and that new institutions cannot be constructed easily or quickly. Despite this, there is often a tendency among external actors to assume that old structures have collapsed, and there is a blank slate for introducing new policies, institutions and processes. Such assumptions about the lack of state structures have proved to be misplaced. In Afghanistan, for example, the strength of many government institutions (though not necessarily in agriculture) has caught planners off guard (AREU, 2004).

Evidence from the case studies and other experience present varying approaches to institutional reform. In Afghanistan, the question of land tenure, for example, has received attention relatively late in the recovery process, and is primarily seen to be of practical concern only in relation to the return of refugees. Current thinking in southern Sudan, on the other hand, suggests that land tenure must be addressed as early as possible, with pilot initiatives already taking place prior to the signing of a final peace agreement (Caroline Gullick, pers. comm.). In Sierra Leone, the World Bank, for instance, has emphasised the need for land tenure reform, and the topic has been the source of much debate among international agencies and lawyers in Freetown, but at the time of writing there appeared to be no concrete plans for change. It would seem reasonable to suggest that the urgency of the need for the reform of specific institutions is determined by the extent to which they are regarded as a causal factor relating to the conflict. In this respect, the slow pace of reform of local authorities in Sierra Leone is of particular concern (see Box 5).

The view that crisis can be used to motivate reform may be out of step with political processes in post- and chronic crises more generally. Boin and 't Hart point out that the narrative of crisis as an opportunity for reform is widespread in the North as well, but is profoundly flawed as 'the requirements of crisis management are inherently incompatible with the requisites for effective reform' (2003: 545; see also Christoplos, 2000). The former requires the reinforcement and mobilisation of existing capacities for immediate response (e.g. in service delivery), while the latter demands taking a step back from the current structure and accepting the political risks of major restructuring. Citizens' expectations and other factors put pressures on political leaders and the aid community to show quick results and provide visible public services. But whether outsiders can ever set up viable institutions is a question open to debate; typically, they set up organisations, not institutions (Ottaway, 2003).

\section{Box 5: Reform of local authorities in Sierra Leone}

Grievances against chiefdom authorities are recognised as one of the major factors leading to conflict in Sierra Leone (Fanthorpe, 2001; Richards, 2001). Prior to the war, many chiefs served as the willing instruments of an oppressive patrimonial regime, delivering votes to the governing party and suppressing rural protest, whilst abusing their powers and imposing extortionate fines on their subjects to make up for their lack of salaries (Fanthorpe, 2002). Corruption in the local justice system at both chiefdom and district levels was rife. Prior to the signing of the peace agreement, at a time when the democratically-elected government was struggling to 'reclaim the countryside' (Richards et al., 2004: 32), DFID funded the Chieftancy Reform Project. The project was initiated with a consultative process undertaken at chiefdom level through which separate groups of chiefdom authorities, women and youth were invited to air their grievances over a two-day facilitated exercise. The results of these consultations (about 70 were conducted in total) clearly point to the need for reform of the chieftancy authorities, and in particular the local justice system. Local people put forward ideas as to how to proceed with such reforms, but the consultation findings were not followed up (Richards et al., 2004). No systematic effort has been made to undertake reform. Instead, the chiefdom administrations and customary courts have been reinstated in a way that shows many signs of a return to 'business as usual', and the 'resentments revealed through the chiefdom consultation exercise are likely to be further fuelled by the slow pace of reform' (Richards et al., 2004: 34-35).

\section{$5.4(\mathrm{Re})$ engaging with the state}

\subsubsection{New Public Management: towards a leaner state in Afghanistan?}

Within the National Development Framework (NDF), Afghanistan's crisis has been transformed into an opportunity for reform according to what is elsewhere referred to as 'New Public Management' (NPM). ${ }^{46}$ The formal endorsement of the NPM approach is widely perceived to be more a product of donor pressure than domestic commitment, and the continuing strength of the government's opposition to NPM has revealed that the state was not as collapsed as expected. There is intense pride in the civil service (AREU, 2004), and both the state and the civil service have been surprisingly vigorous in striving to rebuild (rather than reform) structures of the past.

46 NPM refers to the models for attempting to minimise the role of the state and increase the role of the private sector and civil society; it was implemented widely in Europe during the 1980s, and has been increasingly promoted as part of structural adjustment programmes in the South and East. More recently, these ideas have gained favour in international strategies for rebuilding 'failed' or 'collapsed' states. Whether the state has actually collapsed, or is merely constructed as such by those who wish to reform it (Duffield, 2000), is a contentious point. 
When the current government assumed power in late 2001, the majority of politicians and civil servants in agriculture took for granted that a large and well-financed state-led agricultural development effort was going to be put into place. There is thus a major gap between the plans for agriculture and rural development outlined in the NDF and prevailing agricultural policy as it is perceived by most of those working with the MAAH, and in the NGOs providing agricultural services. Despite formal endorsement of new policy concepts by key actors at central level, there is little sign that these are either understood or accepted at other levels. Provincial and district officials retain the view that, since agriculture is the 'backbone' of the local economy, this therefore justifies state dominance in the financing and provision of agricultural services and in planning production priorities. A majority of those in provincial and district political and civil service structures involved in agriculture retain expectations of a return to state-led development, requiring a large bureaucracy and public service provision. Even relations to civil society are assumed to require a strong leading role for the state.

Agencies including FAO, ADB and DFID are investing in capacity-building for the MAAH in order to increase awareness of international norms and practices among key staff. Most acknowledge that these efforts have made limited headway. Even where NPM has been accepted, there is no consensus regarding what a facilitating and regulating state actually consists of on the ground, and what could be done to promote the growth of the private and civil society structures that the state should eventually facilitate and regulate. The fault does not necessarily lie with aid efforts per se, but rather with uncertainty within the system about what capacities should be built. The implications of the NDF for setting priorities have only just begun to be absorbed at a conceptual level. Genuine, widespread and sustainable ownership can only be expected to emerge once it is determined what these concepts imply about who does what.

Reform as exemplified in Afghanistan's NDF has its roots in efforts around the world to reduce the role and scale of state bureaucracies and create a lean state. Public sector reform is assumed to consist, to a large extent, of reduictions in public sector staff. A paradox in these countries is that there is presently little agricultural bureaucracy to actually retrench. Instead, there is a need for expansion to meet the challenges of a facilitating and regulating state. There is a contradiction between the retrenchment narrative and the actual make-up of the agricultural civil service. For example, even if the state was to abandon its hopes for engaging again in direct service provision, the challenges it faces in shouldering the regulatory and facilitatory tasks envisaged in the reform narrative are enormous. Border controls, inspection of imported fertiliser and pesticides and the need to monitor and regulate a transparent system for agricultural finance are all pressing needs where capacity will need to be enhanced.

\subsubsection{Decentralisation in Sierra Leone}

Restoring state authority at both national and local levels was the first of four priority areas under Sierra Leone's National Recovery Strategy for 2002-2003. The consolidation of state authority was seen as necessary 'to provide security, law and order, policy, coordination and control of economic resources' (GoSL, 2002: 17). The restoration of core government services was also considered to be critical to support the resettlement process. At the same time, a process of decentralisation announced by the government in 1996 was being implemented. An overly centralised state controlled from Freetown was considered to be a contributing factor to the war; as such, addressing this was seen as necessary for sustainable peace. The process of decentralisation initially involved revitalising local councils, but this has been hindered by a lack of capacity at the district level, compounded by a lack of funds.

Whilst there is reportedly overwhelming support for decentralisation among the population, levels of government corruption are such that concerns have also been voiced over the possibility that it would merely bring corruption closer to the people (Richards et al., 2004). In any case, the decentralisation policy has not been fully accepted by the central government, which retains tight control over local councils (Katarikawe, 2003). There has been considerable confusion over what was meant by decentralisation: whether it referred to merely a deconcentration of administrative offices, or to the political devolution of power. This confusion exists in the Ministry of Agriculture: a donor-funded review discusses the need to decentralise services, but what it actually means is deconcentrating services to district offices. Despite a desire for agricultural inputs and services to be provided through district-level offices and for the district council to play a role in deciding how such inputs would be allocated, the actual structures through which this could be achieved remain vague in practice.

The role of NGOs in supporting the decentralisation process has been questioned (Nickson, 2003), and the part played by NaCSA also appears to prevent the effective functioning of district councils in areas where the council supports parties in opposition to the government. Although NaCSA claims to work closely with the District Recovery Committees (DRCs), and there are plans for the regional disbursement of NaCSA funds through decisionmaking processes that involve the DRC, NaCSA can effectively bypass state structures completely. Although this means that it can operate more efficiently, it does little to help build government capacity. 


\subsection{Strengthening the private sector}

Sierra Leonean and Afghan government policies stress that development should be led by the private sector. The private sector is expected to generate an internal dynamism that will stimulate increased agricultural productivity, while not unduly burdening the limited capacities of a state that must rapidly move towards becoming 'self-sustaining'. Although this broad policy is ostensibly agreed, there is less understanding of what it entails. In Sierra Leone, government officials point to the development of an enabling environment for private sector investment (see Box 6). But experience from Afghanistan illustrates practical challenges specific to realising such investment in postconflict situations.

In Afghanistan, experiments with market-based approaches are at an early stage. NGOs and the government provide the majority of aid- and public sector-financed services. Both 'NGOist' and 'statist' services are supply-driven and lack a 'customer' or demand-driven orientation. Neither includes accountability mechanisms or elements of competition. This problem has been recognised in Securing Afghanistan's Future, but few evaluations, assessments or plans explore the possible or

\section{Box 6: Creating an enabling environment for private sector development in Sierra Leone}

In Sierra Leone, a number of steps have been taken to create an enabling environment for private sector expansion. These include:

- Macro-economic measures on exchange and interest rates regimes, control of inflation, and trade liberalisation.

- The appointment of a Commission to carry out divestiture. The Commission is identifying potential ventures for privatisation.

- The government has removed subsidies on key inputs to make them more competitive.

- An Investment Code has been formulated, and the government is in the process of finalising it.

It is envisaged that the investment climate will be further enhanced by improvements in the road and communication networks, the energy sector and the irrigation and drainage infrastructure; there are also plans to improve the data available on the country's natural resources.

In addition to promoting a large-scale commercial sector, support to Farmers' Associations, Rural Community Groups and Cooperatives (initially in the form of grants, loans and training in managerial skills) is designed to enable them to become viable private sector entities for the delivery of services, inputs and marketing. actual impact on private sector development of investment in either the NGO or the statist model. ${ }^{47}$ Little attention is paid to the danger that NGO programming will crowd out private service providers. Even where the private sector is given priority, the desire to demonstrate 'quick impact' encourages the provision of large and presumably very soft loans to a limited group of selected entrepreneurs.

USAID and other agencies are starting to invest in value (or commodity) chain initiatives, bringing together producers, traders, processors and other service providers involved in the development of commercial products. By looking at the entire chain related to a given commodity, it is hoped that prohibitive transaction costs can be identified and addressed. One of the first hurdles that must be overcome in such an approach is to find a way of establishing greater trust among these different actors. This is not easy even in 'normal' development contexts, and it is particularly difficult where key stakeholders do not believe that they can resort to formal legal mechanisms if agreements are not upheld. Pashtu traders are important actors in rural Afghan service markets, but do not trust local or national governmental and judicial structures to treat them fairly and equitably (ICG, 2003). Through the USAID-funded Revitalising Agricultural Markets Project (RAMP), commodity chain support is being considered for 'food processing incubators' in order to help fledgling enterprises that might seek to sell services such as drip irrigations systems, post-harvest storage facilities or transport (see Heierli, 2000).

At the time of writing, the largest engagement with the private sector was in seed production, where serious attention is being paid to redefining farmers as customers rather than beneficiaries. Current thinking within FAO indicates that a commercially viable seed system will require far more attention on how to actively market the product. There is also a realisation that, due to small margins between seed and grain prices, wheat seed is unlikely to provide a commercially viable base for a seed enterprise. Higher-value products, such as vegetable seed, must be part of an eventual marketing strategy. It should be stressed, however, that although FAO is discussing these ideas with the MAAH at central levels, seed enterprises and NGOs continue to plan levels of seed production according to government targets and donor promises of procurement, with little regard for whether farmers want to buy the seeds produced. The result has been that only half of the seed produced by FAO's implementing partners has been resold to farmers.

\subsection{Civil society capacity-building}

In both of the case study countries, efforts to build or empower 'local organisations' have led to questions about 


\section{Box 7: Shuras and agricultural development in Afghanistan}

For the aid community, and to some extent for the government as well, Afghanistan's traditional councils or shuras are the lynchpins of the institutional infrastructure that will support future agricultural and rural development, and the rebuilding of what is popularly assumed to be heavily depleted social capital. But both the rationale and the sustainability of shura-based community development must be questioned. Even otherwise laudatory reviews of the role of the shuras acknowledge that 'What the agency expects the shura to do, in the function of a Village Development Association, is something very different from what the shura used to do, what it is set up to do, and what the community expects it to do' (Harpviken, 2001: 11). Despite concerted efforts at 'empowerment', extending over a decade, an evaluation of one major integrated rural development programme notes with concern that not a single shura has 'graduated' from programme support (Reddick, 2003).

Another central question regarding the role of shuras in supporting agricultural development concerns whether they can be considered to be, or can be transformed into, 'farmers' organisations'. At the centre of this issue is whether shuras can develop into genuine producer organisations, accountable to their members (rather than to the community as a whole), and whether they can manage economic transactions in a competitive market economy. This is doubtful. First, the

which types of local organisations should be the focus of such efforts. Current understanding of 'traditional' local organisations suggests caution in assuming that these organisations can be expected to share (or be induced to share) the same objectives as the aid community (Cooke $\&$ Kothari, 2001; Grünewald, 2003; Harvey, 1997; Keen, 1994). Studies have shown that the consensus formed through participatory methods rarely represents the concerns of the poor or marginalised. In Sierra Leone, for example, the village development committees that relief agencies relied on for the distribution of relief (generally comprised of village elders and elites) systematically excluded residents of smaller, remote 'satellite' settlements, and those who lacked power or political connections (particularly youth, women and IDPs) (Archibald \& Richards, 2002). Similarly, in Afghanistan, the role of the shuras (traditional councils) in supporting agricultural development has been questioned (see Box 7).

Research into the role of traditional institutions and social capital has recognised that, while these institutions are the first (and most reliable) source of support for the destitute and those experiencing livelihood shocks, they also reinforce the types of structural vulnerability described in section 4.2. Kothari and Hulme write:

When poor people in Bangladesh face problems their first port of call for social support are these local/informal networks prospects for sustainability are poor as long as aid projects are the main buyers of produce (as is the case in much seed production). Many project plans are vague about how the supporting agency will eventually withdraw, to be replaced either by market relations with commercial traders and processors, or by a higher-level organisational structure that can assume responsibility for marketing and other tasks. There are efforts to work with intermediate levels, but there is little indication that these organisations are motivated by a genuine desire to engage in cooperative economic activities. Furthermore, mechanisms to ensure financial accountability to 'members' have not been developed. This should come as no surprise, since the shuras are ultimately not economically oriented membership organisations, but political bodies.

The second problem in treating shuras as if they were farmers' organisations is the tendency to combine community development efforts, which have primarily social aims, with efforts to organise producers, which must be led by commercial and market prerogatives focusing on the interests of individual households. Agricultural development efforts channelled through shuras may be effective in dealing with some public goods, such as locust control, but are unlikely to develop into the type of structures that would be necessary to address private goods.

and not 'professional' poverty reduction agencies. Hoving said this, there is a need to shift our focus in contemporary development policy from an uncritical valorisation of civil society in order to recognise that social capital is not always and inevitably a positive asset but one which can also keep poor people poor (2003: 13).

This could be expected to be especially true where the local power structures that lead 'civil society' have the kind of unfettered power they have in Afghanistan. There is, however, little acknowledgement of such ambivalence about the power of civil society in Afghan rural development programming. A typical programme document states: 'Participatory decision-making can empower the marginalised and develop a community's capacity to analyse its environment, identify and address its problems, and take responsibility for development' (FAO 2003b: 13). Despite evidence and experience of the abuse of power by warlords, commanders and village elites, the myth of egalitarianism in Afghan civil society persists.

Agricultural rehabilitation in Sierra Leone remains anchored in supply-driven service provision, and farmers' organisations are seen as useful interlocutors in the supply of services to farmers. Few agencies would question the need to strengthen farmers' organisations and civil society, and significant investment has been made in strengthening the capacity of organisations that claim to represent 
communities and farmers. At the same time, the supplydriven nature of aid flows has meant that efforts to build capacity appear to be focused on building capacities to absorb aid, rather than to demand it. Donor funding also creates pressure to identify, build, create or strengthen 'implementing partners' - that is, formal organisations that can receive and utilise aid, rather than the wider formal and informal institutions that farmers rely upon to access capital, inputs, markets and knowledge.

\subsection{Summary}

Recognising and building on the strengths of informal institutions is important. Yet it is also necessary to be aware of the potential dangers of reinforcing structural causes of poverty and vulnerability through support to such institutions. In cases where particular institutions (local authorities in Sierra Leone or land tenure in Southern Sudan) are regarded as a causal factor relating to the conflict, reform may be deemed necessary, but it must be accepted that institutional reform is a very slow process. It is also important to be able to identify which local institutions are the most appropriate to community development. Despite considerable rhetoric about 'community-based' or 'communitydriven' interventions, 'participation' and 'empowerment', such approaches will only be effective once agencies start shifting some of their power to their community partners. The case of the shuras in Afghanistan suggests that sustainable impact may only be achieved if a more transparent distinction is made between the different tasks of civil society: between farmers' organisations/cooperatives providing services for members; implementing partners providing investment in public goods; bearers of civic responsibility in the political sphere; and mechanisms for the delivery of social protection.

Civil society institutions, the state and the private sector each have a role to play in the delivery of agricultural inputs and services, but there is a lack of clarity as to what these roles should be. Policy documents emphasise the private sector, but there is little evidence of practical initiatives in the agricultural sector to promote private enterprises which do not involve large loans or even grants. At present, a plethora of NGOs are providing agricultural services and inputs, and there is a risk of 'crowding out' private sector involvement because a level playing field for commercial competition is lacking.

In both Afghanistan and Sierra Leone, post-war public sector reform agendas met with varying levels of resistance among politicians and civil servants, raising the question of whether crisis can really be used to motivate effective reform. Citizens' expectations for effective service and input delivery may mean that plans for reform are accorded a lower priority by politicians keen to be seen to respond to the needs of their publics, rather than to donor pressure to restructure. In this respect, existing institutions are often stronger than external actors assume. Finally, the question of whether outsiders can ever set up viable institutions remains to be answered. In sum, although reform is often necessary, the challenges involved must not be underestimated. 



\section{Chapter 6 Policies, programming and principles in post-conflict transitions}

\subsection{Introduction}

This final chapter reviews aspects of aid architecture and policy and offers suggestions as to how post-conflict agricultural programming might be conceptualised and implemented in a pragmatic manner which also respects core humanitarian principles and the principles of livelihoods and rights-based approaches. The greater willingness of development aid actors to provide funding in post-conflict situations brings with it a range of new opportunities, but existing aid policy tools are inadequate in guiding programming decisions, largely because they fail to address micro-macro linkages, and thus overlook the need for institutional and policy reform in the countries in question. In this respect, this section considers whether a focus on livelihood protection and promotion can enhance existing aid policy tools, and to what extent this is programmatically feasible.

\subsection{Aid architecture and policy considerations}

\subsubsection{Looking beyond project fixes}

Chapter 3 has shown how post-conflict agricultural programming tends to consist of collections of projects, without clear exit strategies or links to longer-term visions for agricultural development. In lieu of broad-based rural development policies, the sum collection of programmes and projects become a proxy for operationalisable policies. One result is that competition over supplies and pressure to expend them quickly (and achieve 'quick impacts') take precedence over coordination and strategic direction. In Afghanistan, an evaluation from 2002 stated that 'Current reconstruction practice - what agencies actually do and how they do it - in practice bears more resemblance to regionalism and warlordism than to a coherent and effective aid programme' (Kempenaar et al., 2002: 7). Coordination has improved since then, but it is still rudimentary in many respects. Rather than a thought-through transition, the tendency has been for rehabilitation programming simply to peter out.

Effective agricultural interventions need to be linked either with policies or, at a minimum, with a clear understanding of where aid fits into production processes. The usefulness of a sack of seeds can only be determined in relation to everything that is happening on farms, in markets and among the public, private and civil society actors that are servicing, regulating and trading with farmers. Potentially positive innovations have been developed, for example through projects that aim to provide technical support, training and information services to implementing agencies in areas such as integrated pest management and water management (as in Somalia). Overcoming a projectised approach requires effective coordination and strategic planning in which an overall goal or objective is clearly defined. In section 6.3.1 we suggest that the overall objective of agricultural programming in countries emerging from conflict should be to effect a transition from supply-led to demand-driven systems for service delivery.

\subsubsection{Coordination}

Improving coordination is arguably the key to effective post-conflict agricultural programming. Macro-level aspects of coordination include policy dialogue, resource mobilisation, coherence between politics, peacekeeping and humanitarian and development aid frameworks (Jones, 2004) and prioritising allocations to sectors and projects. Micro issues include project implementation, harmonising approaches and monitoring and evaluation. Particular challenges lie in linking the micro and the macro, and ensuring that agencies take heed, especially where coordinating bodies lack the means or the mandate to enforce their policies, and broadly defined objectives and principles are subject to interpretation. In the agricultural sector, FAO's experience has shown that one way of achieving more effective coordinating control over agencies is through guiding the provision of inputs (i.e. seeds and tools). Obstacles to effective coordination include the costs of administration and logistics, and the need to develop agreed frameworks in the context of differing donor priorities.

One clear shift in coordination systems in post-conflict situations is the transfer of responsibility for coordination systems from the UN to the World Bank and other international financial institutions that work together with government agencies. This has happened in Afghanistan, and is happening in some of the countries affected by the Indian Ocean tsunami of December 2004. There are also attempts to move away from coordination based on sectoral lines to coordination based on broader, multisectoral issues, such as food security in the case of Sierra Leone. At any one time, it is not uncommon for there to be a multiplicity of overlapping coordination mechanisms.

The Good Humanitarian Donorship Initiative (www.reliefweb.int/ghd/) is searching for ways to ensure that donors support (or at least do not undermine) 
coordination efforts. Generic guidelines are being developed that may provide a basis for better humanitarian coordination in the future. Difficulties can be expected, however, in linking the interagency coordination process with the transitions in coordination that are required for coherent and contextually relevant links between aid and the wider spectrum of factors affecting agricultural production. There is a danger that the need for simplicity (and manageable accountability mechanisms) in the former may lead back to standardised packages of seeds and tools as the lowest common denominator of response.

\subsubsection{Agency capacity and mandates}

The gap between rehabilitation programming and the need for agricultural policies is also related to the capabilities of agencies in the field. Protracted crises result in the presence of a large number of agencies accustomed to relief modalities. Staff take 'supply-side', distributionfocused programming for granted, and there is a tendency among relief workers to regard the communities with which they work as being too poor to pay for any form of services. Relief-oriented staff often have little experience of more participatory ways of working. Although many international agencies are now making efforts to work with local NGOs and provide capacity-building support to local agencies, the aim is primarily to facilitate the implementation of aid projects, rather than to contribute to sustainable service provision or to address the problems of weak institutions and poor access. Limited technical capacity among relief-oriented agencies means that they miss the institutional forest for the projectised trees.

For these reasons, relief-oriented agencies are probably not best-placed to take responsibility for planning post-conflict agricultural programming. Agronomists and developmentoriented personnel, on the other hand, often lack awareness of the issues and debates within the humanitarian sector that inform principled approaches to post-conflict agricultural programming (see section 6.3.3). In countries experiencing particularly long-lasting conflicts, there is the additional problem that agricultural bureaucracies are often isolated from changes in international markets and patterns of publicsector reform. Pre-war plans are dusted off, but these are perhaps a decade or more old, and are based on assumptions of a large, well-funded public sector bureaucracy with the capacity to manage a national development process without significant attention to international market trends. Ministry of agriculture staff (almost invariably old and male) may not be receptive to being retrained by international advisors.

\subsubsection{Donor funding}

A range of funding initiatives and instruments has been developed in recent years to improve the effectiveness of aid in protracted crises and post-conflict situations (Randel et al., 2004). Yet interviews with agencies in Afghanistan and Sierra Leone suggest that the phasing out of emergency funding has yet to be matched by an increase in the development resources available to NGOs. Operational agencies either have to scale down their programmes, or they are criticised for being stuck in relief modalities. Funding structures available to NGOs have largely not been supportive of those actors who wish to take on a more forward-looking agenda; strategic considerations are largely overshadowed by tactical considerations around accessing different funding windows. The difference between what is labelled 'humanitarian' or 'development' programming is usually not directly related to modalities or to needs. The choice of whether to label an intervention as 'humanitarian' or 'developmental' has more to do with which label best ensures access to funding, rather than with the nature of the support given. Some 'emergency programming' consists of projects that the implementing agency would like to use for development purposes, but short-term funding is used since it is the only resource available. In cases where NGOs have private funding sources, this money is often spent in more strategic ways.

The funding that is available for longer-term programming in post-conflict situations tends to be channelled through UNDP, the IFIs and/or the government. The Afghan Reconstruction Trust Fund (ARTF), managed by the World Bank with support from UNDP, channels donor funding from a range of sources to provide budgetary support. The lack of government capacity appears to be less of an issue than whether the government can be trusted not to misuse these funds. In Sierra Leone, World Bank social funds have been channelled, not through the government, but through parallel structures. Whether this arrangement has prevented corruption and misuse is debatable. Neither the ARTF nor social funds in Sierra Leone provide funding explicitly for the agricultural sector.

\subsubsection{Aid policies}

Changes in funding for post-conflict situations reflect donors' increasing stress on the links between security, development and humanitarian assistance (Randel et al., 2004), but the policies needed to provide practical guidance in how to allocate this money in the agricultural sector have yet to become workable. This section examines two policy frameworks - the EC's Linking Relief, Rehabilitation and Development (LRRD) and the FAO's Twin Track Approach and considers whether the concept of social protection might provide a way forward.

The EC's 1996 and 2001 Communications on LRRD put forward various proposals relating to coordination and flexibility in implementation, as well as the procedures within the EC to promote more coherent links between relief, rehabilitation and development. Although some progress has been made, and examples of successful LRRD exist, these depend more on personal commitment than on EU policy (Viciani, 2003). Individuals with the EC in Sierra Leone and Somalia who have used the LRRD 
framework (in the health and food security/rural development sectors respectively) claim that they have had to go beyond the guidance contained in the LRRD documents and develop their own strategies for applying LRRD in practice. There remain a number of impediments to LRRD implementation; various elements have been identified as either lacking or unclear; and there is a need to continue thinking about and debating what LRRD means in practice (Viciani, 2003; EuronAid, 2002; ActionAid Alliance, 2003). In short, available evidence suggests that the LRRD framework has proved to be inadequate in countries emerging from conflict.

FAO's Twin Track Approach to food security seeks to combine investment in agriculture and rural development (track one) with targeted programmes to enhance direct and immediate access to food for the most seriously undernourished (track two). Although the two tracks are designed to be mutually reinforcing and to generate incentives for recovery (Pingali et al., 2005: 11), it is unclear whether this framework is substantially different from conventional understandings of development and relief. Table 4 describes possible actions and policies that could be implemented under each track of the Twin Track Approach, and relates them to the four dimensions of food security (availability, access, utilisation and stability). Although the framework has yet to be fully tested in protracted crises and post-conflict situations, its lack of political analysis is potentially a major limitation.

Can a social protection and livelihood promotion framework, as described in Chapter 4, potentially provide an alternative policy approach to structure interventions in postconflict situations? The Twin Track Approach described above places social safety nets within track 2 (to meet immediate needs) yet apparently fails to consider their productive potential under track 1 . We would argue that, if social protection is to provide a policy framework for agricultural support in countries emerging from conflict, the linkages between social protection and pro-poor agricultural growth need to be explored more fully. We return to this question in the conclusion (6.4).

The policies that have the greatest impact on post-conflict agricultural programming are those that describe what are considered to be viable paths to development and food security. Belief in these policies tends to be resilient, despite growing evidence that they are out of step with the reality of rural livelihoods. There may be a tacit understanding of the limits of these policies as a basis for rehabilitation programming, but alternatives involve venturing into uncharted territory. As a result, the efforts of the aid community to move beyond standard

\section{Table 4: FAO's Twin Track Approach and the dimensions of food security}

\section{Twin Track Approach \\ Rural development/ productivity enhancement}

\section{Availability}

Enhancing food supply to the most vulnerable

Improving rural food production, esp. by small-scale farmers

Investing in rural infrastructure

Investing in rural markets

Revitalisation of livestock sector

Resource rehabilitation and conservation

\section{Access and utilisation}

Enhancing income and other entitlements to food

Re-establishing rural institutions

Enhancing access to assets

Ensuring access to land

Reviving rural financial systems

\section{Strengthening labour market}

Mechanisms to ensure safe food

Social rehabilitation

Programmes

Transfers: food-/cash-based

Asset redistribution

Social relief/rehabilitation programmes

Nutrition intervention programmes

\section{Stability}

Diversifying agriculture and employment

Monitoring food security and vulnerability

Dealing with the structural causes of food insecurity

Reintegrating refugees, displaced people

Developing risk analysis and management

Reviving access

to credit system and saving mechanisms

Re-establishing social safety nets

Monitoring immediate vulnerability and intervention impact

Peace-building efforts 
programme modalities in order to live up to the rhetoric about empowering civil society, putting the government 'in charge' and creating a 'level playing field' for the private sector have been highly erratic. The aid community is still risk-averse: the focus on seeds, which can be implemented with relatively limited engagement from the government or the private sector, may in some ways be a product of aid agencies' ambivalence towards institutional development. The seeds and tools treadmill primarily survives because it is a low-level engagement, and therefore low-risk, strategy. Innovations, even if they are in line with formal policy, are not necessarily encouraged.

\subsubsection{Aid and politics: peacebuilding, sovereignty and social transformation}

Development policy debates surrounding aid to 'fragile states' (including post-conflict states) are beginning to place increasing attention on what has been termed the 'sovereignty gap' (Ghani et al., 2005). These debates recognise that aid often acts as a constraint rather than an asset in allowing the state to perform its functions. Specifically, it is argued that a lack of coherence between political, security, financial and social issues tends to diminish rather than build state capacity (ibid.). Used in its broadest sense, proponents of coherence 'believe that those involved in aid, politics, trade, diplomacy and military activities should work together towards common interests of liberal peace, stability and development' (Curtis, 2001: 9). From a humanitarian perspective, such an integrationist position implies that conflict management becomes the ultimate objective, yet - in the absence of development aid - it is humanitarian aid that provides the primary form of political engagement responsible for delivering the 'liberal peace' (Dillon \& Reid, 2000) that has come to shape global governance. Macrae and Leader (2000) argue that the belief that humanitarian aid should be expected to contribute to conflict reduction is mistaken. Not all states subscribe to the ethics of the 'liberal peace' agenda, and humanitarian aid is a weak tool for conflict management; attempts to use it as such risk undermining its effectiveness in relieving poverty and suffering.

What signs are there that development aid can do any better in closing the sovereignty gap? It would appear that not all states necessarily want to become sovereign. The inability of mulfilateral and bilateral donors to reduce levels of state corruption or misdirected policy decisions in countries like Kenya and Zimbabwe illustrates that development aid cannot in itself promote good management. Ghani et al. call for 'a fundamental change in the way the international system works, towards a model where partnership and $\mathrm{CO}^{-}$ production of sovereignty becomes the aim of both national leaders and international partners' (2005: 2). Yet such a change seems unlikely in the kind of states of interest to this debate (Duffield, 2003). In Afghanistan, for example, predatory commanders, unscrupulous entrepreneurs, uncivil society and the 'weak state' are going to be around for some time. Even the most enthusiastic promoters of alternative livelihoods do not expect to sweep away the "narco-mafia state' in the next few years.

Current aid perspectives that seek to promote coherence and stability suggest that social transformation and political reform are necessary in post-conflict situations. But humanitarian and other non-state actors are limited in the extent to which they can promote political or institutional reform and social transformation. Practical interventions tend to focus on campaigns against various forms of discrimination, making citizens aware of their rights and entitlements and promoting greater transparency and accountability in public sector decision-making. Such interventions are only appropriate once there is a legitimate state in place, interested in being accountable to its citizens. According to Cliffe et al., approaches to community-driven reconstruction currently promoted through the use of World Bank social funds can only provide 'an entry point for a longer-term reform strategy in post-conflict society' through 'building local capacity and opening new channels for voice' (2003: 6). Collective action by social movements to challenge institutional failures has been shown to have a positive influence in addressing social exclusion, governance problems and corruption (Kabeer, 2002). But how relevant is this in countries emerging from conflict, where civil society is weak or non-existent?

\subsection{Principled agricultural programming in post-conflict transitions}

\subsubsection{Multiple transitions}

The notion of 'transition' is commonly applied to postconflict situations, both in terms of the transition from war to peace and the various associated shifts that are perceived as necessary in aid interventions, coordinating agencies and programming approaches (e.g. from relief to development; from UN agencies to the state; from food aid to food security). Transition can involve a change in either direction, but does not necessarily imply that there is continuity from one context or approach to another. The UNDP/ECHA working group on transition issues focuses on the processes of transition from war to peace, although it also incorporates a range of other types of transition which occur in postconflict situations: 'For the UN, transition refers to the period in a crisis when external assistance is most crucial in supporting or underpinning still fragile cease-fires or peace processes by helping to create the conditions for political stability, security, justice and social equity' (UNDG/ECHA, 2004: 6). What is evident from this definition is that transition is not regarded as a distinct event, but something which spans an undefined period of time.

There are in fact multiple different transitions (Forman et al., n.d.). Here, we use the notion of 'multiple transitions' to describe the changing contexts of post-conflict situations 
and the shift in agricultural aid programming that we consider to be necessary. The three types of contextual transition that we consider are defined in terms of:

1. Security - from a situation in which there is insecurity involving high levels of violence to a more secure situation of relative tranquillity. It is important to note that the transition can also take place in the other direction (from tranquillity to violence).

2. Livelihood strategies, markets and local institutions - this transition is often closely related to the local security context, and involves a shift from livelihood strategies that are asset depleting (i.e. coping or survival strategies) to strategies that are asset maintaining or asset building (i.e. adaptive or accumulative strategies). This transition also involves the strengthening of markets and local institutions, made possible through increased levels of trust and collective action at local levels. Again, the transition in livelihood strategies and local institutions can also be reversed if security is not maintained.

3. The nature of the state and formal institutions - this involves a political transition from a government that is absent, ineffective or illegitimate to one that is legitimate and effective. It may involve a period of rule by an interim or transitional authority, followed by democratic elections, though there is no guarantee that a democratically elected government will necessarily be effective.

Although we describe these three transitions as contextual, they should not be regarded as completely external to the shifts that must be promoted through agricultural assistance. The ways in which assistance is programmed can either hinder or help each of these three transitions. For example, inappropriate input procurement or targeting mechanisms can increase local tensions; an understanding of local livelihoods and how they have been affected by conflict can help determine ways in which assets can be maintained and accumulated; and capacity-building support to formal state institutions can enhance the legitimacy of these institutions in the eyes of citizens. It is important to observe principled approaches if programming interventions are to support and promote positive contextual transitions. We will return to the issue of principles below, after a discussion of the shift in agricultural programming that we consider a necessary part of post-conflict transitions.

Agricultural support in conflict and post-conflict situations should facilitate the transition from supply-led programming to the establishment of sustainable (marketdriven) systems for service delivery, developed within a framework of broad-based efforts to protect and promote rural livelihoods. This transition can be broken down into a number of measures, as follows:

- To ensure that vulnerable farmers have access to agricultural inputs and services (food for agriculture, seed, irrigation, pest control, animal health, microfinance, extension), either through direct distribution or interventions designed to stimulate choice, such as vouchers.

- To increase agricultural production through access to appropriate technology options.

- To increase rural incomes through the promotion of agricultural product and labour markets.

- To establish the capacity, structures and institutions necessary for the sustainable delivery of inputs and services.

- To address vulnerability and social inequality through social protection and livelihood promotion.

- To promote the reforms necessary to address the structural causes of vulnerability.

In terms of linking social protection and agricultural productivity objectives, the first four programming approaches might be regarded as agricultural productivity infused with risk and vulnerability objectives, and the last two might be social protection mechanisms that are also productivity-enhancing.

Chapter 3 has shown that some interventions represented by each of these steps are already being implemented in both case studies. Thus, we are not suggesting a dramatic change (though more effort needs to be placed on promoting markets), only that these interventions are regarded as part of a broader transition, and that there is greater emphasis on addressing issues of vulnerability and institution-building. Most importantly, the overall aim of a transition from supply-led programming to sustainable systems for service delivery offers a strategic vision that allows for the projectised nature of agricultural interventions to be overcome.

\subsubsection{Dynamic and pragmatic principles}

Given the multiple and dynamic contextual transitions taking place as countries emerge from conflict, we suggest that the range of different principles that agencies strive to observe in the provision of assistance cannot remain static, but must be pragmatically applied according to the broader political and security context. The application of humanitarian principles often involves the agreement of country-specific interagency voluntary codes. A pragmatic approach would imply that the principles defined by these codes would change according to the overall security, political and institutional contexts, and that these codes must necessarily be dynamic over time. Accurate information about these contexts, particularly political aspects relating to security and institutions, is essential for ensuring that principles are appropriate (Leader, 2000). The relief, livelihood and rights-based principles that we have touched on in this paper are summarised in Table 5, and discussed further below. 
Table 5: Core principles from humanitarian relief, livelihoods and rights-based approaches

\begin{tabular}{|c|c|}
\hline Principle & Definition (and origin) \\
\hline Impartiality & $\begin{array}{l}\text { The provision of aid to all individuals and groups who are suffering, without discrimination by } \\
\text { nationality, political or ideological beliefs, race, religion, sex or ethnicity. The provision of aid } \\
\text { according to and in proportion to need. (Humanitarian.) }\end{array}$ \\
\hline Neutrality & $\begin{array}{l}\text { Dealing equally with both sides of a conflict: relief should be provided without bias towards or } \\
\text { against one or more of the parties to the political, military, religious, ideological or ethnic controversy. } \\
\text { (Humanitarian.) }\end{array}$ \\
\hline Independence & $\begin{array}{l}\text { Independence of humanitarian objectives from political, military or economic considerations. } \\
\text { (Humanitarian.) }\end{array}$ \\
\hline Participation & $\begin{array}{l}\text { Enabling people (beneficiaries) to play an active part in planning, implementing and evaluating } \\
\text { interventions and to access information relating to decision-making processes. (Livelihoods/RBA.) }\end{array}$ \\
\hline Multi-level & $\begin{array}{l}\text { Ensuring that interventions are informed by micro-level analysis and support an effective enabling } \\
\text { environment, and that macro-level structures and processes support people to build upon their own } \\
\text { strengths. (Livelihoods.) }\end{array}$ \\
\hline Accountability & $\begin{array}{l}\text { Ensuring that responsibilities are identified and actions are monitored, and that there are means of } \\
\text { claiming redress if obligations are not met. Accountability is often promoted through standard } \\
\text { setting. (RBA.) }\end{array}$ \\
\hline
\end{tabular}

Humanitarian actors confront particular challenges in maintaining principles of neutrality and independence in the transition to democratic forms of governance. In the case of Afghanistan, for example, the government position is that 'it is committed to holding itself accountable for its performance and ensuring that partner agencies support processes to further collective accountability'. This apparently allows it to override humanitarian agencies' desire for independence by claiming that what really matters is that Afghans are able to access effective and impartial assistance, and that the state is best positioned to ensure this when an effective political process makes it accountable to the people (MRRD, 2002).

Neutrality and independence would also suggest that institutional capacity-building is inappropriate because it implies having to make decisions about which institutions to support, and thus involves 'taking sides'. This may indeed be the case in relation to formal private or public sector institutions, and for this reason support to such institutions may only be possible once a conflict is officially declared over and a legitimate government has been installed. Support to informal institutions, on the other hand, is often provided at a local level before a conflict is over. Capacity-building support to civil society groups, for example, might be promoted as part of local peacebuilding efforts, and support to local NGOs may allow for the delivery of humanitarian assistance in areas that international agencies cannot reach. The strengthening of the market may encourage a re-emergence of private services. Such forms of assistance may well be contrary to the principle of neutrality, and may instead represent a position that is either pragmatic or solidarist. From a livelihoods perspective, on the other hand, support to local institutions tends to be considered as necessary if the outcomes of interventions are to be self-sustaining in the long term. The principle of sustainability can thus be seen to conflict with neutrality and independence. Clearly, there is a need for these different principles to be observed at different times, but defining the precise point at which the principle of sustainability might take precedence over neutrality and independence in post-conflict situations is extremely difficult, and requires agreement among the agencies that are providing assistance.

At a programming level, the drive to promote sustainability often involves a shift away from the delivery of free inputs to loans or a system requiring some level of community contribution. In the latter case, it is assumed that these contributions provide a form of participation in programme implementation and will lead to a greater sense of local ownership. In Somalia, there has been considerable debate 
over the mechanisms for community contributions to agricultural projects, but this has overlooked the larger question of whether community contributions really lead to greater community ownership of projects, promote participation or result in greater sustainability. This debate also diverts attention away from the need to ask whether (a) 'communities' have the power to demand anything, and if external agencies are therefore accountable to them, and (b) whether the emphasis on 'communities' distracts from the need to develop accountability to 'farmers' who are, after all, independent operators with their own commercial interests. The assumption that promoting local ownership through participation will necessarily lead to sustainability needs to be examined in the context of specific programmes.

Similarly, the emphasis on community-based programming as part of a desire to achieve sustainability and/or empowerment is not always appropriate (or indeed itself sustainable). A community-based approach is simply a means to an end, yet NGOs frequently conflate different objectives in promoting community-based approaches, which become an end in themselves. There are limits to community-based programming even in 'normal' developmental settings with responsive institutional frameworks. The central question is what aspects of agricultural inputs and service delivery are best managed at which level (community, local government, private sector, central government). Working with community-based organisations as implementing partners may only provide a veneer of sustainability. Through their role as channels for distributions, institutions representing the 'people' are expected to achieve a level of participation such that people are 'empowered' to manage their own affairs after a short-term injection of aid. Empowerment is not such an easy task, especially in a post-conflict situation, and achieving sustainability clearly requires multi-level analysis and support. There is widespread acknowledgement that sustainability cannot be achieved solely through participatory or community-based approaches, but also requires action at meso and macro levels, including institutional and structural reform.

Sustainability in post-conflict settings thus also has a political dimension. A key objective is building trust and confidence between citizens and the state, and reestablishing the social contract between the two. As illustrated by the case of Afghanistan described above, the legitimacy of an emerging government depends largely on its ability to provide goods and services on a reliable and accountable basis. The transition in agricultural interventions from supply-led to demand-based approaches involves shifting the lines of accountability downwards to beneficiaries and clients (rather than upwards to donors). In countries emerging from conflict, where the state is weak and non-state service providers predominate, establishing mechanisms of accountability is a major challenge. In their haste to rebuild quickly and ensure adequate service provision, donors frequently create parallel structures to bypass the government, thereby arguably undermining accountability and legitimacy. The case of NaCSA in Sierra Leone is a good example. This 'accountability gap' forms part of the 'sovereignty gap' described in section 6.3.6.

The discussion above would suggest that mechanisms for accountability within the humanitarian sector (e.g. the Sphere Standards) are not necessarily appropriate once a legitimate government has been installed, or where efforts are underway to support viable markets. Such mechanisms tend to assume that a simple relationship between an aid provider and an aid recipient can be discerned (although the Sphere Charter seeks to locate the responsibility of the aid provider in a broader framework of responsibility (Darcy, $2004 \mathrm{~b})$ ). It is not self-evident that these conceptual frameworks are applicable to, or adaptable in, post-conflict contexts. Moreover, the level of focus of humanitarian standards may not be appropriate to the broader structural and institutional changes that inevitably form part of postconflict transitions. Sphere, for example, focuses on technical issues at the micro level, not on more macro-level policy issues such as land tenure, or meso-level issues such as markets.

Finally, the principle of impartiality requires a detailed understanding of need, including an understanding of how political and economic relations determine whether certain groups or individuals are restricted from aid, or benefit disproportionately from it. Such levels of understanding rarely exist in practice (Darcy and Hofmann, 2003), and the provision of aid to different sides of a conflict (e.g. in Darfur), may be subject to aid agency bias. Social transformation may be necessary for aid to be truly impartial.

The discussion above shows how principles relate to one another; some contradict others, and some reinforce others. This suggests that not all the principles considered above can be applied simultaneously, and that some are most effective when applied in combination with others. Certain principles, for example accountability and impartiality, appear to be applicable both to chronic conflict and post-conflict situations, yet each has very different implications depending on the context, the actors and the level at which they are applied. Which principles are appropriate to which contexts, and how should they be applied in practice? While there are no easy answers to this question, the following section attempts to provide examples relating to specific programming objectives for the different contextual transitions described earlier. In practice, it is necessary for aid agencies working in specific post-conflict countries to agree on voluntary codes of conduct and to revise these as the security, political and institutional contexts change over time. 


\subsubsection{Principled agricultural programming in post-conflict transitions}

The table below presents a pragmatic approach to principles, depending on the aim of the intervention and the context within which it is being implemented. Certain types of interventions are appropriate in certain contexts. Although overly simplistic in terms of the aims of the interventions and contextual aspects, the need to consider all three aspects of the context may highlight inconsistencies or contradictions. Priorities must be agreed on a country basis, and revised as demanded by the political context. If a pragmatic approach to humanitarian and livelihoods principles is to be adopted, greater clarity is required both in terms of the political agenda and the impact of conflict on local livelihoods and informal institutions.

\section{Table 6: Contextual considerations and principles necessary to achieve specific aims}

\section{Intervention aim}

To ensure that vulnerable farmers have access to agricultural inputs (FFAg; seed, irrigation, pest control, animal health, microfinance, extension), either through direct distributions or interventions designed to stimulate choice, such as vouchers

\section{Security context}

Where sporadic insecurity exists, maintaining the humanitarian space necessary

to allow agency access for input distribution requires that principles of neutrality and independence are upheld. Where security exists (and markets are functioning), direct distribution may be inappropriate because inputs are probably already available (though not necessarily in sufficient quantities or accessible to all), so vouchers or cash might be considered
To increase agricultural production through access to appropriate technology
Technology options can be promoted where technologies are known to be appropriate and the security situation allows for effective knowledge transfer to ensure accountability to farmers

\section{Livelihood strategies, markets and informal institutions}

May be appropriate where large numbers of refugees or IDPs are returning to their homes. Where livelihood strategies include some level of agricultural production and markets are functioning, direct distribution may be inappropriate because inputs are already available (though not necessarily accessible to all), so vouchers or cash might be considered.

Vouchers or cash are participatory provided that they allow beneficiaries to make decisions on the inputs that they require, but such interventions cannot achieve sustainability. Detailed needs assessments should promote impartiality. Neutrality and independence are also attainable

Importance of ensuring technology is appropriate to the broader livelihood strategies, market priorities and management capacity of user. groups. Testing of new technologies usually requires some element of a participatory approach. New technologies are not necessarily appropriate or readily adopted by all farmers, implying that impartiality may not be possible

\section{Nature of the state and formal institutions}

Direct distribution or vouchers implemented by NGOs or UN agencies are appropriate where state and formal institutions are non-existent or non-functional. Accountability on the part of the implementing agency is required to ensure the good quality of inputs directly provided. Government-run programmes for direct distribution or vouchers require a level of staff and logistical capacity that may be lacking in post-conflict situations
Certain technologies (e.g. those based on existing indigenous practices) may be promoted in the absence of broader formal institutional structures. Others, however, require institutional support structures (e.g extension, a reliable source of improved seed and veterinary drugs, etc) and supply chains to ensure sustainability and accountability. Developing such support structures requires multi-level interventions 
Table 6 (continued)

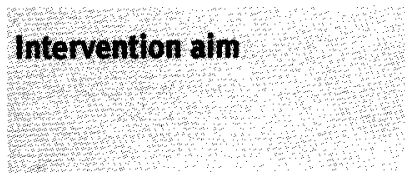

To increase rural incomes through promotion of agricultural markets

\section{Security context}

In contexts of insecurity, markets may be distorted by high transaction costs (transport, taxes) and profits disproportionately benefit certain groups or individuals. In such cases, market promotion may be inappropriate. In more secure contexts, sustainability and the ability to apply multi-level approaches are key considerations in promoting markets
To establish the capacity, structures and institutions necessary for sustainable delivery of inputs and services
Sustainability and accountability are key principles. Widespread insecurity precludes major investment in infrastructure and market structures necessary for input delivery systems. Capacity-building support to legitimate informal or emerging formal institutions might be appropriate where insecurity is localised, but this would override principles of neutrality and independence. In such cases, decision-making must be in line with agreed codes of conduct and political economy analysis
To address vulnerability and social inequality through social protection and livelihood promotion
Impartiality is key and requires an understanding of who is vulnerable and what the causes of vulnerability are. The degree to which vulnerability can be addressed through social protection and livelihood promotion depends on the extent to which the security situation allows for multi-level analysis and intervention approaches

\section{Livelihood strategies, markets and informal institutions}

Multi-level analysis is essential to determine which product markets should be promoted, and to ensure that these are based on demand not supply, since sustainability is a key concern. Targeted assistance to specific groups (e.g. traders, well-resourced farmers) implies that impartiality may not be possible, but political-economy analysis can ensure that traders do not benefit at the expense of producers. Investment in basic infrastructure (roads, market facilities, etc) and capacitybuilding of producers and farmers necessary

Capacity-building interventions are only possible where markets are functional and livelihood strategies have the potential to maintain or accumulate assets. It may be necessary to work with informal or imperfect institutions.

Political economy analysis is required to determine which informal institutions to work with to ensure that these institutions are accountable to farmers

Nature of the state and formal institutions

Basic levels of law and order are necessary to ensure some rudimentary forms of market regulation to prevent extortionate taxation; ensure the quality of production and handling of goods; and promote sustainability. Multilevel interventions are essential. Where products are exported, trade associations or the government must be able to negotiate favourable terms of trade. Impartiality, neutrality and independence may not be possible, given the need to support specific groups and institutions along the market chain

Such support is appropriate where a legitimate government and/or private sector exists. Capacity-building may also require substantial institutional reform, involving shifts in the role of NGOs from service providers to facilitators and in the function of the state from service provider to a supervisory and regulatory role. Regulation is necessary to ensure the quality of inputs provided to farmers and to promote accountability. Impartiality, neutrality and independence may not be possible, given the need to support specific groups and institutions along the market chain

Social protection linked with productivity enhancement is only appropriate where livelihood strategies have the potential to maintain or accumulate assets. Social protection must be based on an understanding of the informal norms and rules that govern social relations. Formal social protection mechanisms may otherwise risk reinforcing inequality and may unintentionally prove to be partial
In the absence of a legitimate state or formal state institutions with sufficient capacity, NGOs might consider the implementation of social protection/ livelihood promotion programmes. Where state capacity is sufficient for public-sector programmes, social protection and livelihood promotion require collaboration between different ministries and government departments. Impartiality is key and requires an understanding of who is vulnerable and what the causes of vulnerability are, of which agricultural experts may have little understanding 


\section{Table 6 (continued)}

\section{Intervention aim}

To promote reforms to address the structural causes of vulnerability

\section{Security context}

Attempts at social transformation are inappropriate in situations where power structures are maintained through violence

\subsection{Conclusions}

For agricultural programming in countries emerging from conflict to move beyond projectised interventions, we suggest that the overall objective of donor-funded support should be to facilitate the transition from supply-led programming to the establishment of sustainable (marketdriven) systems for service delivery, developed within a framework of broad-based efforts to protect and promote rural livelihoods. Such a transition necessarily requires capacity-building at all levels (community, agency, government, private sector), a fundamental shift in the role of NGOs from implementers to facilitators, and clarity and consensus on the functions of the state as a regulatory body. In general, much greater emphasis should be placed on needs assessment and impact monitoring to enable a move towards empirically-based strategies with realistic, shared objectives. We have suggested a number of measures that might contribute to this transition. Each of these measures combines the need to link social protection and agricultural productivity objectives, either as agricultural productivity programmes infused with risk and vulnerability objectives, or as social protection mechanisms that are also productivity-enhancing.

At a conceptual level, the idea of positioning social protection at the centre of rehabilitation efforts is conceptually attractive as it avoids the controversial relief-to-development terminology. Furthermore, recent definitions of social protection that address risk and vulnerability and promote growth and equity bring it closer to humanitarian protection. The need to identify coherent strategies for moving from a "chaotic and haphazard collection of relief projects to a more reliable and regularised system' is widely

\section{Livelihood strategies, markets and informal institutions}

Principle of impartiality is key. Requires detailed socioeconomic and political analysis to determine the causes of structural vulnerability. Neutrality may be compromised where structural vulnerability is associated with the exclusion or marginalisation of specific groups. Interventions may involve the need to establish mechanisms of voice and choice whereby citizens can hold authorities to account

\section{Nature of the state and formal institutions}

Requires a strong, legitimate and capable state. Need to balance the expectations of 'the people' for service delivery with the need for reform. Impartiality and independence are key to ensuring that reforms are actually designed to address the causes of vulnerability, rather than stemming from political motives

recognised, but it remains to be seen whether the concept of social protection can be translated into a practical framework for action. There are significant challenges to be faced in implementing social protection, even in 'normal' development settings. These challenges are compounded in post-conflict situations, where institutions are either unwilling or unable to fulfil this function and/or the legitimacy of emerging authorities is contested. Evidence from Afghanistan and Sierra Leone suggests that there is a long way to go before effective social protection in postconflict settings will become a reality.

A central focus of social protection in the context of postconflict agricultural support should be on mitigating risk and reducing vulnerability, but both remain poorly understood in post-conflict settings, and agricultural experts tend to be poorly equipped to address vulnerability. Ensuring that formal social protection mechanisms do not inadvertently undermine or 'erode' existing informal mechanisms (e.g. mechanisms for acquiring seed) is another key concern. Finally, power imbalances are often particularly acute in countries emerging from conflict, and there is a danger that these may be exacerbated if political-economy considerations are not given adequate attention.

How to address such structural inequalities remains one of the biggest challenges for social protection: where inequalities render formal social protection unavailable to the majority of the population, it tends to exacerbate rather than reduce inequality (Norton et al., 2002). Considerably more work needs to be done on finding ways in which social protection can appropriately assist the most vulnerable, marginalised or deprived members of 
society. This is particularly crucial in post-conflict situations where existing inequalities of power are related to the underlying causes of conflict and persist into the post-conflict period. Under such conditions, wellmeaning attempts to implement social protection strategies may inadvertently exacerbate tensions between the powerful and the vulnerable. For social protection to be effective in post-conflict situations, therefore, social transformation and political reform are often necessary, but these are fraught with difficulties and require a longterm approach.

This paper has argued that the focus of agricultural interventions should not be solely on increasing agricultural production but on livelihoods more broadly, with specific attention focused on enhancing agricultural and labour markets. Again, experience from the case study countries on market development and enhancing the role of the private sector remains limited. Market chain approaches show promise, particularly in their ability to link micro-, meso- and macro-level concerns, but considerably more work remains to be done. In theory, voucher-based systems that allow vulnerable farmers to access agricultural inputs through agricultural input 'fairs' promote market development (Remington et al, 2002). Preliminary investigations from four years of agricultural voucher programmes in Mozambique suggest that, although agricultural fairs encourage commercial activity at a local level, the most successful fairs (in terms of levels of participation and overall turnover) are those that take place in areas where markets are already well-developed (Longley et al., 2005). The links between social protection, market development and pro-poor agriculture-based growth need to be explored much more fully before these elements can be combined into a viable policy framework.

Our exploration of the interface between humanitarianism, social protection and agriculture-based interventions has addressed the need for principled approaches. If humanitarianism is defined by the objective of saving lives and a strict adherence to humanitarian principles, then what is commonly referred to as 'agricultural rehabilitation' should not be seen as strictly humanitarian. However, that is not to say that it cannot be principled. We have argued for a pragmatic use of a range of principles from humanitarian relief, livelihood and rights-based approaches. A principled approach requires enhancing the humanitarian capacity of developmental/technical experts. 


\section{References}

ActionAid Alliance (2003) Improving European Development Cooperation: The Link Between Relief, Rehabilitation and Development. ActionAid, January 2003.

ADB (2002) Natural Resources and Agriculture Sector Medium Term Development Framework Multi-Donor Phase II Mission, April 2002.

Addison (2005) 'Reconstructing and Reforming the Financial System in Conflict and "Post-Conflict" Economies', Joumal of Development Studies, 41 (4): 703-718.

Agrisil (January 2003) The monthly newsletter of the FAOSL Coordination. Issue 35. Freetown, FAO.

Ahmed, I. (2000) 'Remittances and their economic impact in post-war Somaliland', Disasters 24 (4): 380-389.

Alden Wily, L. (2003) Land Rights in Crisis: Restoring Tenure Security in Afghanistan. Issues Paper Series. Afghanistan Research and Evaluation Unit. Kabul: AREU.

Alden Wily, L. (2004) Land Relations in Bamyan Province: Findings from a Minor Field Study in 15 Hindu KushVillages. Kabul: AREU.

Allen, M. (1999) Feasibility Studies on the Social and Economic Aspects of Agricultural Production, DACAAR.

ALNAP (2003) Humanitarian Action: Improving Monitoring To Enhance Accountability and Leaming. London: ALNAP.

Anderson, J. and G. Feder (2003) 'Agricultural Extension: Good Intentions and Hard Realities', World Bank Research Observer, vol. 19

Anderson, M. (1996) Do No Harm: Supporting Local Capacities for Peace. Cambridge, MA: Local Capacities for Peace Project, the Collaborative for Development Action Inc.

Archibald, S. and P. Richards (2002) 'Seeds and Rights: New Approaches to Post-war Agricultural Rehabilitation in Sierra Leone', Disasters 26 (4): 356-367.

AREU (2004) How the Government Works in Afghanistan: A Study of Sub-national Administration. Kabul: AREU.

Ashley, C. and S. Maxwell (2002) 'Rethinking Rural Development', Development Policy Review 19 (4): 395-425.

Ashley, C. and D. Carney (1999) Sustainable Livelihoods: Lessons from Early Experience. London: DFID.

Bebbington, A. and O. Sotomayor (1996) 'Demand-led and Poverty-Oriented ... Or Just Subcontracted and Efficient? Learning from (Semi-) Privatized Technology Transfer Programmes in Chile', Journal of International Development 10(1) 17-34.

Boin, Arjen, \& P.'t Hart (2003) 'Public Leadership in Times of Crisis: Mission Impossible?', Public Administration Review, 63/5 544-553.

Bonnard, P. (2001) Increasing the Nutritional Impacts of Agricultural Interventions, Food and Nutrition Technical Assistance (FANTA)
Project Paper, Academy for Educational Development, Washington DC. www.fantaproject.org.

Bramel, P., T. Remington and M. McNeil (eds) (2004) CRS Seed Vouchers and Fairs: Using Markets in Disaster Response. Nairobi: CRS.

Brigaldino, G. (1995) Using Rehabilitation To Bridge the Institutional Gap between Relief and Development, ECDPM Working Paper 95-4. Maastricht, the Netherlands, European Centre for Development Policy Management (ECDPM).

Bryceson, D. (2000) Rural Africa at the Crossroads: Livelihood Practices and Policies, Natural Resource Perspectives, 52, April 2000. London: Overseas Development Institute.

Captier, C. (2003) 'What Does Humanitarian Protection Really Mean?', Humanitarian Exchange 23, March.

CARE International Sierra Leone (2003) Food Security - A Rightsbased Approach Project: Progress Review Report (Phase 1), unpublished report.

CARE International Sierra Leone (2004) Food Security - A Rightsbased Approach Project: Lessons-learned study (Phase 1), unpublished report.

Catley, A. (1999) Monitoring and Impact Assessment of Communitybased Animal Health Projects in Southern Sudan: Towards Participatory Approaches and Methods, report for Veterinary Sans Frontières Belgium and Switzerland, Vetwork UK.

Charny, J. R. (2004) 'Upholding Humanitarian Principles in an Effective Integrated Response', Ethics and International Affairs, 18, no. 2: 13-20.

Christian Aid (2003) Against the Grain, www.reliefweb.int, 15 September.

Christiansen, K., E. Coyle and C. Lockhart (2004) Senior Level Forum On Development Effectiveness In Fragile States, Harmonisation and Alignment in Fragile States. London: ODI/ Paris: OECD.

Christoplos, I. (2000) 'Natural Disasters, Complex Emergencies and Public Services: Rejuxtaposing the Narratives after Hurricane Mitch', in P. Collins (ed.), Applying Public Administration in Development: Guideposts to the Future. Chichester: John Wily \& Sons.

Christoplos, I. (2001) Extension, Poverty and Vulnerability in Nicaragua, ODI Working Paper No. 150.

Christoplos, I. (2002) Evaluation Report: The Humanitarian Accountability Project's Second Triol in Afghanistan, May-July 2002.

Christoplos, I., C. Longley and T. Slaymaker (2004) The Changing Roles of Agricultural Rehabilitation: Linking Relief, Development and Support to Rural Livelihoods. ICRISAT Working Paper.

Cliffe, L. and R. Luckham (2000) 'What Happens to the State in Conflict? Political Analysis as a Tool for Planning Humanitarian Assistance', Disasters, 24:4 291. 
Collinson, S. et al. (2002) Politically Informed Humanitarian Programming: Using a Political Economy Approach, Network Paper 41. London: Humanitarian Practice Network.

Collinson, S. (ed.) (2003) Power, Livelihoods and Conflict:Case Studies in Political Economy Analysis for Humanitarian Action, HPG Report 13. London: ODI.

Cooke, B. and U. Kothari (eds) (2001) Participation: The New Tyranny, London: Zed.

Cullather, N. (2002) 'Damming Afghanistan: Modernization in a Buffer State', Journal of American History, September: 512-37.

Curtis, D. (2001) Politics and Humanitarian Aid: Debates, Dilemmas and Dissension, Report of a conference organised by ODI, POLIS at the University of Leeds and CAFOD, London, 1 February, HPG Report 10. London: ODI.

Darcy, J. and C.-A. Hofmann (2003) Rights-based Approaches to Humanitarian Action: A Challenge to Humanitarian principles?. London: ODI.

Darcy, J. (2004a) Social Protection in the Context of Armed Conflict and Its Aftermath, Background Paper prepared for DFID, September. London: ODI.

Darcy, J. (2004b) 'Locating Responsibility: The Sphere Humanitarian Charter and Its Rationale', Disasters, vol. 28, no.

2, June 2004

De Goede, M. (2003) 'Hawala Discourses and the War on Terrorist Finance, Environment and Planning', Society and Space, 21, 513-32.

De Sousa, M. A., T. Addison, B. Ekman and A. Stenman (2001) From Humanitarian Assistance to Poverty Reduction in Angola, Discussion Paper No. 2001/22. Helsinki: United Nations University/ World Institute for Development Economics Research.

de Waal, A. (1997) 'Contemporary Warfare in Africa', in M. Kaldor and B. Vashee (eds), Restructuring the Global Military Sector: NewWars. London: Pinter.

Deng, L. B. (2002) Confronting Civil War: A Comparative Study of Household Assets Management in Southern Sudan, IDS Discussion Paper 381. Brighton: Institute of Development Studies.

Devereux, S. (1992) 'Household Responses to Food Insecurity in Northeastern Ghana', Unpublished D.Phil. thesis, Balliol College, Oxford.

Devereux, S. (1999) Making Less Last Longer. Informal Safety Nets in Malawi, IDS Discussion Paper 373. Brighton: Institute for Development Studies.

Devereux, S. and R. Sabates-Wheeler (2004) Transformative Social Protection, IDS Working Paper 232. Brighton: Institute of Development Studies.

Devereux, S. (2002) Social Protection for the Poor: Lessons from Recent International Experience, IDS Working Paper 142. Brighton: Institute of Development Studies.

DFID (2003) DFID Transitional Country Assistance Plan Afghanistan 2003-2004, Western Asia Department, DFID, August.
Dillon, M. and J. Reid (2000) Global Governance, Liberal Peace and Complex Emergency, Mimeo. Lancaster: University of Lancaster.

Duffield, M. (1994) 'Complex Emergencies and the Crisis of Developmentalism', IDS Bulletin, vol. 25.

Duffield, M. (1997) 'NGO Relief in War Zones: Toward an Analysis of the New Aid Paradigm', ThirdWorld Quarterly 18(3): 527-42.

Duffield, M. (1998) 'Aid Policy and Post-Modern Conflict: A Critical Review', Occasional Paper 19, University of Birmingham School of Public Policy.

Duffield, M. (2000) The Emerging Development-Security Complex', in P. Collins (ed.), Applying Public Administration in Development: Guideposts to the Future. Chichester: John Wily \& Sons.

Duffield, M., P. Gossman and N. Leader (2002) Review of the Strategic Framework for Afghanistan. Kabul: AREU.

EC (1996) Linking Relief, Rehabilitation and Development (LRRD) Communication from the Commission of 30 April 1996. Brussels: European Commission Humanitarian Office.

EC (2001) Linking Relief, Rehabilitation and Development - An Assessment. Communication from the Commission to the Council and the European Parliament. COM (2001) 153 final. Brussels.

Eide, E. B. (1997) 'Conflict Entrepreneurship: On the "Art" of Waging Civil War', in A. McDermott (ed.), Humanitarian Force, PRIO report 4/97: 41-70. Oslo: International Peace Research Institute.

Eldeen, S. et al. (2005) Livelihoods and Social Protection (Refugees and IDPs, Community Driven Recovery, DDR and Mine Action), Cluster 7 Report of the Joint Assessment Mission Sudan (Volume III), www.unsudanig.org/JAM.

Ellis, F. and S. Biggs (2001) 'Evolving Themes in Rural Development 1950s-2000s', Development Policy Review 19 (4): 437-448.

EuronAid (2002) Food Security: The Ideal Link Between Relief, Rehabilitation and Development? Chances and Challenges. A Reader Compiled for EuronAid.

Fairhead, J. and M. Leach (1998) Reframing Deforestation: Global Analyses and Local Realities - Studies in West Africa. London: Routledge.

Fanthorpe, R. (July 2001) 'Neither Citizen nor Subject? "Lumpen" Agency and the Legacy of Native Administration in Sierra Leone', African Affairs, vol. 100.

FAO (2002) Thematic Evaluation of Strategy A.3: Preparedness for, and Effective and Sustainable Response to, Food and Agricultural Emergencies (Report prepared by the Evaluation Service). Rome: FAO.

FAO (2003) Strengthening Coherence in FAO Initiatives to Fight Hunger (Conference Document C 2003/16).

FAO (2003a) Guiding Principles Governing the Production, Distribution and Import of Seed and Planting Material (SPM) of Field Crops for Afghanistan, http://www.fao.org/world/afghanistan/pubs_ code_en.htm. 
FAO (2003b) The Development of Sustainable Agricultural Livelihoods in the Eastem Hazarajat, Project Document GCP/AFG/029/UK.

FAO (2003C) Afghanistan: Survey of the Horticultural Sector 2003. Rome: FAO.

FAO/MAFS (2002) Sierra Leone Special Programme for Food Security: Community-based Extension and Capacity Building. Plan of Operations. Rome: FAO Investment Centre Division/Ministry of Agriculture and Food Security of Sierra Leone.

Farrington, J., I. Christoplos and A. Kidd, with M. Beckman (2002) Extension, Poverty and Vulnerability: The Scope for Policy Reform, Working Paper 155. London: Overseas Development Institute.

Farrington, J. and A. J. Bebbington (1992) From Research to Innovation: Getting the Most from Interaction with NGOs in Forming Systems Research-Extension. Invited paper for the International Farming Systems Research/Extension symposium, Michigan State University, 14-18 September.

Farrington, J., R. Slater and R. Holmes (2004) Social Protection and Pro-poor Agricultural Growth: What Scope for Synergies?, Natural Resource Perspectives 91. London: Overseas Development Institute

Favre, R. (2003a) Contributions to Food Aid Policy Development for Afghanistan: Wheat Balance by Region and Province July 2003. Kabul: FAO.

Feldafing Declaration (2002) Declaration of the Feldafing Conference on the Role of Altemative Development in Drug Control and Development Cooperation, January 2002.

FEWS Net (2003) Afghanistan Monthly Food Security Bulletin (August). Kabul: MRRD.

FIFC (2004) 'Background Note: The Relevance of Humanitarian Principles', Informal Meeting, Humanitarian Aid Committee, Dublin, 25-26 March.

Forman, S., S. Patrick and D. Salomons (no date) Recovering From Conflict: Strategy for an international response. Paying for Essentials. A Policy Paper Series. New York: Center on International Cooperation.

Fox, J., J. Kajume and M. Ombai (2001) 'Rinderpest Prevention and Surveillance within the Frame of the Household Food Security Programme in South Sudan: A Review'. Nairobi: UNICEF-OLS.

Fumo, C., A. de Haan, J. Holland and N. Kanji (2000) Social Funds: "An Effective Instrument to Support Local Action for Poverty Reduction", Social Development Department, DFID, Working Paper No. 5.

Future Harvest (2002) 'Science Consortium Established to Rebuild Afghanistan's Agriculture', news release, www.futureharvest.org/news/afghanistan.shtml.

Gebert, R., and K. Rerkasem (2002) Community Empowerment in Alternative Development: Prerequisite for Success or Mutually Exclusive Concepts?, paper presented at the Feldafing Conference on the Role of Alternative Development in Drug Control and Development Cooperation, January.
Ghani, A., C. Lockhart and M. Carnahan (2005) 'Closing the Sovereignty Gap: How to Turn Failed States into Capable Ones', Opinion, no. 44, ODI.

Global Study (2003) http://globalstudyparticipation. urd.org/.

Government of Afghanistan (2004) Livelihoods and Social Protection Public Investment Programme. Submission for the SY 1383-1385 National Development Budget.

Government of Afghanistan (2004) Securing Afghanistan's Future. Goldman, I. et al. (2000) 'Institutional Support for Sustainable Rural Livelihoods in Southern Africa: Framework and Methodology', Natural Resource Perspectives 49. London: ODI.

Goodhand, J. and D. Hulme (1999) 'From Wars to Complex Political Emergencies: Understanding Conflict and Peacebuilding in the New World Disorder', Third World Quarterly, 20 (1): 13-26.

Goodhand, J. (2001) Violent Conflict, Poverty and Chronic Poverty, CPRC Working Paper 6. Chronic Poverty Research Centre, University of Birmingham, May.

Government of Sierra Leone (2004) Agricultural Sector Review. Freetown: Ministry of Agriculture and Food Security.

Green, R. (2000) 'Rehabilitation: Strategic, Proactive, Flexible, Risky?’, Disasters 24 (4): 343-362.

Grünewald, F. (2001) From Emergency Agricultural Recovery to Sustainable Food Security: $A A A$ Conceptual Framework and Project (sic) Ideas, FAO-TCOR, mimeo.

Grünewald, F. (2003) ALNAP Global Study:The Case of Afghanistan. London: ODI.

Harmer, A. (2005) 'IFIs and Social Protection in Conflict and Transitional Environments'. Unpublished notes.

Harpviken, K. B., M. Suleman and M. Taksdal (2001) Strengthening the Self-Reliance of Returnee Communities: The Enjil Community Development Programme, Herat Province, Afghanistan. Report from an Independent Mid-Term Review for Ockenden Venture.

Harroff-Tavel, M. (2003) 'Does It Still Make Sense To Be Neutral?', Humanitarian Exchange 25.

Harvey, P. (1997) Rehabilitation in Complex Political Emergencies: Is Rebuilding Civil Society the Answer?, IDS Working Paper 60. Brighton: Institute of Development Studies.

Harvey, P (2005) Cash andVouchers in Emergencies, HPG Discussion Paper. London Overseas Development Institute.

Harvey, P. and J. Lind (2005) Dependency and Humanitarian Relief: $A$ Critical Analysis, HPG Report 19. London: Overseas Development Institute.

Heierli, U. (2000) Poverty Alleviation as a Business:The Market Creation Approach to Development. Berne: SDC.

Hemani, Mahmood (2003d) Agriculture and Rural Development Ministrie's (sic) Level Strategy Development Workshop, 28 September 2 October 2003, Kabul.

Hockley Associates (2002) Afghanistan: A Report Following Participation in the 2002 Crop and Food Supply Assessment on Behalf of Chemonics. Suffolk: Hockley Associates. 
ICG (2003) Afghanistan:The Problem of Pashtun Alienation, ICG Asia Report 62.

IFAD (2001) Rural Poverty Report 2001 - The Challenge of Ending Rural Poverty. Rome: International Fund for Agricultural Development.

İmbleau, L. (2003) 'Towards a Food Safety Net', in Report on the National Symposium on Operationalising the Right to Food in Sierra Leone, 19-21 May, Freetown, Sierra Leone. Volume 2: Presentations. Freetown: Ministry of Agriculture Forestry and Food Security. Italtrend (2003) Pre-feasibility for Animal Health in Afghanistan, report for the European Union.

Jallow, H. B. (2004) New Challenges and Opportunities for Human Rights Promotion and Protection in Africa, Keynote Address to the International Conference on 'The African Commission on Human and People's Rights and the Current Challenges of Promoting and Protecting Human Rights', Uppsala, Sweden, 9-10 June (unpublished).

Jamal, A., and E. Stigter (2002) 'Real-time evaluation of UNHCR's response to the Afghanistan Emergency', Bulletin 3, 31 May.

Jaspars, S. and J. Shoham (2002) A Critical Review of Approaches to Assessing and Monitoring Livelihoods in Situations of Chronic Conflict and Political Instability, Working Paper 191. London: Overseas Development Institute.

Johnson, C. (2000) Hazarajat Baseline Study -Interim Report. Kabul: UN Coordinator's Office.

Johnson, C. (2003) British Red Cross: Afghanistan Drought Response Case Study, notes for seminar.

Johnson, C. and D. Start (2001) Rights, Claims and Capture: Understanding the Politics of Pro-Poor Policy, ODI Working Paper 145.

Johnson, C. and D. Start (2001) Rights, Claims and Capture: Understanding the Politics of Pro-Poor Policy, ODI Working Paper 145.

Jones, B. A., B. Deemer, T. J. Leyland, W. Mogga and C. Stem (1998) Community-based Animal Health Services in Southern Sudan:The Experience and the Future, Proceedings of the 9th International Conference of Institutes of Tropical Veterinary Medicine (AITVM), 14-18 September, Harare, Zimbabwe.

Jones, R. B., P. Bramel, C. Longley and T. Remington (2002) 'The Need To Look Beyond the Production and Provision of Relief Seed: Experiences from Southern Sudan', Disasters 26 (4): 302-315.

Jorgensen, S. L. and J.V. Domelen (1999) Helping the Poor Manage Risk Better:The Role of Social Funds. Washington DC: World Bank.

Kabeer, N. (2002) 'Safety Nets and Opportunity Ladders: Addressing Vulnerability and Enhancing Productivity in South Asia', Development Policy Review, 20/5 569-588.

Kaldor, M. (1999) New and Old Wars: Organized Violence in a Global Era. Cambridge: Polity Press.

Kampenaar, K., T. Silken and A. Pain (2002) DACAAR Mid-Term Review, June.
Kanbur, R. (2001) Obnoxious Markets, Working Paper 2001-08, Department of Applied Economics and Management, Cornell University, Ithaca, NY, July.

Katarikawe (2003) Draft report on my visit to Sierra Leone, 6-20 February 2003, unpublished notes.

Keen, D. (1998) The Economic Functions of Violence in Civil Wars, Adelphi Paper 320. Oxford: OUP for the International Institute for Strategic Studies.

Kenefick, E. and A. Conteh (2003) Sierra Leone Rural Food Security, Livelihoods and Nutrition Survey and Household Food Security Profiles.Vulnerability Analysis and Mapping Report. Freetown: WFP.

Kent, I. and S. P. Mokuwa (2001) "The "Rescue from the Pot" Project', Low External Input and Sustainable Agriculture Newsletter, March: 22-23.

Khan, M. A. (1996) Afghanistan: Promotion of Agricultural Rehabilitation and Development Programmes, Extension and Training. Islamabad: FAO.

Kothari, U. and D. Hulme (2003) Narratives, Stories and Tales: Understanding Poverty Dynamics Through Life Histories. Manchester: IDPM.

Kreutzmann, H. (2003) 'Ethnic Minorities and Marginality in the Pamirian Know: Survival of Wakhi and Kighiz in a Harsh Envisonment and Global Contexts', The Geographical Journal 169/3, September: 215-235.

Lautze, S. (1997) Saving Lives and Livelihoods: The Fundamentals of a Livelihoods Strategy. Medford, MA: Feinstein International Famine Center.

Lautze, S., Y. Aklilu, A. Raven-Roberts, H. Young, G. Kebede and J. Leaning (2003) Risk and Vulnerability in Ethiopia: Learning from the Past, Responding to the Present, Preparing for the Future. Medford, MA: Feinstein International Famine Center.

Lautze, S., E. Stites, N. Nojumi and F. Najimi (2002) Qaht-ePool "A Cash Famine": Food Insecurity in Afghanistan 1999-2002. Medford, MA: Feinstein International Famine Center.

Lawrence, M. and M. Banham (2002) Community Food Security Profiling. A Community Level Assessment of Food Security. Summary of Findings from the Six Study Areas, final report to WFP-Sierra Leone Technical Support Unit.

Le Billon, P. (2000) The Political Economy of War:What Relief Agencies Need to Know, Network Paper 33. London: ODI.

Leader, N. (2000) Principles in Practice: A Comparative Analysis of the Humanitarian Principles in Relief Operations, HPG Report 2. London: ODI.

Lepenies, P. H. (2004) 'Exit, Voice and Vouchers: Using Vouchers to Train Microentrepreneurs - Observations from the Paraguayan Voucher Scheme', World Development 32(4): $713-724$.

Longley, C. and D. Maxwell (2003) Livelihoods, Chronic Conflict and Humanitarian Response: A Synthesis of Current Practice, ODI Working Paper 182. London: ODI. 
Longley, C. (2006, forthcoming) Agricultural Rehabilitation in Sierra Leone: Linking Relief, Development and Support to Rural Livelihoods. ODI Background Report.

Longley, C. and L. Sperling (2002) Beyond Seeds and Tools: Effective Support to Farmers in Emergencies, special issue of Disasters, 26 (4).

Longley, C., C. Dominguez, M. A. Saide and W. J. Leonardo (2002) 'Do Farmers Need Relief Seed? A Methodology for Assessing Seed Systems', Disasters 26 (4): 343-355

Longley, C., C. Dominguez and M. Devji (2005) Agricultural Input Trade Fairs and Vouchers in Mozambique: Experiences and Lessons Learned, ICRISAT/ODI Working Paper, http://www.icrisat. org/Publications/EBooksOnlinePublications/Publications2005/LongleyvoucherreportMozambique(Ajay).pdf.

Macrae, J. et al. (2004) Aid to 'Poorly Performing' Countries: A Critical Review of Debates and Issues. London: ODI.

MAFFS (2002) Medium-Term Agricultural Strategic Plan. Freetown: Government of Sierra Leone.

Maimbo, S. M. (2003) The Money Exchange Dealers of Kabul:A Study of the Hawala System in Afghanistan, World Bank Working Paper 13. Washington DC: IBRD.

Maletta, H. (2002) Wages of War, Wages of Peace: Food Prices and Unskilled Labour Pay in Afghanistan 1996-2002. Kabul: Afghanistan Food Security Monitoring Programme.

Maletta, H. (2003a) Winters of Discontent: Seasonal Changes in Wages and Food Prices in Afghanistan, 2002-2003: A Discussion Paper. Kabul: $\mathrm{FAO} / \mathrm{MAAH}$.

Maletta, Hector (2003b) Women at Work: Gender, Wages and Employment in Rural Afghanistan 2002-2003: A Discussion Paper. Kabul: FAO/MAAH

Mansfield, D. (1999) 'Alternative Development: The Modern Thrust of Supply-Side Policy', Bulletin on Narcotics $51 / 1$ \& 2, www.unodc.org/unodc/bulletin/bulletin_1999-01 01_1_page004.html.

Mansfield, D. (2001) The Economic Superiority of Illicit Drug Production: Myth and Reality/ Opium Production in Afghanistan, paper prepared for the International Conference on the Role of Alternative Development in Drug Control and Development Cooperation, Feldafeng/Munich, Germany, January.

Marcus, R., L. H. Piron and T. Slaymaker (2004) Basic Services and Social Protection, background paper prepared for DFID. London: ODI.

Marek (1992) Ending Malnutrition:Why Increasing Income is Not Enough, Africa Technical Department Working Paper No. 5. Washington DC: World Bank.

Martens, B., U. Mummert, P. Murrell and P. Seabright (2002) The Institutional Economics of Foreign Aid. Cambridge: Cambridge University Press.

Minear, L. and T. Weiss (1995) Mercy under Fire:War and the Global Humanitarian Community. Boulder, CO: Westview Press.

Molla, D. (2003) Food Aid, Wheat Prices and Poppy Cultivation in Afghanistan: Is there a Link? Kabul: MRRD/WFP.
Moore, K., C. Squire and F. MacBailey (2003) Sierra Leone National Recovery Strategy Assessment Final Report. Freetown: Government of Sierra Leone.

MRRD (2002) 'From Humanitarian Assistance to Social Protection', paper prepared for the Afghanistan Support Group Oslo Meetings, 17-18 December.

Murray, C. (2001) Livelihoods Research: Some Conceptual and Methodological Issues. Manchester: University of Manchester Chronic Poverty Research Centre.

Narbeth, S. and C. McLean (2003) Livelihoods and Protection: Displacement andVulnerable Communities in Kismaayo, Southern Somalia. London: ODI.

Narbeth, S. (2001) The Targeting of Emergency Food Distribution in Somalia. Vulnerability, Distribution and Beneficiary Participation. Nairobi: WFP-Somalia.

Norton, A. Conway, T. and Foster, M. (2002) 'Social Protection: Defining the field of action and policy" Development Policy Review vol. 20, No. 5, pp. 541-567.

Okoth, J. R., J. S. Khisa and J. Thomas (2003) 'Towards SelfFinanced Farmer Field Schools', LEISA Magazine, vol. 19, no. 1: 28-29.

Ostrom, K. (1997) Self-sustainability of Veterinary Field Units, AFG/96/007, Integrated Livestock Programme Afghanistan, FAO (mimeo).

Ottaway, M. (2003) 'Promoting Democracy After Conflict: The Difficult Choices', International Studies Perspectives, 4, 314-322.

Pain, A. and S. Lautze (2002) Addressing Livelihoods in Afghanistan, AREU Issues Paper, September.

Pain, A. (2002) Understanding and Monitoring Livelihoods Under Conditions of Chronic Conflict: Lessons from Afghanistan, ODI Working Paper No. 187.

Pain, A. and J. Goodhand (2002) Afghanistan: Current Employment and Socio-Economic Situation and Prospects, InFocus Programme on Crisis Response and Reconstruction, Working Paper 8 Geneva: ILO.

Pain, A. and J. Sutton (eds) (2006) Light Footprints at the Crossroad: Learning from Responses to Food Insecurity in Afghanistan?. Rome and Rugby: Food and Agricultural Organisation and ITDG Publications

Pearce, J. (1999) 'Peace-building in the Periphery: Lessons from Central America', ThirdWorld Quarterly, 20(1): $51-68$.

Pictet, J. (1979) The Fundamental Principles of the Red Cross: A Commentary. Geneva: Henri Dunant Institute.

Pingali P., L. Alinovi and J. Sutton (2005) 'Food Security in Complex Emergencies: Enhancing Food System Resilience', Disasters, 29, Supplement 1: S5-S24.

Piron, L. H. (2004) Rights-based Approaches to Social Protection, Background Paper prepared for DFID, September. London: ODI. 
Randel, J. with M. Cordeiro and T. Mowjee (2004) 'Financing Countries in Protracted Humanitarian Crisis: An Overview of New Instruments and Existing Aid Flows', in A. Harmer and J. Macrae (eds), HPG Report 18. London: ODI.

Rawlings, L. B. L. Sherburne-Benz and J. van Domelen (2004) Evaluating Social Funds. A Cross-Country Analysis of Community Investments. Washington DC: World Bank.

Reddick, M. (2003) Evaluation of Oxfam Hazarajat Integrated Rural Development Programme, Final Report, July-August.

Reilly, B. (2004) Electoral Assistance and Post-Conflict Peacebuilding What Lessons Have Been Learned?, paper prepared for Conference on 'Making Peace Work', WIDER, June.

Remington, T. et al (2002) 'Getting Off the Seeds and Tools Treadmill with CRS Seed Vouchers and Fairs', Disasters 26(4).

Richards, P. (1996) Fighting for the Rain Forest:War,Youth and Resources in Sierra Leone. Oxford: James Currey.

Richards, P., K. Bah and J. Vincent (2004) "Social Capital and Survival: Prospects for Community-driven Development in Post-conflict Sierra Leone." Social Development Papers: Community Driven Development, Conflict Prevention and Reconstruction, No. 12, April. Washington DC: The World Bank.

Rocha, J. L. and I. Christoplos (2001) 'Disaster Mitigation and Preparedness in the Nicaraguan Post-Mitch Agenda', Disasters 25(3)

Roe, E. (1991) “"Development Narratives" or Making the Best of Blueprint Development', World Development 19 (4), 287-300.

Sauvinet-Bedouin, R. and J. Erikson (2001) Evaluation of Sida Supported Projects: Synthesis Report by Joint FAO-Sida Mission, FAO Emergency Operations, 30 August.

Schafer, J. (2002) 'Supporting Livelihoods in Situations of Chronic Conflict: Overview of Conceptual Issues', Working Paper 183. London: ODI.

Scott, C. and I. Bannon (2003) 'Mind the Gap', the World Bank, Humanitarian Action and Development - A Personal Account, Conflict Prevention and Reconstruction Unit Dissemination Notes No. 10, World Bank Social Development Department.

Scott, J. C. (1976) The Moral Economy of the Peasant: Rebellion and Subsistence in Southeast Asia. New Haven, CT:Yale University Press.

Semple, M. (1998) Strategies for Support of Sustainable Rural Livelihoods for the Central Highlands of Afghanistan. Islamabad: Pattan Development Organisation.

Sen, A. (1981) Poverty and Fomines: An Essay on Entitlement and Deprivation. Oxford: Clarendon Press.

Sen, A. (1999) Development as Freedom. New York: Oxford University Press.

Sen, A. and J. Drèze (1989) Hunger and Public Action. Oxford: Clarendon.

Shepherd, A., R. Marcus and A. Barrientos (2004) Social Protection, background paper prepared for DFID. London: ODI.

Smith, L. E. D., M. Stockbridge and H. R. Lohano (1999) 'Facilitating the Provision of Farm Credit: The Role of
Interlocking Transactions Between Traders and Zaminders in Crop Marketing Systems in Sindh', World Development, 27/2: 404-418.

\section{Solidarités (2001) UNAMA Survey:Agriculture, Kabul.}

Solidarités (2003) Reinforcement of Food Security, In Order To Stabilize Local Populations and To Favour the Return of Displaced Persons and Refugees, Intermediate Report Period from April 1, 2002-April 1, 2003.

Spitz, P. (2003) 'What Is Meant By the Right to Food', Report on the National Symposium on Operationalising the Right to Food in Sierra Leone, 19-21 May 2003, Freetown, Sierra Leone. Volume 2: Presentations. Ministry of Agriculture, Forestry and Food Security.

Tendler, J. with R. Serrano (1999) 'The Rise of Social Funds: What Are They a Model Of?', draft report for the MIT/UNDP Decentralization Project, Management Development and Governance Division, UNDP.

Tripp, R. (2001) Seed Provision and Agricultural Development: The Institutions of Rural Change. London, Oxford and Portsmouth, NH: ODI in association with James Currey and Heinemann.

Tunwar, N. S. (2002) Annual Report: Crop Improvement and Seed Components, January - December 2001. Islamabad: FAO.

UNDG/ECHA (2004) Report of the UNDG/ECHAWorking Group on Transition Issues, UN Development Group Executive Committee on Humanitarian Affairs.

UNODC/GoA (2003) Afghanistan Opium Survey 2003, Kabul.

Viciani, I. (2003) 'EU Reform Could Make Or Break LRRD’, Humanitarian Affairs Review, Spring, http://www.humanitarianreview.org.

Weijer, F. de (2002) Pastoralist Vulnerability Study, AFSU/VAM Unit of the World Food Programme

Weiss, T. G. (1999) 'Principle, Politics and Humanitarian Action', Ethics and International Affairs 13:1-21.

Westley, K. and V. Mikhalev (2002) The Use of Participatory Methods for Livelihood Assessment in Situations of Political Instability: A Case Study from Kosovo, ODI Working Paper 190.

WFP (1998) From Crisis To Recovery. Policy Issues, Agenda Item 4. Executive Board Annual Session, 18-21 May, 1998. Rome:World Food Programme

WFP (2003) Protracted Relief and Recovery Operation - Afghanistan 10233.0, Projects for Executive Board Approval Agenda Item 6, Executive Board Regular Session, 5-7 February 2003. Rome: WFP.

White, P. (1999) 'The Role of UN Specialised Agencies in Complex Emergencies - A Case Study of FAO', Third World Quarterly 20 (1): 223-238.

White, J. D. and G. B. Adams (1994) 'Making Sense with Diversity: The Context of Research, Theory, and Knowledge Development in Public Administration', in J. D. White and G. B. Adams (eds) Research in Public Administration: Reflections on Theory and Practice. Thousand Oaks, CA: Sage.

Wilson, T. (2002) Microfinance During and After Armed Conflict: Lessons from Angola, Combodia, Mozambique and Rwanda. Durham: Mountjoy Research Centre. 
Wilson, R.T. et al. (2004) Somalia:Towards a Livestock Sector Strategy, Draft Final Report commissioned by the World Bank, FAO and $\mathrm{EU}$.

Wood, G. (2003) 'Staying Secure, Staying Poor: The "Faustian Bargain"”, World Development, 31/3 455-471.
World Bank (2002) World Bank GroupWork in Low-Income Countries Under Stress: 'A Taskforce Report'. Washington DC: World Bank.

World Bank (2003) Breaking the Conflict Trap: Civil Wars and Development Policy. Washington DC: World Bank.

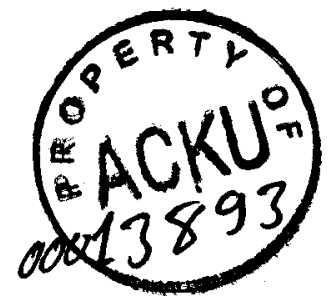




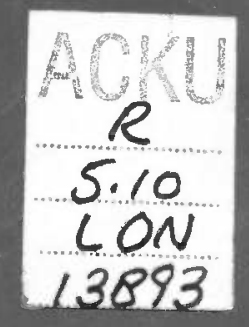

United Kingdom

Tel. +44 (o) 2079220300

Fax. +44 (o) 2079220399

E-mail: hpg@odi.org.uk 